(Aus dem tierphysiologischen Institut der kgl. landw. Hochschule zu Berlin.

[Geh.-Rat Prof. Dr. Zuntz.])

\title{
Untersuchungen über den Einfluss der Muskelarbeit auf die Organe des tierischen Organismus, ins besondere ihren Wassergehalt.
}

Von

Heimrich Gerhartz.

(Mit 4 Textfiguren.)

Inhaltsübersicht.

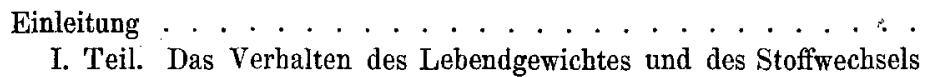
bei der Arbeit. . . . . . . . . . . . . . . . . . . . 405-448

1. Versuche am wachsenden Tier . . . . . . . . 405-408

2. Versuche am erwachsenen Tier . . . . . . . . . . 409-448

a) Methodik . . . . . . . . . . . . . . . . . . . 409-417

b) Einfluss der Arbeit auf:

c) das Lebendgewicht . . . . . . . . . . 417-420

8) die Diurese . . . . . . . . . . . . . . . 420-421

y) die Peristaltik ............... . . 421

8) die Ausnutzung. . . . . . . . . . . . . . 422-426

๘) die Eiweisszersetzung . . . . . . . . . . . . . 426-428

६) den Energieumsatz . . . . . . . . . . . . . . 429-435

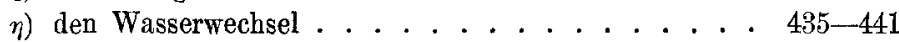

๑) die Mineralstoffausfuhr ............. . 441-448

Anhang. Einfluss der Brunst auf die Stickstoffausscheidung 427-428

II. Teil. Die chemische Abänderung der inneren Organe infolge der

Arbeitsleistung. . . . . . . . . . . . . . . . . . 448-487

Einfluss der Arbeit auf:

1. das Blut. . . . . . . . . . . . . . . . . . 448-450

2. die inneren Organe . . . . . . . . . . . . 450-456

3. die peripherische Muskulatur. . . . . . . . . . . 457-487

a) des wachsenden Tieres.......... 459-462

b) des erwachsenen Tieres . . . . . . . . . . 462-487

Anhang. 1. Über die topographischen Unterschiede in der peripherischen Muskulatur desselben Individuums . . 472-477

2. Allgemeine Zusammensetzung des Hundemuskels, insbesondere seines Extraktes . . . . . . . 487-497

Irgebnisse . . . . . . . . . . . . . . 497-499 


\section{Einleitung.}

Besser als die Tatsache, dass das Wasser einen integrierenden Teil des Körpergewichtes ausmacht ${ }^{1}$ ), beweist seine ausserordentliche Bedeutung für den Ablauf der Lebensfunktionen, dass Vorenthaltung des Wassers dem Organismus verderblicher wird als die Entziehung der festen Nährstoffe.

Obwohl nun auch grosse Wasserverluste eine ernstliche Schädigung der Lebensfunktionen nach sich ziehen, gibt es doch unzweifelhaft Variationen des physiologischen Optimums des Wassergehaltes der Organe, die ohne Schaden vertragen werden. Das beweisen die vielfältigen Beobachtungen von Lebendgewichtsschwankungen, die nicht auf Änderungen der Trockensubstanz bezogen werden können.

Solche Gewichtsänderungen sind nach plötzlichem Wechsel in der Ernährung notiert worden. Wir können heute viele Tatsachen dafür, dass Differenzen im Nährstoffgehalt eine Quelle für Variationen im Wasserreichtum des Körpers und der Organe sein können, anfübren ${ }^{2}$ ). Żuntz erklärte aus diesen Gesichtspunkten die früheren Erfahrungen von Bisch off und Voit über die grossen Gewichtsänderungen, die auftreten, wenn von Brot- zu Fleischfütterung übergegangen wird. Da nun die Arbeitsleistung unter den physiologischen Funktionen in erster Linie den Stoffbestand des Organismus variicrt, so ist von vornherein anzunehmen, dass die Arbeit der etwa die Hälfte des gesamten Wasservorrates des tierischen Körpers enthaltenden Muskelmasse ${ }^{3}$ ) die intensivste Modifikation im Wasserbestand nach sich zieht.

1) Über $60 \%$ i. d. R. Siehe Vierordt, Daten und Tabellen S. 378. Jena 1886.

2) H. Grouven, Vorträge über Agrikulturchemie mit besonderer Rücksicht auf Tierphysiologie, 3. Auf., Bd. 3 S. 343. Köln 1872. - L. Adamet z, Einfluss des Ernährungszustandes, des Alters und der Rasse auf die Zusammensetzung der Muskel des Rindes. Preuss. Landw. Jahrb. 1888 S. 577 - Vgl. ferner M. Rubner's Arbeiten, z. B.: Arch. f. Hyg. Bd. 38 S. 155 ff. 1900, ebenda Bd. 51 S. 48 ff. 1904. - Die Gesetze des Energieverbrauches bei der Ernährung. S. 19 n. a. a. O. Leipzig 1902. - N. Zuntz, A. Loewy, F. Müller und W. Caspari, Höhenklima und Bergwanderungen in ihrer Wirkung auf den Menschen S. 114. Berlin 1906. (Glykogen wird mit dem vierfachen Gewicht Wasser angesetzt.)

3) Die Muskeln machen etwa $43 \%$ des Gesamtgewichts des erwachsenen Menschen aus. Sie enthalten $2 / 3$ ihres Gewichtes Wasser, so dass also das Wasser der Muskeln etwa 30\% des Körpergewichtes, d. b. etwa die Hülfte der 67,6-70\% 
In der Tat ist es ja eine alltäglich vom gemeinen Manne zu gewinnende Erfahrungstatsache, dass während der Arbeit der Körper Wasser verliert. Ebenso bekannt ist jedoch auch die Tendenz des Körpers, seine Verluste durch Aufnahme von Flüssigkeit auszugleichen ${ }^{1}$ ). Ob er die Deckung des gesetzten Defizits erreicht, kann nur durch direkte Messung des Wasserwechsels erschlossen werden.

Die ersten exakten Unterlagen für den Umfang, in welchem Aufnahme und Abgabe von Wasser sich abspielt, haben die Zuntz$\mathrm{Schumburg}$ 'schen. Studien am marschierenden Soldaten ${ }^{1}$ ) (S. 151) geschaffen. Sie zeigten, dass „die Muskeltätigkeit zu einer Wasserverarmung des Körpers führt, welche durch die der Willkür vollkommen überlassene Getränkaufnahme nicht alsbalı kompensiert wird. Sowohl aus dem kombinierten Studium von Respiration und Gewichtsänderungen als aus positiven Beobachtungen am Verhalten des Blutes (Blutdichte und Zahl der Erythrocyten), sowie endlich aus dem Studium der Marschdiurese (S. 178) ging das unzweideutig hervor.

Diese Beobachtungen von Zuntz wurden durch analoge im Hochgebirge wesentlich gestützt und erweitert. Die hier während der Märsche gesehenen Wasserverluste übertrafen bei weitem die früher gefundenen. „Es ist auffallend und beachtenswert - lesen wir darüber ${ }^{2}$ ) - , dass der grosse Wasserverlust während der Märsche kein entsprechendes Bedürfnis der Wasseraufnahme, welche stets bei uns dem freien Ermessen überlassen war, herbeiführte. Erst am späten Nachmittage, mehrere Stunden nach der Rückkehr von den Märschen, wurde durch reichliches Trinken der normale Wasserbestand des Körpers wiederhergestellt."

Auch $\mathrm{Kaup}^{3}$ ) bat Äbnliches während der Arbeit beobachtet. Während im ersten und zweiten seiner Versuche sich kein erheblicher Wassermangel feststellen liess, berichtet der Autor auf Grund der

betragenden Wassermasse des Körpers ist. (Siehe Moleschott, Physiol, d. Nahrungsmittel, 2. Aufl., S. 224. 1859. - Vierordt, Tab. S. 378. A. Spiegler, Zeitschr. f. Biol. Bd. 41 S. 239.

1) Zuntz-Schumburg, Studien zu einer Physiologie des Marsches. Bibl. v. Coler Bd. 6. Berlin 1901. - Külbs, Experimentelles über Herzmuskel und Arbeit. Arch. f. exp. Path. u. Pharm. Bd. 55 S. 288-306. 1906.

2) Zuntz, Höhenklima S. $398 \mathrm{ff}$.

3) J. Kaup, Ein Beitrag zu der Lehre vom Einflusse der Muskelarbeit auf den Stoffwechsel. Zeitschr. f. Biol. Bd. 43 S. 221. 1902. 
Wägungen vom dritten Versuche, dass der Körper während und infolge der Arbeit grössere Wassermengen abgab und den Verlust bis zum Ende des Versuches nicht vollständig wieder ersetzte. Bei länger dauernder Arbeitsleistung scheint also das Wasserbedürfnis des Organismus allmählich abzunehmen. Da nun gerade die Muskeln die erheblichsten Wasservorräte enthalten, liegt die Annahme auf der Hand, dass in diesen Fällen der Wassergehalt der Ruhe- und Arbeitsmuskulatur differiert.

Mit der Untersuchung der Wasserverarmung der unter dem Einflusse der Arbeit gewesenen Muskeln ist die Frage nach den durch die Arbeit bedingten Veränderungen des Chemismus überhaupt angesehnitten.

Nach anfänglich erfolgreicher Bearbeitung ist dieses Thema bald verlassen worden; und bis durch die Arbeiten von Zuntz die. Frage wieder in Fluss kam, lag im wesentlichen nur die Hypothese von G. Jä ger ${ }^{\mathbf{1}}$ ) vor, dass Arbeit zur Anreicherung von Eiweiss und Wasser und zur Abnahme von Fett führt. Ausserdem konnten für diese Frage Beobachtungen, welche $\mathrm{Ranke}^{2}$ ) am tetanisierten Muskel gemacht hatte, und Untersuchungen Danilewsky' $\mathrm{s}^{3}$ ) und von Ku rajef $f^{4}$ ), $\mathrm{Saxl}^{5}$ ) und Steyrer ${ }^{6}$ ) ausser zahlreichen Arbeiten, welche die Glykogen-, Phosphor- und Extraktivstoffverteilung und Säureverhältnisse bei Ruhe und Arbeit betreffen und hier nicht zur Sprache kommen sollen, herangezogen werden.

1) G. Jäger, Die menschliche Arbeitskraft. 1878.

2) Ranke, Verhandl. d. Würzb. physik.-med. Gesellsch. 1857-1858. Zit. A. v. Korányi u. P. Fr. Richter, Physik. Chemie u. Medizin Bd. 1 S. 439 (Boruttau). Leipzig 1907.

3) Al. Danilewsky, Über die Abhängigkeit der Kontraktionsart der Muskeln von den Mengenverhältnissen einiger ihrer Bestandteile. Beitrag für eine zukünftige Theorie der Kontraktion. Zeitschr. f. physiol. Chem. Bd. 7 S. 124. 1882-1883.

4) J. K. Kurajeff, Über das Verhältnis des Eiweissgehaltes des tätigen und ruhenden Muskels. Wratsch $1895 \mathrm{Nr}$. 39. - Über die Restitution der festen Bestandteile und Eiweisskörper während des Ausruhens nach geleisteter Arbeit. Russ. Arch. f. Path. Bd. 2 S. 597. 1896. - Ref. Maly's Jahrb. für Tierchemie Bd. 26 S. 487 u. Bd. 30 S. 335.1898.

5) P. Saxl, U̇ber die Mengenverhältnisse der Muskeleiweisskörper unter physiologischen und pathologischen Bedingungen. Hofmeister's Beitr. Bd.99 S. $1-27$.

6) A. Steyrer, Ein Beitrag zur Chemie des entarteten Muskels. Hofmeister's Beitr. Bd. 4 S. 243.1904. 
Ranke batte in den geruhten Muskeln im Mittel 80,4\% Wasser und 19,6\% feste Stoffe, im tetanisierten $82,1 \%$ Wasser $=17,9 \%$ Fixa gefunden ${ }^{1}$ ).

Die wichtigsten Untersuchungen Danilewsky's stammen aus neuerer Zeit.

Zwar haben seine Wassergehaltsbestimmungen weder dem Autor selbst noch Anderen genügend Aufschluss gebracht ${ }^{2}$ ). Immerhin aber sind die Ergebnisse seiner umfassenden und sorgsamen Studien über die Beziehungen des Bewegungscharakters verschiedener Tiere zu der Zusammensetzung ihrer Muskulatur als wertvolles Material anzusehen, nachdem jetzt die Frage nach dem Verhalten des Wasserwechsels des arbeitenden Tieres wesentliche Aufklärung gefunden hat. Danilewsky gibt an, dass Muskeln, welche zu schnelleren Bewegungsphänomenèn $f$ ähig sind, oft mehr Trockensubstanz enthalten: „Diese Schlüsse aber haben, scheint es, nur für verschiedenartige Muskeln eines und desselben Tieres Geltung. Denn vergleicht man ganze Tiere mit unzweifelhaft sehr versehiedener Bewegungsart, so sind diese Schlüsse nicht immer zutreffend. Wahrscheinlich existieren in verschiedenen zoologischen Ordnungen versehiedene Grenzen für die Mengenverhältnisse der Muskelbestandteile, welche eine Vergleichung der Tiere innerhalb weiterer Gebiete nicht erlaubt."

Ich führe, weil es für die späteren Mitteilungen von Wert ist und diese erst den Schlüssel dazu liefern, absichtlich einzelne Abschnitte und Tabellen der vortrefflichen Arbeit in extenso an und füge hier zunächst eine Zusammenstellung (Tab. 1) ein, deren Studium ohne Zweifel das Resümee Danilew sky's rechtfertigt, dass in manchen Fällen, wo die Verschiedenheit des Bewegungscharakters der Tiere sehr scharf ausgesprochen ist, die Differenz in der Menge der Trockensubstanz nur höchst unbedeutend ist. Insbesondere lehren auch diese

1) Schon zur damaligen Zeit wurden die Angaben nicht als beweisend hingenommen. Ich führe hier die Worte an, mit denen W. K üh n e (Lehrb. d. physiol. Chemie S. 318. Leipzig 1868) den damaligen Stand der Kenntnis charakterisierte: „Der Wassergehalt der Muskel ist indessen grossen individuellen Schwankungen unterworfen, und auch die einzelnen Muskel desselben Leibes enthalten ungleiche Wassermengen. Die am meisten arbeitenden Muskel (Herz) sollen auch die wasserreichsten sein, und andererseits diejenigen Muskel die leistungsfähigsten, welche am wasserärmsten sind."

2) Die Gründe dafür decken sich zum Teil mit denen, welche das Ergebnis der Arbeiten Rognzinski's verschleierten und später Erwähnung finden. 
Zahlen, dass Muskel aus verschiedenen Regionen des Körpers nicht immer denselben Wassergehalt besitzen. Wie man aus der Tabelle ersehen kann, ist es hier unmöglich, die Unterschiede im Wassergehalt der Muskel mit ihren grösseren oder geringeren Arbeitsleistungen in ursächlichen Zusammenhang zu bringen.

$$
\text { Tabelle } 1 .
$$

Beispiel aus Danilewsky's Muskelanalysen.

\begin{tabular}{|c|c|}
\hline & $\begin{array}{c}\text { Trockensubstanz } \\
\text { (\%o der frischen } \\
\text { Muskeln) }\end{array}$ \\
\hline Kaltblüter $\left\{\begin{array}{l}\text { Schildkröte } . . . \\
\text { Fisch. . . . . . . }\end{array}\right.$ & $\begin{array}{l}20,2 \\
21,5\end{array}$ \\
\hline Huhn $\left\{\begin{array}{l}\text { Schenkelmuskel . } \\
\text { Brustmuskel. . . }\end{array}\right.$ & $\begin{array}{l}25,0 \\
25,4\end{array}$ \\
\hline Sperling $\left\{\begin{array}{l}\text { Schenkelmuskel . . } \\
\text { Brustmuskel. . . }\end{array}\right.$ & $\begin{array}{l}26,6 \\
27,0\end{array}$ \\
\hline Taube $\left\{\begin{array}{l}\text { Schenkelmuskel . } \\
\text { Brustmuskel. . }\end{array}\right.$ & $\begin{array}{l}25,8 \\
28,6\end{array}$ \\
\hline 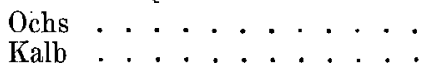 & $\begin{array}{l}25,8 \\
25,1\end{array}$ \\
\hline
\end{tabular}

Es wurden noch Untersuchungen in der Art angestellt, dass Muskeln von gutgenährten Haustauben mit denen wildlebender Tauben verglichen wurden (Tab. 2). Der Unterschied in der Verteilung des Wassers zwischen den viel in Bewegung befindlichen wilden Tauben und den für den Markt gezüchteten Tieren ist hier allerdings eklatant. Doch bleibt es zweifelhaft, wieweit hier Einflüsse der verschiedenen Ernährung obwalten.

$$
\text { Tabelle } 2 .
$$

Wassergehalt der Tanbenmuskel (Danilewsky).

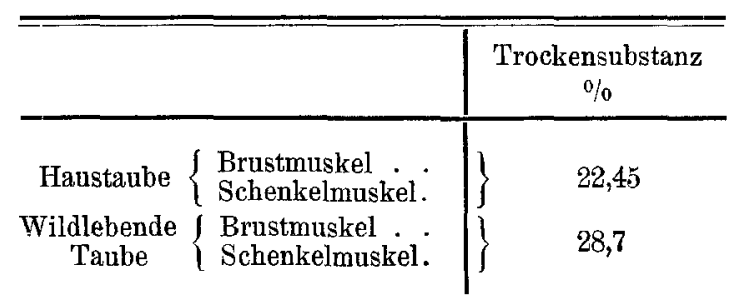

Vergleiche zwischen normalen und hypertrophischen Herzen ergaben unsichere Resultate. Ich kann nicht anerkennen, dass von Danilewsky der Beweis dafür geliefert ist, dass sich im hyper- 
trophierenden Herzen allmählich spezifische chemische Umwandlungen ausbilden ${ }^{1}$ ).

Die Analysen von Siegert ${ }^{2}$ ) lassen sich ebensowenig für die Entscheidung der Frage, ob Muskelgruppen, welche intensivere Arbeit leisten, konstante Veränderungen ihrer chemischen Zusammensetzung erleiden, heranziehen.

Auf experimentellem Wege hat in allerjüngster Zeit Ferrarini ${ }^{3}$ ), dessen Arbeit mir leider nur im Referat bekannt geworden ist, das Gebiet betreten. Er immobilisierte eine der hinteren Extremitäten für eine Zeit bis zu drei Monaten und fand dann, dass in dem ruhig gehaltenen Glied das Wasser um $0,7 \%$ zugenommen hatte. Dieser Zuwachs an Wasser war nicht proportional zur Dauer der Immobilisation erfolgt, sondern hatte sehr schnell eine gewisse Grenze erreicht, welche dann konstant beibehalten wurde. Die Versuche sind kompliziert durch ein infolge der Einwickelung der Extremität entstandenes Ödem, so dass, obwohl die Salze der Muskeln progressiv abnahmen, die Abänderung der chemischen Zusammensetzung nicht als einwandfrei erwiesen gelten kann; um so mehr dies, als Ferrarini selbst die beobachteteh Veränderungen später ${ }^{4}$ ) einem der Ermüdung analogen Zustande zugeschrieben hat. Der Versuch Ferrarinis erinnert an eine Angabe von $\mathrm{Zuntz}$ und $\mathrm{Hagemann}{ }^{5}$ ), nach der diese Autoren bei Pferden, die durch entsprechende Befestigung an ansgiebigen Bewegungen der Extremitaten gehindert wurden, eine Wasseraufstaunng von $8 \mathrm{~kg}$, die an einem Tage hei wieder freier Bewegung schwand, beobachteten.

Auch bei Krankheiten, welche zur Körperkonsumption führen und also den Kranken zur Ruhe zwingen, ist Zunahme des Wasser-

1) Vgl. auch die neueren Erfahrungen von J. Bence (Die Verteilung des Stickstoffes im hypertrophischen Herzmuskel. Zeitschr. f. klin. Med. Bd. 66 S. 441-453. 1908.

2) Siegert, Grouven's Vorträge über Agrikulturchemie, 3. Aufl, S. 347.1872.

3) G. Ferrarini, Sopra la composizione chimica dei muscoli degli arti sottopasti ad immobilizzazione. Nota $1^{\text {a }}$ Contenuto in acqua e in sali. Studie ricerche sperimentali. Ref. (A scoli) Biochem. Centralbl. Bd. 5 S. 544. 1906.

4) G. Ferrarini, Études et recherches expérimentales sur la physiopathologie des muscles des membres sonmis à l'immobilisation. Arch. ital. de Biol. t. 46 p. $83-96.1906$. - Ferner Archivio di Ortopedia. t. 22 p. 507. 1905. Ref. Biophys. Zentralbl. Bd. 2 S. 329. 1906.

5) Zuntz und Hagcmann, Untersuchungen über den Stoffwechsel ies Pferdes. Berlin 1898 
gehaltes der willkürlichen Muskulatur beobachtet worden (v. Hoess $\left.\operatorname{lin}^{1}\right)$, v. Moraczewski $\left.{ }^{2}\right)$ ).

Trotz der zahlreichen Untersuchungen tritt also eine grosse Unsicherheit darüber, in welcher Richtung die Modifikationen des Chemismus, namentlich des Wassergehaltes, infolge der Arbeitsleistung sich bewegen, zutage.

Um Aufschluss zu erhalten, unternahm Rogozinski ${ }^{3}$ ) auf Anregung von Zuntz, durch dessen Studien am marschierenden Soldaten und in den Alpen diese Frage akut geworden war, direkte diesbezugliche Untersuchungen, welche sich auf die Organe, insbesondere die Muskeln, sowie das Blut erstreckten und an Tieren, welche auf der Tretbahn genau dosierte Arbeit leisteten, vorgenommen wurden. Die Arbeit Rogozinski's hat eine Reihe wichtiger Tatsachen bekannt gegeben und insbesondere wahrscheinlich gemacht, dass lange fortgesetzte Arbeit zu einer Verarmung der Muskelsubstanz an Wasser führt, das Blut aber, weder was seine physikalische, noch seine chemische Zusammensetzung angeht, verändert wird.

Rogozinski hatte aber selbst "wegen der erheblichen, durch Individualität, Alter und Rasse bedingten Schwankungen der Organgewichte und auch des Wassergehaltes der Organe" weitere Untersuchungen für erforderlich gehalten. Bezüglich verwandter Fragen war durch Rogozinski's Untersuchungen so viel erreicht worden, dass es als sicher gelten konnte, dass eine erneute Untersuchung, welche den durch diese Arbeit aufgedeckten grossen individuellen und Rassendifferenzen zwischen den zum Vergleich herangezogenen Tieren Rechnung trug, wichtigeres Material zur Lösung der aufgeworfenen Fragen bringen würde. Namentlich gilt dies binsichtlich der Arbeitshypertrophie der Organe; auch schienen genügend Anhaltspunkte gewonnen, eine auf Rechnung der Arbeitsleistung von manchen Autoren gesetzte Depression der Fettverdauung des arbeitenden Tieres von der Hand zu weisen. Ich bin deshalb

1) v. Hoesslin, Deutsch. Arch. f. klin. Med. Bd. 33 S. 600.1883.

2) W. v. Moraczewski, Die Mineralbestandteile der menschlichen Organe. Zeitschr. f. physiol. Chem. Bd. 23 S. 483-496. 1897.

3) N. Zuntz, Über die Einwirkung der Muskelarbeit auf die Organe des Tierkörpers, nach Versuchen von Dr. F. Rogozinski, aus Krakau. Sitzungber. d. Berl. physiol. Gesellsch. vom 11. Mai 1906. Arch. f. (Anat. u.) Physiol. 1906 Supplbd. S. 432. - F. Rogozinski, Über den Einfluss der Muskelarbeit auf Gewicht, Zusammensetzung und Wassergehalt der Organe des Tierkörpers. Biochem. Zeitschr. Bd. 1 S. 207. 1906. 
gern der Aufforderung des Herrn Geh.-Rat Prof. Zuntz, dem ich die praktische Einführung in das Gebiet der Physiologie des Stoffwechsels und viele Ratschläge verdanke, gefolgt, die Untersuchungen über den Einfluss der Muskelarbeit auf Gewicht, Zusammensetzung und insbesondere den Wassergehalt der Organe wieder aufzugreifen. Ich spreche Herrn Geh.-Rat Zuntz auch an dieser Stelle den gebührenden herzlichsten Dank aus. Auch den Herren Kollegen im Laboratorium bin ich für ihre freundliche Unterstützung bei den Versuchen zu Dank verpflichtet.

Mittlerweile sind, während ich mit diesen Untersuchungen beschäftigt war, von anderer Seite Beiträge geliefert worden. Soweit sie direkt die Dinge, welche in Untersuchung stehen, betreffen, kommen sie weiter unten zur Sprache. Die übrigen haben hauptsächlich die Erkenntnis von den grossen individuellen Schwankungen, welche die Menge des in den Organen vorhandenen Wassers erleidet, mit neuen Belegen gestützt und durch den Widerstreit, der in ihren Resultaten liegt, auf Fehler der Technik und Versuchsanlage hingewiesen, deren Vermeidung sehr im Interesse der Gewinnung klarer Ergebnisse lag. Nicht zuletzt haben auch sie dazu angeregt, den Umfang der Aufgabe immer mehr zu erweitern. Dies gilt namentlich für die Bilanzversuche am lebenden Tier, die immer mehr in den Kreis der Untersuchung einbezogen wurden. Für dieses Vorgehen war die Auffassung maassgebend, dass diese indirekte Methode, den Stoffwechsel der Muskeln kennen zu lernen, sowohl über den Umfang als die Art des Verbrauchs von Körpersubstanz wertvollen Aufehluss zu geben gestattet und somit die direkte Untersuchung aufklärend ergänzt.

\section{Teil. Das Verhalten des Lebendgewichtes und des Stoffwechsels bei der Arbeit.}

Bereits früher wurde angeführt, dass Lebendgewichtsbestimmungen bekannt wurden, welche nur die Deutung zuliessen, dass es während langdauernder Arbeitsleistung zu einer Wasserverarmung des Organismus gekommen war. Um weiteres Material in dieser Hinsicht $\mathrm{zu}$ gewinnen, wurde das Verhalten der Körpergewichte sowohl heranwachsender wie erwachsener Hunde einesteils in der Ruhe, anderenteils unter dem Einflusse einer gemessenen Arbeitsleistung verglichen.

\section{Versuche am wachsenden Tier.}

Um zu untersuchen, welche Gestalt die Körpergewichtskurve noch in der Entwicklung begriffener Tiere infolge intensiver Arbeit 
aunimmt, wurden vier Terriers von demselben Wurf untersucht. Über diese sind in einer früheren Arbeit ${ }^{1}$ ) nähere Mitteilungen gemacht worden; ich verweise deshalb auf die dortigen Angaben. Die zur Tretbahnarbeit erzogenen Hunde arbeiteten nicht von der gleichen Zeit an, sondern der "Arbeitshund" des ersten, völlig gleichen Paares vom 24. September 1906 (28. Lebenswoche), der arbeitende Hund des zweiten, etwas differierenden Paares (,Schwarzer Arbeitshund") vom 21. Oktober desselben Jahres (32. Lebenswoche) an. Es sind für unsere Fragestellung also nur die Lebendgewichte von diesen Daten an verwertbar. Die Tiere erhielten stofflich gleiches Futter, Eiweiss und Mineralstoffe in genügender Menge; die Energiezufuhr für Erhaltung und Zuwachs war für jedes Tier identisch, und zur Bestreitung des der Arbeit äquivalenten Energiebetrages wurde eine in der früher ${ }^{1}$ ) angegebenen Weise berechnete Zulage von Fett gegeben. Die vier Tiere empfingen also Nahrungsmengen, welche bei allen in gleicher Weise dem Bedarf angepasst waren.

Tabelle 3.

Vergleich der Lebendgewichte der Ruhe- und Arbeitstiere.

\begin{tabular}{|c|c|c|c|c|}
\hline \multirow{2}{*}{ Lebenswoche } & \multicolumn{4}{|c|}{ Körpergewicht (Mittel jeder Woche) } \\
\hline & $\begin{array}{c}\text { Rub ehund } \\
\text { I. }\end{array}$ & $\begin{array}{l}\text { Arbeitshond } \\
\text { II. }\end{array}$ & $\begin{array}{l}\text { Weiblicher } \\
\text { Ruh e hund }\end{array}$ & $\begin{array}{c}\text { Schwarzer } \\
\text { Arbeits hund }\end{array}$ \\
\hline $\begin{array}{c}\text { 30. (2. Hälfte) } \\
31 . \\
32 . \\
\left.\left[33 . .^{2}\right)\right]\end{array}$ & $\begin{array}{c}6868 \\
7039 \\
7104 \\
{[7000]}\end{array}$ & $\begin{array}{c}6820 \\
7020 \\
6952 \\
{[7022]}\end{array}$ & $\begin{array}{c}5252 \\
5152 \\
5090 \\
{[5003]}\end{array}$ & $\begin{array}{c}4636 \text { (Rune) } \\
4567 \text { (Ruhe) } \\
4456 \\
{[4460]}\end{array}$ \\
\hline
\end{tabular}

\begin{tabular}{c|c|c|c|c}
\hline \hline \multirow{2}{*}{ Lebenswoche } & \multicolumn{2}{|c|}{$\begin{array}{c}\text { Tägliches mittleres Gewichtsintervall } \\
\text { Endgewicht:7 }\end{array}$} \\
\cline { 2 - 5 } & $\begin{array}{c}\text { Ruhehund } \\
\text { I. Anfangsgewicht }\end{array}$ & $\begin{array}{c}\text { Arbeitshund } \\
\text { II. }\end{array}$ & $\begin{array}{c}\text { Weiblicher } \\
\text { Ruhehund }\end{array}$ & $\begin{array}{c}\text { Schwarzer } \\
\text { Arbeit shund }\end{array}$ \\
\hline $30 .(2$. Hälfte) & $+32,5$ & $+40,0$ & $-12,5$ & $+12,5$ (Ruhe) \\
31. & $+8,3$ & $-3,3$ & $-5,0$ & $+3,3$ (Ruhe) \\
32. & $+45,0$ & $-25,0$ & $-1,7$ & $-25,0$ \\
$[33.2)]$ & {$[-110,0]$} & {$[-82,0]$} & {$[-136,0]$} & {$[-14,0]$}
\end{tabular}

1) H. Gerhartz, Zur Physiologie des Wachstums. Biochem. Zeitschr. Bd. 12 S. 97-118. 1908. geltend.

2) Es macht sich am Schlusse der 33. Woche der Einfluss der Staupe 
Untersuchungen über den Einfluss der Muskelarbeit auf die Organe etc. 407

Tabelle 4.

Vergleich der Lebendgewichtsänderungen der Rnhe- und Arbeitshunde.

\begin{tabular}{|c|c|c|c|c|}
\hline & $\begin{array}{c}\text { Rub ehund } \\
\text { I. } \\
\mathrm{g}\end{array}$ & $\begin{array}{c}\text { Arbeits - } \\
\text { hund } \\
\text { II. } \\
\mathrm{g}\end{array}$ & $\begin{array}{c}\text { Weiblicher } \\
\text { Ruhehund } \\
\mathrm{g}\end{array}$ & $\begin{array}{c}\text { Sehwarzer } \\
\text { A rbeits - } \\
\text { hund } \\
\mathrm{g}\end{array}$ \\
\hline Anfangsgewicht (Anfang & 6700 & 6750 & $\left.5070^{1}\right)$ & $\left.4600^{1}\right)$ \\
\hline 33. Woche) . . . & 6950 & 6850 & $\left.5370^{2}\right)$ & $\left.4650^{2}\right)$ \\
\hline Absolute Differenz . . . & +250 & +100 & +300 & +50 \\
\hline $\begin{array}{l}\text { Differenz in } \% \text { des } \\
\text { Anfangsgewichts. }\end{array}$ & 3,7 & $\mathbf{1 , 0}$ & 5,9 & 1,1 \\
\hline
\end{tabular}

Aus den durch tägliche morgendliche Wägung gewonnenen Körpergewichtswerten habe ich Mittelzahlen für je eine Woche berechnet, da solche zur Beurteilung genügen und die Übersicht erleichtern (Tab. 3). Die Unterschiede sind nicht sehr dentlich; und da alle Hunde ihr Gewicht nur um einen minimalen Betrag (vgl. Tab. 4) verändert haben, dürfen sie kaum nach der einen oder anderen Seite hin gedeutet werden. Will man auf sie Wert legen, so können sie allerdings nur im Sinne einer Gewichtsabnahme der Arbeitstiere ausgelegt werden (Kurve I). Nach vielfältigen Erfahrungen ist an Eiweissverluste bei der Arbeit hier nicht zu denken; die Ausnutzung der gereichten Nährstoffe (vgl. später) war in keiner Weise verschlechtert; es kann sich also nur um Verluste von Glykogen, Fett oder Wasser gehandelt haben. Zur Erklärung der Differenzen kommt zuerst die Wahrscheinlichkeit in Betracht, dass Glykogen geschwunden ist und dafür die äquivalente Menge Fett angesetzt wurde. Da etwa $9 \mathrm{~g}$ wasserhaltiges Glykogen $1 \mathrm{~g}$ Fett kalorisch äquivalent sind, würde hierdurch ein Teil des Gewichtsverlustes erklärt werden. Wollen wir aber nicht ganz unwahrscheinliche Annahmen über den vorher vorhandenen Glykogengehalt machen, so kommt wohl eine direkte Verarmung der Gewebe an Wasser in Betracht, die allerdings nur gering sein kann.

1) Gewicht zu Anfang der 32. Lebenswoche, d. i. bei Beginn der ArbeitsLeistung des schwarzen Arbeitshundes.

2) Mitte der 33. Lebenswoche (30. Oktober 1906), d. h. vor dem durch Krankheit bedingten Gewichtssturz. 


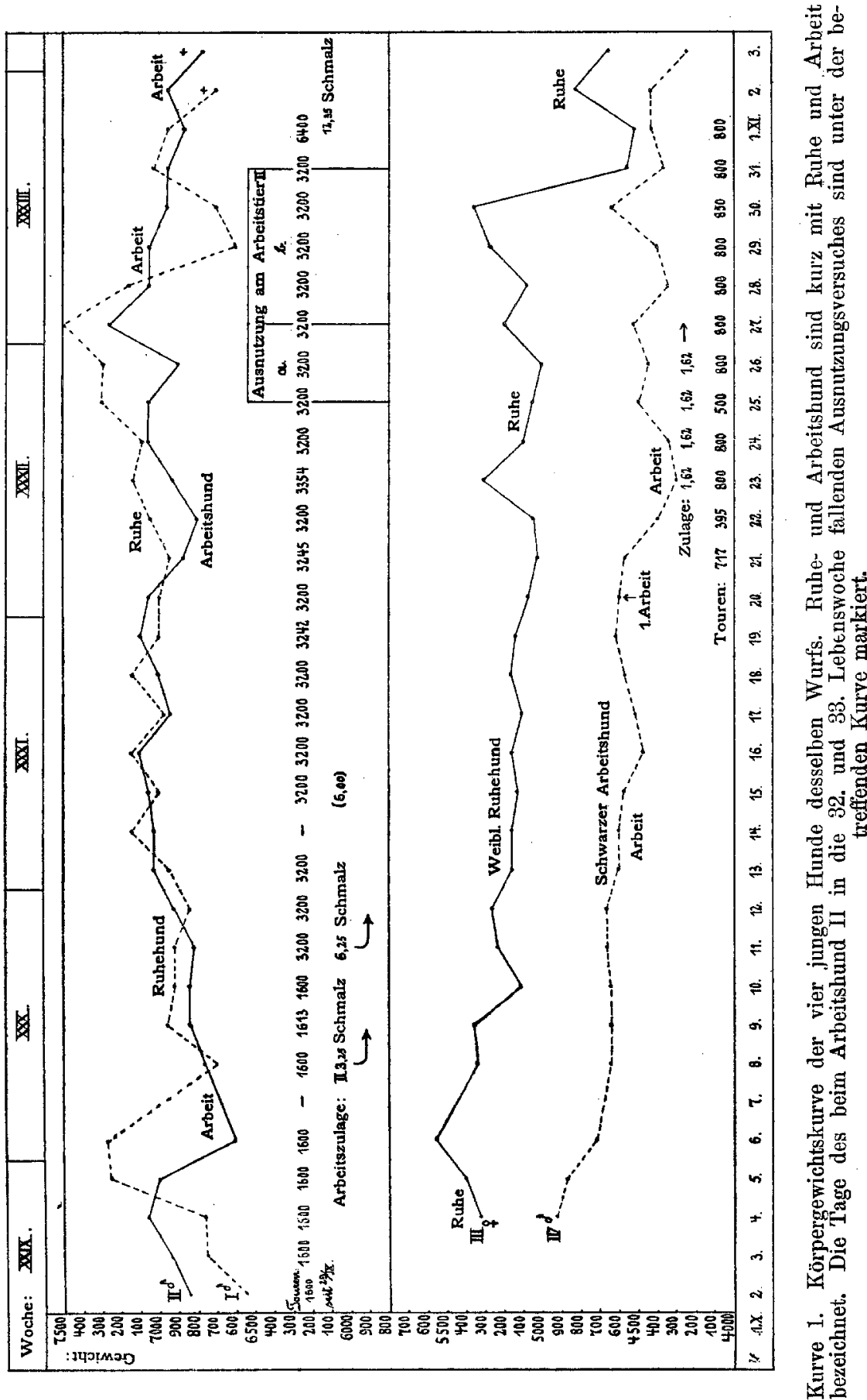




\section{Versuche am erwachsenen Tier.}

Ausser an den besprochenen jungen Tieren wurden die Gewichtsänderungen an erwachsenen Hunden während Ruhe- und Arbeitsperioden beobachtet. Es wurden dazu Tiere benutzt, an denen durch Amputation eines Beines Material für die chemische Untersuchung von Muskeln, die durch die Arbeit alteriert waren, gewonnen wurde. Diese Hunde sind deshalb im folgenden kurz als Amputationshund I und II bezeichnet.

Amputationshund I war ein schöngewachsener Foxterrier von ca. $9 \mathrm{~kg}$ Gewicht. Bei diesem Tier musste natürlich, um verschiedene Lebensperioden vergleichen zu können, dahin gestrebt werden, das einmal erreichte Gewicht konstant zu erhalten. Durch Tastversuche wurde also zu Beginn der Versuchsreihe diejenige Menge Nahrung bestimmt, welche dazu ausreichte. Es stellte sich dabei heraus, dass

$$
\begin{array}{r}
320 \mathrm{~g} \text { Pferdefleisch }=\text { ca. } 448 \text { Cal. }=313,6 \text { Cal. } \\
+35 \mathrm{~g} \text { Schweineschmalz }=\frac{325,5 \text { Cal. }=311,5 \text { Cal. }}{\text { insgesamt }} \\
773,5 \text { Cal. }=625,1 \text { Cal., }
\end{array}
$$

d. s. 93,2 Rohcal. bzw. 75,3 Nutzcal. pro Kilogramm Körpergewicht (im Mittel $8300 \mathrm{~g}$ ) und Tag, genügten; denn wie Tab. 5 lehrt, blieb das Lebendgewicht $8270 \mathrm{~g}$, das am 12. Juni mit 774 Cal. erreicht war, sechs Tage hindurch kurz vor dem Beginn der Arbeitsleistung konstant (vgl. auch Kurve II). Dieser Energiewert stellt also auch für die nun folgende Arbeitszeit den Erhaltungsbedarf dar. Dem für die Arbeit benötigten Mehr an Energie wurde durch eine Schmalzzulage, die in der früher angegebenen Weise berechnet worden war, Genüge getan. Sie musste natürlich mit wechselndem Gewicht des Tieres variieren. Da sie aber tags vorher bzw. für einige Tage im voraus berechnet worden war, deckte sich nicht das berechnete mit dem zugeführten Äquivalent. Ich habe deshalb in Tab. 5 die pro Tag der Theorie nach für die Arbeit erforderlich gewesene Energiemenge angegeben. Aus diesen Zahlen folgt, dass in Wirklichkeit die Arbeitszeit hindurch der Erhaltungsbedarf nicht erreicht worden war. Im ganzen machte diese Differenz zwischen zugeführter Gesamt-

1) Siehe bezüglich der Nutzwertberechnung meine Arbeit: Zur Physiologie des Wachstums. Biochem. Zeitschr. Bd. 12 S. 101-106. 1908. 


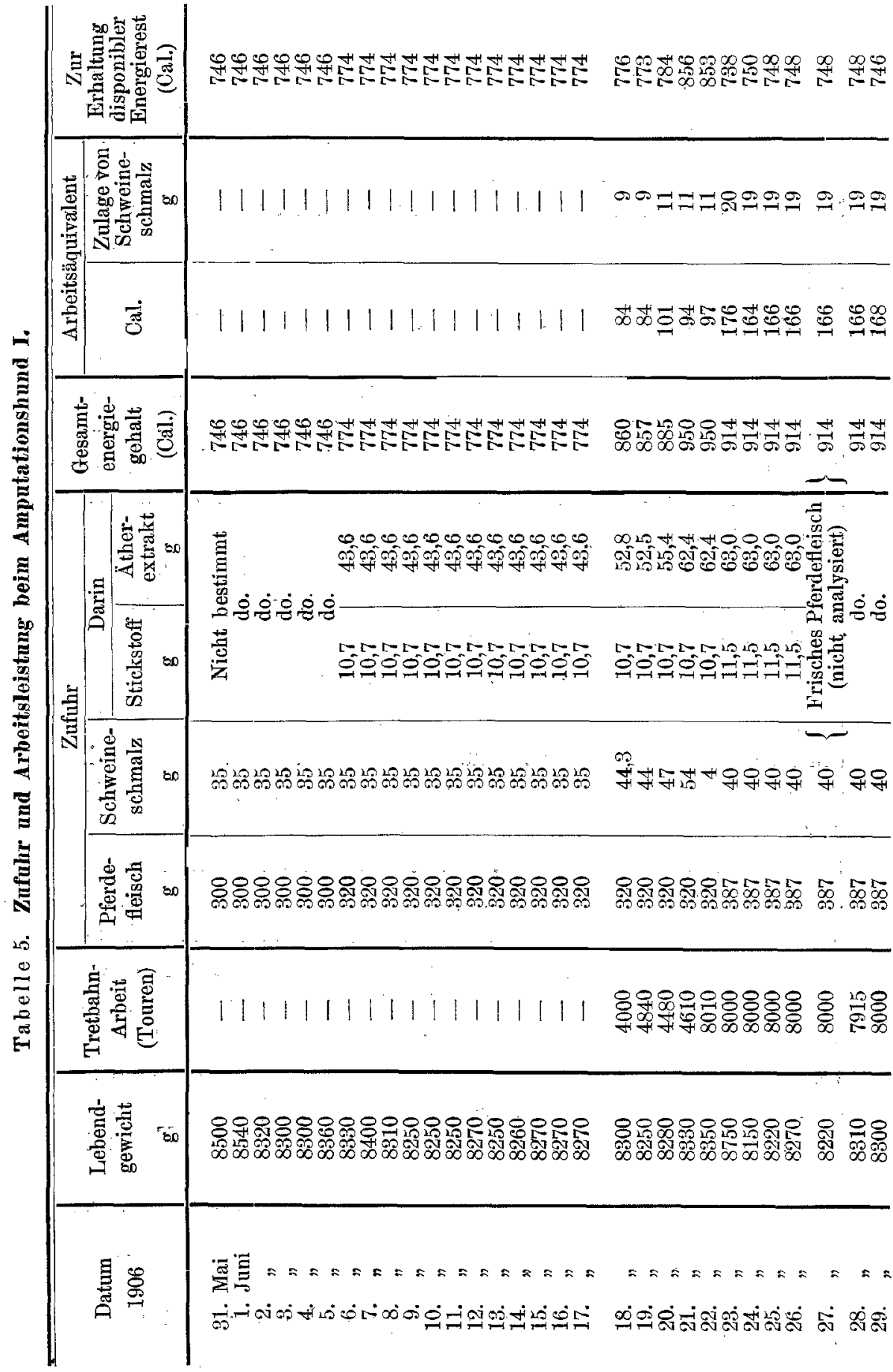


Untersuchungen über den Einfluss der Muskelarbeit auf die Organe etc. 411

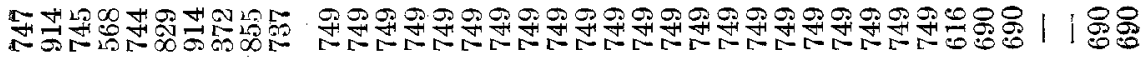

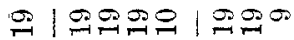

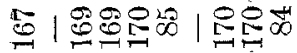

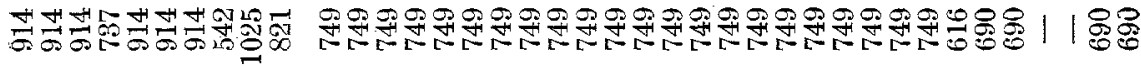

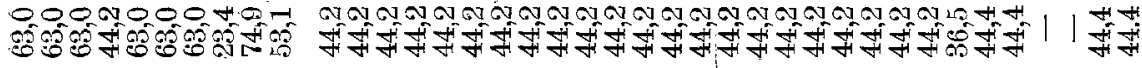

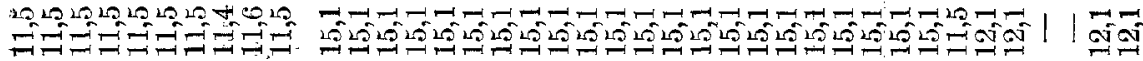

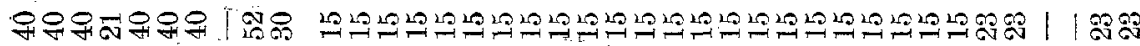

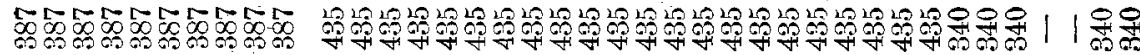

量|

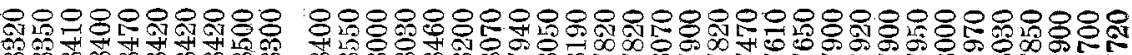

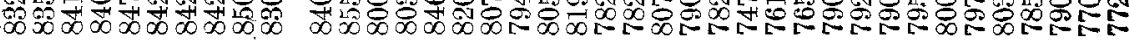

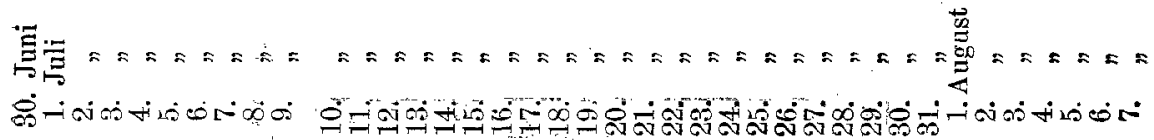



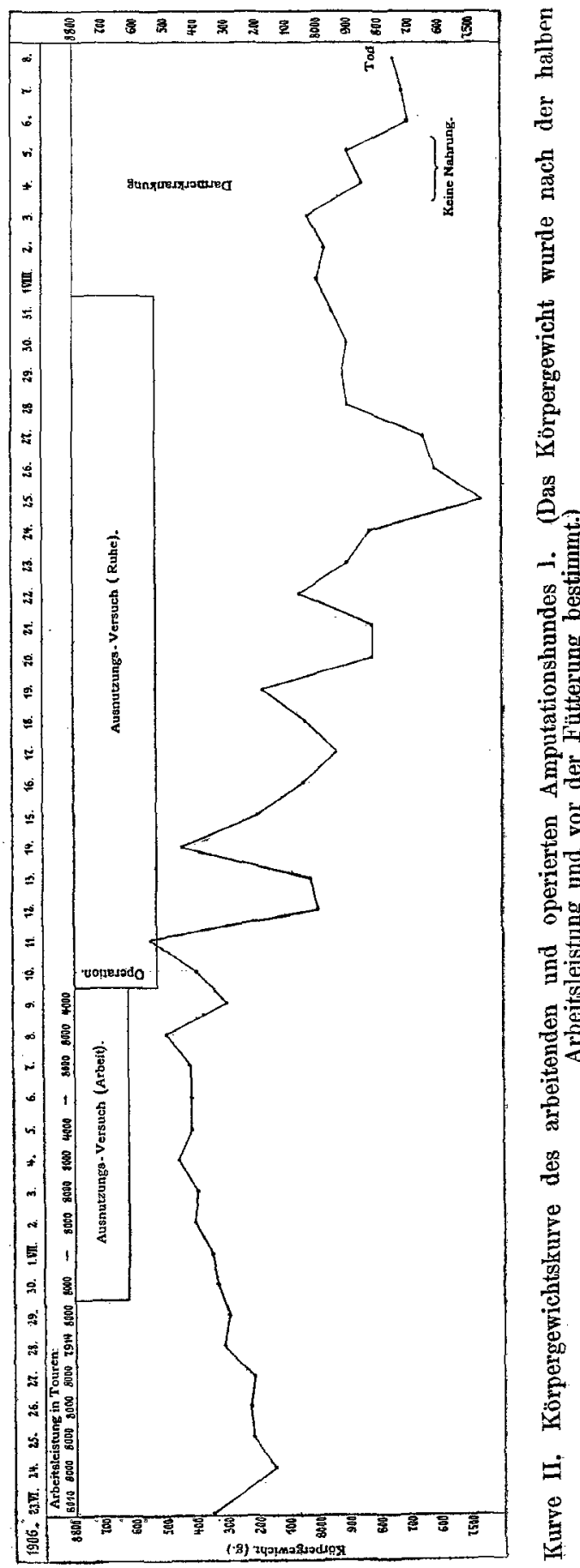
energie und Arbeitsäquivalent, d. h. also die nach Abzug des Arbeitsäquivalentes für die Erhaltung disponible Energiemenge

$$
\begin{aligned}
& \text { in } 22 \text { Tagen } 19509 \text { Calorien, } \\
& -\quad 2817 \text { Calorien, } \\
& \hline 16692 \text { Calorien, also pro Tag }
\end{aligned}
$$

759 Calorien aus. Der Erhaltungsbedarf war also nicht erreicht worden, sondern es blieb ein Defizit von 15 Calorien pro Tag. Da es sich wohl nur um Fettverluste gehandelt haben kann, würde sich hieraus ein Verlust von $1,7 \mathrm{~g}$ pro Tag berechnen. In der Tat bestand aber eine geringe Zunahme an Gewicht; denn in der ersten Arbeitswoche war das mittlere Gewicht $8344 \mathrm{~g}$ (18.--24. Juni einschliesslich), in der letzten Woche (3.-9. Juli einschliesslich) $8419 \mathrm{~g}$. Es muss also der aus dem Energieverbrauch berechnete Verlust durch einen entsprechenden Ansatz, wahrscheinlich von Eiweisssubstanz, verdeckt worden sein. Für einen Wasserverlust durch die Arbeit haben sich also in diesem Versuch keine Anhaltspunkte ergeben.

Bei der vorausgegangenen Berechnung sind Standard-Bruttoenergiewerte zugrunde gelegt. Die Zahlen für Stickstoff und Ätherextrakt sind durch direkte Analysierung des Pferdefleisches gewonnen. Nur für die Zusammensetzung des Schmalzes wurden von Koenig ${ }^{1}$ ) angegebene Zahlen benutzt. Die Analysen des verfütterten Fleisches hatten die in Tab. 6 (siehe S. 414) zusammengestellten Werte ergeben.

Ich mache noch darauf aufmerksam, dass bei dem operierten und ruhenden Tier (nach dem 10. Juli 1906), wie sich an den Zahlen zwischen dem 23. Juli und 30. Juli erkennen lässt (Tab. 5 und Kurve II), pro Kilogramm Körpergewicht eine gleiche Energiemenge, wie vor der Operation, zur Erhaltung des Gewichtes erforderlich war.

Der $\mathrm{z}$ weite Amputationshund, ein weiblicher, $12,15 \mathrm{~kg}$ schwerer und 2 Jahre alter Pudel, bot ein günstigeres Objekt zum Studium dar. Nicht nur gelang es hier, den Harn unter allen Kautelen aufzufangen, sondern es war auch möglich, eine Reihe naheliegender Untersuchungen anzuknüpfen, welche unsere Kenntnisse von dem Einfluss der Arbeitsleistung auf den Stoffumsatz

1) J. Ko enig, Chemie der menschlichen Nahrungs- und Genussmittel Bd. 1 S. 38. 1903: Wasser $0,7 \%$; Rohprotein $0,26 \%$; Fett $99,04 \%$. Ähnliche Werte habe ich selbst in späteren Analysen von Schmalz derselben Herkunft gefunden. 
Tabelle 6 .

Znsammensetzung des dem Amputationshund I verfütterten Pferdefleisches.

\begin{tabular}{|c|c|c|c|c|c|c|c|c|c|c|c|}
\hline \multirow{2}{*}{ 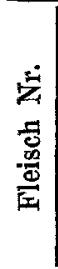 } & \multirow{2}{*}{ Datum } & \multicolumn{4}{|c|}{$\begin{array}{c}\% \text { der frischen Sub- } \\
\text { stanz }\end{array}$} & \multicolumn{3}{|c|}{$\begin{array}{l}\% \text { der Trocken- } \\
\text { substanz }\end{array}$} & \multicolumn{2}{|c|}{$\begin{array}{l}\% \text { der fett- } \\
\text { freien } \\
\text { Trocken- } \\
\text { substanz }\end{array}$} & \multirow{2}{*}{$\begin{array}{l}\text { Stiekstoff } \\
\text { in \% oder } \\
\text { fett- und } \\
\text { asche- } \\
\text { freien } \\
\text { Trocken- } \\
\text { substanz }\end{array}$} \\
\hline & & 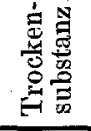 & 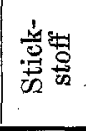 & 事密 & 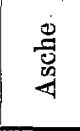 & 竞转 & 焉离 & 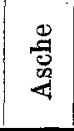 & 莺密 & 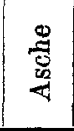 & \\
\hline I \{ & $\begin{array}{c}\text { 6.-22. Juni } \\
\text { einschliesslich }\end{array}$ & $\{6,20$ & 3,31 & 2,78 & 1,15 & 12,62 & 10,61 & 4,40 & 14,13 & 4,91 & 14,86 \\
\hline $\begin{array}{l}\text { II } \\
\text { III } \\
\text { IV }\end{array}$ & $\begin{array}{l}\text { 23. Juni bis } 9 \text {. Juli } \\
\text { 10.-31.Juli } \\
1 .-7 \text {. August }\end{array}$ & $\begin{array}{l}26,97 \\
29,92 \\
28,77\end{array}$ & $\begin{array}{l}2,96 \\
3,46 \\
3,37\end{array}$ & $\begin{array}{l}6,04 \\
6,74 \\
6,37\end{array}$ & $\begin{array}{r}1,21 \\
0,93 \\
-\end{array}$ & $\begin{array}{l}10,96 \\
11,57 \\
11,71\end{array}$ & $\begin{array}{l}22,41 \\
22,53 \\
22,14\end{array}$ & $\begin{array}{l}4,48 \\
3,09 \\
-\end{array}$ & $\begin{array}{l}14,14 \\
14,93 \\
15,04\end{array}$ & $\begin{array}{c}5,78 \\
4,01 \\
-\end{array}$ & $\begin{array}{c}15,01 \\
15,55 \\
-\end{array}$ \\
\hline \multicolumn{2}{|c|}{ Mittel : $\left.{ }^{1}\right) \ldots$} & 27,965 & 3,275 & 5,483 & 1,097 & 11,7 & 19,6 & 3,9 & 14,6 & 4,9 & 15,3 \\
\hline
\end{tabular}

fördern sollte. Ihre Besprechung soll gleich hier erfolgen, da sie zum grössten Teil erst die notwendigen Anbaltspunkte für die Diskussion der Wassergehaltssehwankungen des arbeitenden Tieres gibt.

Die Hündin kam am 8. März 1907 in meinen Besitz und wurde gleich zur Arbeitsleistung, die sie ohne Schwierigkeit und Angewöhnung $\mathrm{zu}$ vollziehen vermochte, herangezogen; es wurde also in diesem Falle nicht erst, wie beim Amputationshund I, ein Ausnutzungsversuch eingeschoben. Die Versuchsruhezeit war demnach hier allein die Zeit nach der Amputation. Nach fün Tagen lief das Tier schon vortrefflich 4000 Touren auf der 28,52\% zur Ebene geneigten 'Tretbahn (1 Tour $=$ Weg von $65,16 \mathrm{~cm}$. - Vgl. im übrigen meine frühere Arbeit S. 99-101 1. c. S. 406 Anm. 1); es konnte deshalb alsbald die Tourenzahl auf 8000 Touren $(=5220 \mathrm{~m}$ Weg und $1480 \mathrm{~m}$ Steigung) gesteigert werden (2 Abschnitte). Obwohl so das Tier an grössere Arbeit gewöhnt war, wurden ihm doch während des Bilanzversuchs nur 6000 Touren täglich, allerdings ohne Unterbrechung, zugemutet. Nur an den Tagen des Höhepunktes der "Brunst" wurde die Arbeit sichtlich schwer getragen; es wurden deshalb Pausen eingelegt.

Das Futter erhielt die Hündin gleich nach der Arbeitsleistung. Als Grundration wurden zur Zeit der Ruhe (vom 5. April 1907 an) $350 \mathrm{~g}$ Pferdefleisch und 44,8 g Schweineschmalz gegeben; es wurde

1) Siehe Aschenanalyse S. 437 . 
also auch in diesem Versuch mit den einfachsten Kostmitteln gearbeitet. Dies hat den Vorteil, dass der Stoffumsatz bequemer zu übersehen ist. In der gereichten Ration war das Eiweiss so reichlich bemessen, dass ein unter dem Einfluss der Arbeitsleistung einsetzender vermehrter Eiweisszerfall nicht. zu befürchten war, im Gegenteil angenommen werden konnte, dass die gereichte Zulage von Fett die Kraftleistung bestreiten würde. Ich erinnere auch an die Versuche von Pettenk of er und Voit, Rubner und Magnus Levy ${ }^{1}$ ), aus denen hervorgeht, dass die Zugabe von $30-150 \mathrm{~g}$ Fett fast keine Mehrzersetzung von Fett bei für den Unterhalt des Stoffwechsels genügend grosser Eiweisszufuhr bewirkt. Auch bei dem arbeitenden Tier lag die gereichte Fettmenge innerbalb der genannten Amplitude, denn in der Regel genügten 66,2 g Schmalz; nur am 31. März wurden, der grösseren Arbeitsleistung entsprechend, $67,8 \mathrm{~g}$ Schweineschmalz gegeben; am 4. April wurden 56,9, am 5. April $47,6 \mathrm{~g}$ Fett dem Fleisch beigelegt.

Die Methodik der Analysierung war die gleiche, wie sie bei dèn früheren Untersuchungėn geübt worden war. Die Trockensubstanz wurde im Wassertrockenschrank bei etwa $80^{\circ} \mathrm{C}$. ermittelt. Der Stickstoff wurde nach Kjeldahl's Verfahren in den Modifikationen von Wilfarth und Neuberg ${ }^{2}$ ) bestimmt. Das „Ätherextrakt" ("Fett") wurde so gewonnen, dass erst 24 Stunden mit wasserfreiem Äther, dann mit salzsaurem Alkohol behandelt, digeriert, getrocknet und nochmals ein Tag mit Äther extrahiert wurde. Alle angegebenen Analysenzahlen sind doppelt, oft dreifach kontrolliert. Im Schweineschmalz wurde, was nicht Wasser und Stickstoffsubstanz, die bestimmt wurden, war, als Fett gerechnet. Die Analysierung des Fleisches war an der lufttrockenen Substanz vorgenommen worden. Infolge eines unglücklichen Zufalles war deren Wassergehalt nicht genau genug bestimmt worden, infolgedessen ist die exakte Aufrechnung: der in der Trockensubstanz gefundenen Werte auf frische Substanz unmöglich geworden. Da wäbrend der Ruhe wie bei der Arbeit Fleisch von derselben Mischung benutzt wurde, und nur im Fettgehalt be-

1) M. v. Pettenkofer und C. Voit, Über die Zersetzungsvorgänge im Tierkörper bei Fütterung mit Fleisch und Fett. Zeitschr. f. Biol. Bd. 9 S. 1. 1873. M. Rubner, Die Gesetze des Energieverbrauches bei der Ernährung. Leipzig 1902. - A. Magnus-Levy, Pflüger's Arch. Bd. 55 S. 1. 1893.

2) Wilfarth, Zeitschr. f. analyt. Chem. Bd. 22 S. 336. - C. Neuberg, Hofmeister's Beitr. Bd. 2 S. 214-215. 1902. 
kannte Differenzen obwalteten, bleiben die Ausscheidungen vergleichbar. Ich habe doch dort, wo es wünschenswert war, als Zufubr den Wert eingesetzt, der auf Grund vielfacher früherer Analysierungen und der noch benutzbaren Anhaltspunkte, welche die Analysen des gereichten Fleisches boten, die grösste Wahrscheinlichkeit für sich hat. Natürlich will ich diese Werte nur unter diesem Vorbehalt geben. In den Tabellen, in denen übrigens durch däs Missgeschick nichts wesentliches unsicher wird, sind die betreffenden Zahlen durch Einklammerung kenntlich gemacht.

Nach der Darreichung des Futters erhielt die Hündin ein Liter Wasser vorgesetzt; der stets nachher noch vorhandene Rest wurde im Messzylinder bestimmt.

Der Harn wurde täglich kurz vor der Arbeitsleistung durch Katheterisieren abgegrenzt. Er wurde in einen Messzylinder entleert und das spezifische Gewicht nach der Abkühlung auf $15^{\circ} \mathrm{C}$. bestimmt. Durch vielfache Blasenspülung wurden die letzten Spuren des Harns noch gewonnen. Zum Schluss wurde die Blase mit 1\% iger Borsäurelösung gespült. Die Auffullung des Harns geschah im Messkolben in der Regel auf zwei Liter. In dem gut durchgemischten Harn wurde der Stickstoff sogleich bestimmt, der übrige Harn, durch Thymol und nach einiger Zeit durch Salzsäure konserviert, von drei $\mathrm{zu}$ drei Tagen zusammengebracht und in diesem Mischharn der Phosphorsäuregehalt durch Säuregemischveraschung nach Neumann's Verfahren ${ }^{1}$ ) festgestellt. Die übrigen Aschenbestandteile wurden an einem der ganzen Periode entsprechenden Durchschnittsharn bestimmt.

In den letzten Tagen der Versuche wurde auch in der Zwischenzeit zwischen den Katheterentleerungen Harn in den Stoffwechselkäfig gelassen. Das Gefäss, in welches dieser Harn abfloss, war stets reichlich mit Thymol beschickt. War der Harn während der Nacht gelassen worden, so wurde erst stets bei dem morgens um $9^{1 / 2}$ Uhr vorgenommenen Katheterisieren der Käfig gründlich mit destilliertem Wasser gespült. Dieses Spülwasser wurde, nachdem die Harnmenge (s. o.) bestimmt war, zu dem Tagesharn zugefügt.

Während der "Brunst" des Tieres wurde ab und zu etwas bluthaltiges Sekret auf die Tretbahn gelassen. Dieses wurde mit einer Pipette möglichst vollständig aufgesogen; es wurde dann noch mehr-

1) A. Neumann, Arch. f. (Anat. u.) Phys. 1900 S. 159. 
mals mit destilliertem Wasser nachgespült, in ein Leinentuch eingesogen und die gesamte gewonnene Flüssigkeit zum Harn gebracht.

Obwohl die Hündin vor dem Beginn des Versuchs geschoren war, gingen doch zahlreiche Haare in das Käfigspülwasser hinein. Von diesen wurde abfiltriert und das Filter gut gewaschen; in den gesammelten restierenden Haaren und Epithelgebilden wurde am Schluss des Versuchs der Stickstoff bestimmt.

Der typische Fleischkot wurde immer gleich bei der Entleerung aufgefangen und in tarierter Schale gewogen. Von jeder Portion wurde eine gewogene Menge in einem grossen Wägeglas nach dem Vorgange von Zuntz (l. c. S. 399 Anm. 1) mit 1\% igem SalzsäureAlkohol beschickt und, gut gemengt und verschlossen, im Exsikkator aufbewahrt. Der Rest wurde bei einer Temperatur unter $60^{\circ} \mathrm{C}$. im Vakuum getrocknet, lufttrocken zerkleinert, pulverisiert und so zur Ätherextraktion, Wassergehaltsbestimmung, Aschenanalyse und kalorimetrischen Untersuchung weiter verwendet; der Stickstoff dagegen wurde in der mit Salzsäure versetzten und so vor etwaigen Stickstoffverlusten sicher geschützten Kotpartie bestimmt.

Das Aufsammeln des Harns war am zweiten Tage nach der Operation, also einige Tage nach Abschluss des Ausnutzungsversuchs, dadurch verhindert worden, dass sich infolge einer Darmerkrankung des Hundes diarrhöischer Kot beimischte. Es gelang, durch Ersatz des bis dahin gereichten Pferdefleisches durch 250. g Rindfleisch, $57 \mathrm{~g}$ Schweineschmalz und $20 \mathrm{~g}$ Plasmon (pro Tag) die Darmstörung schnell zu beheben, so dass alsbald wieder zum alten Futter zurückgekehrt und die Abgrenzung für den Ruheversuch am 14. April (am sechsten Tage nach dem Beginn der Erkrankung) ohne Risiko gegeben werden konnte. Auch später erkrankte der Darm nicht wieder.

Für die Beurteilung der Lebendgewichtsveränderungen bietet der Verfolg der Wasseraufnahme und der Harnmengen bei konstantem Futter und ziemlicher Konstanz der Temperaturverhältnisse wertvolle Unterlagen, da diese die einzigen erheblich schwankenden Grössen sind, welche das Gewicht wesentlich beeinflussen. Über die Wasseraufnahme orientieren am besten Tab. 7 und 8 und Kurve III. Ich erwähne hier nur, dass dort, wo grössere Gewichtsschwankungen vorhanden sind, auch erheblichere Differenzen in der Menge des aufgenommenen Wassers beobachtet wurden. Nach der Amputation 
(5. April 1907) wurde einige Zeit hindureh täglich mehr Wasser aufgenommen, als es in der Arbeitsperiode geschehen war. Weder die Körpertemperatur noch die Temperatur des Aufenthaltsraumes des Tieres war in dieser Zeit erhöht über die Werte der vorhergehendlen Enoche.

Tabelle 7.

Tïgliche Wasseraufnahme und Harnmenge beim ruhenden Amputationshund II.

\begin{tabular}{|c|c|c|c|c|}
\hline $\begin{array}{c}\text { Datum } \\
1907\end{array}$ & $\begin{array}{c}\text { Trinkwasser } \\
\mathrm{ccm}\end{array}$ & $\begin{array}{c}\text { Ilarnmenge } \\
\text { cem }\end{array}$ & $\begin{array}{c}\text { Spezifisches } \\
\text { Gewicht } \\
\text { des Harns } \\
\text { g }\end{array}$ & $\begin{array}{c}\text { Jebend } \\
\text { gewicht } \\
\text { g }\end{array}$ \\
\hline 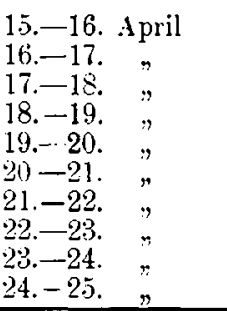 & $\begin{array}{r}95 \\
170 \\
99 \\
205 \\
49 \\
130 \\
260 \\
250 \\
170 \\
100 \\
\end{array}$ & $\begin{array}{l}380 \\
346 \\
290 \\
295 \\
200 \\
238 \\
254 \\
282 \\
363 \\
265\end{array}$ & $\begin{array}{l}1,032 \\
1,036 \\
1,040 \\
1,027 \\
1,041 \\
1,0: 35 \\
1,039 \\
1,038 \\
1,0988 \\
1,040\end{array}$ & $\begin{array}{l}10670 \\
10740 \\
10770 \\
10870 \\
10870 \\
10920 \\
11050 \\
11030 \\
11080 \\
11120\end{array}$ \\
\hline Mittel & 157,8 & 291 & 1,037 & - \\
\hline
\end{tabular}

Tabelle 8 .

Tägliche Wasseraufnahme und Harnmenge beim arbeitenden Anıutationshund II.

\begin{tabular}{|c|c|c|c|c|}
\hline $\begin{array}{c}\text { Datum } \\
1907\end{array}$ & $\begin{array}{c}\text { Trinkwasser } \\
\text { ccm }\end{array}$ & $\begin{array}{c}\text { Harnmenge } \\
\text { ccm }\end{array}$ & $\begin{array}{c}\text { Spezifisches } \\
\text { Gewicht } \\
\text { des Harns } \\
\mathrm{g}\end{array}$ & $\begin{array}{l}\text { Lebend- } \\
\text { gewicht } \\
\text { g }\end{array}$ \\
\hline 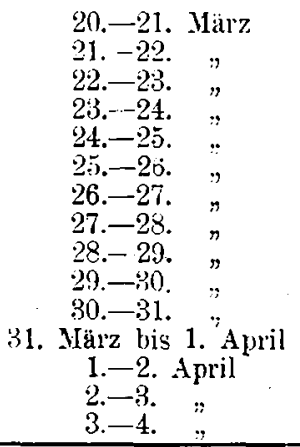 & $\begin{array}{l}337 \\
190 \\
280 \\
70 \\
365 \\
400 \\
17.5 \\
325 \\
350 \\
305 \\
360 \\
320 \\
210 \\
215 \\
292\end{array}$ & $\begin{array}{l}440 \\
430 \\
384 \\
295 \\
325 \\
298 \\
275 \\
343 \\
438 \\
340 \\
317 \\
236 \\
242 \\
220 \\
305\end{array}$ & $\begin{array}{l}1, \overline{032} \\
1,0325 \\
1,0425 \\
1,0: 34 \\
\overline{1} \overline{0} \\
1,040 \\
1,024 \\
1,0315 \\
1,028 \\
1,08375 \\
1,099 \\
1,0875 \\
1,0831\end{array}$ & $\begin{array}{l}11350 \\
11300 \\
11300 \\
11230 \\
11330 \\
11300 \\
11380 \\
11260 \\
11250 \\
11260 \\
11320 \\
11330 \\
11400 \\
11400 \\
11410\end{array}$ \\
\hline Wittel & 279,6 & 326 & 1,034 & - \\
\hline
\end{tabular}


Untersuchungen über den Einfluss: der Muskelarbeit auf dic Organe etc. 419

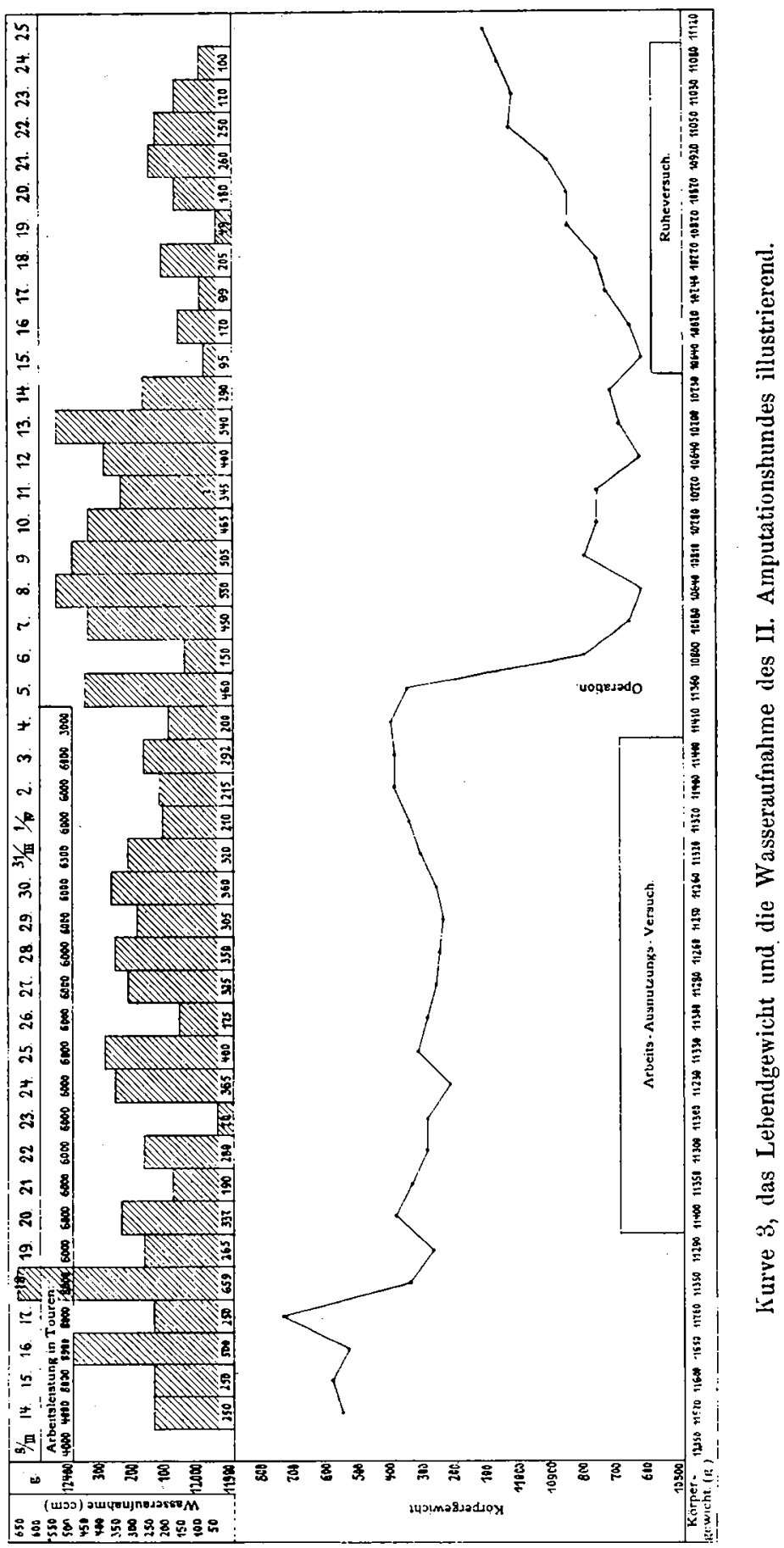


Die $\mathrm{H}$ a r n m e nge, die während der Arbeit ausgeschieden wurde, war grösser als dic, welche das ruhende lier entleerte. In ersteren Falle betrug sie im Mittel pro Tag $326 \mathrm{ccm}$, während der Ruhe dagegen nur $291 \mathrm{ccm}$. Diese Beobachtung, ferner das niedrige spezifische Gewichı des Harns (1034 wäbrend der Muskelarbeit gegenüber einem Ruhewert von 1036) entsprechen durchaus den Angaben, welche sich in der Zuntz-Schumburg'schen Physiologie des Marsches (l. c., S. 147) über diese Verhältnisse finden.

Wird die Menge der im Verlaufe von 24 Stunden abgesonderten festen Stoffe des Harns mit dem $\mathrm{H}$ äser'schen Koeffizienten angenähert berechnet, so bringen meine Zahlen eine Vermehrung der festen Substanzen in dem während der Arbeitsleistung abgeschiedenen Harn zum $\Lambda$ usdruck. da so für den Ruheharn im Mittel pro Tag 23,8 g, für den Arbeitsharn 2̌,8 g feste Bestandteile gefunden werden. Da bei der Arbeit etwas mebr Natrium ausgeschieden wurde $\left(0,53 \mathrm{~g} \mathrm{Na}_{2} \mathrm{O}\right.$ gegentiber $0,47 \mathrm{~g}$ pro Tag bei der Ruhe), dürfte bauptsächlich das die Dichte des Ilarns wegen seines hohen spezifischen Gewichtes besonders modifizierende Chlornatrium an der Vermehrung der Ausscheidung fester Stoffe beteiligt sein.

Ein solches Parallelgehen der Salzausfuhr mit der Diurese, wie es bier der Fall ist, ist auch unter anderen Umständeu vielfach beobachtet worden. So haben schon die Versuche von 0 . Loewi ${ }^{1}$ ) dargetan, dass infolge Hinderung der Rückresorption der gelösten Salze mit dem Ansteigen der Diurese die Trockensubstanzmenge sowie die Chloridausfuhr bedeutend gesteigert werden. Experimente von Dreser und Galeotti ${ }^{2}$ ) bezeugen das gleiche. Dies gilt aber nur für hohen Wassergehalt des Körpers. Bei Wassermangel wirken ja z. B. die Diuretika, die sich sonst der Arbeit analog verbalten, nicht. Fs ist also anzuuehmen, dass, wenn die Arbeitsleistung schon einige Zeit angedauert hat und kein neues Wasser im Überschuss zugegeben wird, dic von $\mathrm{Zuntz}$ und später auch you anderen und hier von mir beobachtete Steigerung der

1) 0. Loewi, Lntersuchungen zur Physiologie und Pharmakologie der Nierenfunktion. Arch f. exp. Path. und Pharm. Bd. 48 S. 410. 1902.

2) H. Ireser, Über das 1,3-Dimethylxanthin und seine diuretische Wirkung beim gesunden Nenschen. Pflüger's Archip Bd. 120 S. 1. 1904. G. Galeotti, ̈̈ber die Arbeit, welche die Xieren leisten, um den osmotischen Druck des Blutes auszugleichen. Arch. f. (Anat, u.) Phys. 1902 S. 200. 
Diurese bei der Arbeit versiegt. Um zu erfahren, wic die tatsächlichen Verhältnisse liegren, habe ich für je eine Hälfte der Arbeitsperiode Wasseraufnabme, Harnmenge und spezifisches Gewicht gesondert pro 'Tag berechnet und die erhaltenen Zahlen in der Tab. 9 zusammengestellt. Man sieht, dass die Diurese in der zweiten Periode der Arbeit stark abgefallen ist, wobei die Aufnahme von Wasser sogar etwas höher als früber liegt. Die Fixa sind von $8 \%$ des Harngewichts auf $7,4 \%$ heruntergegangen. Es verhält sich also wie bei der durch Trinken vongrossen Wassermengen hervorgerufenen Steigerung der Diurese; die gesteigerte Ausfuhr der Fixa hält eben nur so lange an, als noch dem Körper entziehbare Salzeda sind.

Tabelle 9 .

Mittlere tägliche Wasseranfinahme und Harnmenge beim arbeitenden Imputationshund II.

\begin{tabular}{|c|c|c|c|c|c|}
\hline & $\begin{array}{c}\text { Trink- } \\
\text { wasser } \\
\text { ccm }\end{array}$ & $\begin{array}{l}\text { Harn- } \\
\text { menge } \\
\text { ccm }\end{array}$ & $\begin{array}{c}\text { Spez. } \\
\text { Gewicht } \\
\text { des Ilarns }\end{array}$ & $\begin{array}{c}\text { Harnfixa } \\
\text { (Ha es er- } \\
\text { scher Ko- } \\
\text { effizient) } \\
\mathrm{g}\end{array}$ & $\begin{array}{c}\text { Harn- } \\
\text { wasser } \\
\text { g }\end{array}$ \\
\hline $\begin{array}{c}\text { I. Periode }(21 .-27 . \text { März } \\
1907 \text { einschl. })\end{array}$ & $\int 268$ & $849(362 \mathrm{~g})$ & 1036 & 29 & 833 \\
\hline $\begin{array}{l}\text { II. Periode (28. März bis } \\
\text { 3. April } 1907 \text { cinschl.) }\end{array}$ & 293 & $300(310 \mathrm{~g})$ & 1032 & 23 & 287 \\
\hline
\end{tabular}

Fhe ich näher auf die Bilanz eingehe, erwähne ich über das Verhalten der Kotausscheidung, dass in der Arbeitsbilanzzeit $191 \mathrm{~g}$, während das Tier ruhte $146^{\circ} \mathrm{g}$ frischer Kot im ganzen entleert wurden. Das macht im Durchschnitt pro Tag fur das arbeitende Tier 12,7, für das rubende $14,6^{\circ} \mathrm{g}$ frischen Kot. Fs ist also in der Arbeitszeit weniger Kot entleert worden. In dieser Zeit kamen 7 Kotentleerungen auf 15 Tage, also alle 2 Tage eine; bei der Ruhe 5 auf 10 Tage, also dieselbe Zahl der Entleerungen. Ein Einfluss der Arbeit auf die Peristaltik des übrigens während der Arbeit stets nüchterneu Tieres, der sich z. B. in Pflüger's ${ }^{1}$ ) Versuchen ergeben hatte, trat hier also nicht zut age.

1) E. P flüger, Über Fleisch- und Fettmästung. Pflüger's Arch. Bd. 52 S. 15. 1892. 
Auch die Untersuchung der Nährstoffausnutzung hat keine Unterschiede ergeben, welche das arbeitende vom ruhenden Tier in dieser Hinsicht genügend charakterisieren würden. Die Ergebnisse stehen also in Einklang mit dem Resultat der sorgfältigen Untersuchungen von Rosenberg'). In diesen war ja sogar während der Magen- wie wăhrend der Darmverdauung geleistete anstrengende Arbeit nicht imstande gewesen, die Ausnutzung abzuändern. Haben doch auch die Untersuchungen von Atwater, von $7 \mathrm{untz}$ und seinen Mitarbeitern bei der Höhenexpedition, von Heinsheimer ${ }^{2}$ ) nichts ergeben, was die alte Anschauung von der Schädigung der Verdauungsenergie des Darmes bei Muskelarbeit stützen könnte (vgl. bezüglich der Daten Tab. 10 und 11).

Tabelle 10 .

Ausnutzungsversuch am ruhenden Amputationshund II.

\begin{tabular}{|c|c|c|c|}
\hline & $\begin{array}{c}\text { Trocken- } \\
\text { substanz } \\
g\end{array}$ & $\begin{array}{c}\text { Ätherextrakt } \\
\mathrm{g}\end{array}$ & $\begin{array}{c}\text { Stickstoff } \\
\mathrm{g}\end{array}$ \\
\hline $\begin{array}{l}\text { Pferdetteisch } \\
\text { Schweineschmalz } \ldots \ldots\end{array}$ & $\begin{array}{c}(943,1) \\
448,0 \\
\end{array}$ & $\begin{array}{c}(101,7) \\
447,8\end{array}$ & $\begin{array}{c}(117,0) \\
0,2\end{array}$ \\
\hline Sa. & $(1391,1)$ & $(549,5)$ & $(117,3)$ \\
\hline Ausscheidung im Kot .... & 69,1 & 12,0 & $4.7^{-}$ \\
\hline $\begin{array}{l}\text { Also nausgenutzt" } \ldots \ldots . . \\
\text { Prozentsatz der Ausnutzung. . . }\end{array}$ & $\begin{array}{l}1322,0 \\
95 \%\end{array}$ & $\begin{array}{l}5: 37,5 \\
93 \%\end{array}$ & $\begin{array}{l}112,6 \\
\mathrm{si}^{0} ; 0\end{array}$ \\
\hline
\end{tabular}

Tabelle 11 .

Ausnutzungsversuch am arbeitenden Amputationshund II.

\begin{tabular}{|c|c|c|c|}
\hline & $\begin{array}{c}\text { Trocken- } \\
\text { substanz } \\
g\end{array}$ & Ätherextrakt & $\begin{array}{c}\text { Stickstoff } \\
\text { g }\end{array}$ \\
\hline $\begin{array}{l}\text { Pferdefleisch } \\
\text { Schweineschmalz }\end{array}$ & $\begin{array}{c}(1414,7) \\
974,1 \\
\end{array}$ & $\begin{array}{c}(152,6) \\
973,8 \\
\end{array}$ & $\begin{array}{r}(175,3) \\
\quad 0,8 \\
\end{array}$ \\
\hline$\therefore \quad \mathrm{Sa}$ & $(2388,8)$ & $(1125,9)$ & $(176,1)$ \\
\hline Ausscheidung im Kot .... & 80,95 & 11,5 & 7,9 \\
\hline $\begin{array}{l}\text { Also yausgenutzt }{ }^{\alpha} \ldots \ldots \ldots \\
\text { Prozentsatz der Ausputzung } . .\end{array}$ & $\begin{array}{c}(2307,9) \\
9 \% 0_{i 0}^{\prime}\end{array}$ & $\begin{array}{c}(1114,4) \\
90 \%\end{array}$ & $\begin{array}{l}(168,2) \\
95 \%\end{array}$ \\
\hline
\end{tabular}

1) S. Rosenberg, Über den Einfluss kðrperlicher Anstrengung auf die Ausnützung der Nahrung. Pflüger's Arch. Bd. 52 S. 401-415. 1892.

2) F.Hein sheimer, Experimentelle Untersuchungen über die lesorptionskraft des Darmes bei Überernährung und Muskelarbeit. Med. Klin. Bd. 4 S. 1915-1917. 1908. 
Immerhin kann in meinen Zablen für die chemische Zusammensetzung des Kotes eine Bestätigung der Pflüger'schen Angabe, dass der Kot des arbeitenden Tieres (weniger Trockensubstanz und) mehr Stickstoff enthält, gesehen werden. Bezüglich des Fettes ist der Befund weniger sicher. Ich habe aus den vier Versuchen an Hund A Pflüger's Mittelwerte berechnet und sie in Tab. 19 (S. 433) der Zusammensetzung des Arbeitskotes gegenübergestellt.

An dieser Stelle möchte ich noch einfügen, was ich uber die A usnutzung bei einem wachsenden arbeitenden Hund und beim Amputationshund I bei Ruhe und Arbeit erfabren habe.

Bei dem ersteren wurde das Fleisch morgens nach der Arbeitsleistung gereicht, der Milchreis am Nachmittag gegeben. Beim Amputationshund I wurde dagegen anders verfahrev. Er erhielt morgens um $11 \mathrm{Uhr}$, nachdem er die Hälfte der zu leistenden Tretbahnarbeit hinter sich hatte, das ganze Futter (Pferdefleisch und Schmalz), wurde dann aber am Nachmittage, 6-7 Stunden nach der Fütterung, zur Absolvierung der zweiten Hälfte der Arbeit herangeholt. Es fiel also auch diese zweite Hälfte der Arbeitsleistung nicht in das Maximum der Verdauung ${ }^{1}$ ). Es wurde Wert darauf gelegt, dass die Kothildung irgendwie nachweisbar beeinflussende Nährstoffe in den beiden zu vergleichenden Perioden der Ruhe und der Arbeit in genau der gleichen Menge und Form gereicht wurden. Die Zulage von Fett beeinflusst die Kotbildung bekanntlich äusserst wenig.

Für den kleinen Arbeitshund II fehlt ein Vergleichsausnutzungsversuch in der Rube. Ich gebe aber dennoch die Zahlen hier wieder, weil sie zeigen, dass die Stickstoffausnutzung bei diesem arbeitenden Tier immerhin so hoch lag wie bei dem Amputationshund $I$ in der Ruhe und höher als z. B. bei den beiden Hunden Rogozinskis (1. c. S. 404 S. 226 [Arbeit 94,97\%, Ruhe $94,16 \%$ N-Ausnutzung $\mid$ ).

1) Nach den Angaben von E. Zunz (Contribution à l'étude de la digestion de la viande crue et de la viande cuite, chez le chien. Mém. cour. et autr. mém. publ. par l'Acad. roy. de méd. de Belg. t. 19 fasc. 3 p. 36. 1906) ist beim Hunde nach 14 stunden die gastrische Verdauung von $400 \mathrm{~g}$ Pferdefleisch noch nicht beendet. Sie ist aber im Anfang reger als späterhin; jedenfalls ist das Maximum aber 6-7 Stunden nach der Fütterung überschritten. 
Die Versucbsperiode dauerte sieben Tage:

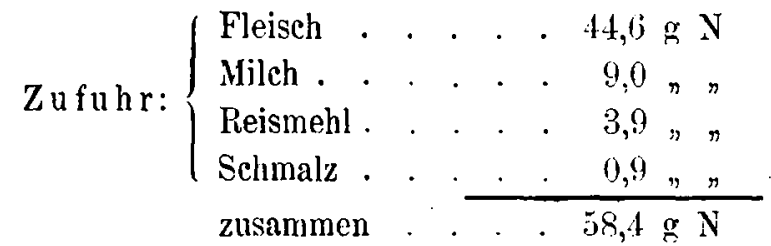

$$
\begin{aligned}
& \text { Ausfuhrim Kot: } \\
& \text { Differenz . . } 55,6 \mathrm{~g} \mathrm{~N} \text {. } \\
& \text { Prozentsatz der Ausnutzung also } 95,2 \% \text {. }
\end{aligned}
$$

Am Amputationshund I wurden drei Ausnutzungsversuche angestellt. Alle dauerten längere Zeit; die beiden Ruhe;ersuche - der eine vor, der andere nach der Amputation - 8 bzw. 22, der Arbeitsversuch 8 Tage.

Iie Analysenzablen sind bereits oben (vgl. Tab. 6) mitgeteilt worden. Der Kot wurde wiederum mit Kieselsäure abgegrenzt. Über die erhaltenen Mengen und die Zusammensetzung orientiert Tab. 12. Hiernach gestaltete sich die Ausnutzung in der Weise, wie Tab. 13, 14 und 15 sie wiedergeben. Wie insbesondere der Vergleich der in der Tab. 16 zusammengestellten Ergebnisse aller Ausnutzungsversuche an der Hündin lehrt, haben wesentliche Unterschiede $z$ wischen den beiden Perioden der Ruhe und Arbeit nicht bestanden.

Tabelle 12.

\begin{tabular}{|c|c|c|c|c|}
\hline & \multirow{2}{*}{$\begin{array}{l}\text { Kot- } \\
\text { menge } \\
\mathrm{g}\end{array}$} & \multicolumn{3}{|c|}{ Prozent der frischen Substanz } \\
\hline & & $\begin{array}{c}\text { Trocken- } \\
\text { substanz } \\
v_{i}\end{array}$ & $\begin{array}{c}\text { Äther- } \\
\text { extrakt } \\
\% \%\end{array}$ & $\begin{array}{c}\text { Stick- } \\
\text { stoff } \\
\%\end{array}$ \\
\hline $\begin{array}{l}\text { Rub e ausnutzungsversuch I } \\
(10 .-18 . \text { Juni 1906.) }\end{array}$ & 225 & 29,3 & 2,7 & 2,0 \\
\hline $\begin{array}{l}\text { Ruhe ausnutzungsversuch II } \\
\quad \text { (14. Juli bis } 1 \text {. August } 1906 \text {.) }\end{array}$ & 479 & 27,4 & 3,4 & 2,3 \\
\hline $\begin{array}{l}\text { Arbeits ausnutzungsversuch. } \\
(1 .-14 . \text { Juli } 1906 .)\end{array}$ & 139 & 35,6 & 4,0 & 3.1 \\
\hline
\end{tabular}

Zusammensetzung des Kotes in den Insnutzungsrersuchen am Imputationshund $I$. 
Tabelle 13.

I. Ausnutzungsversuch am ruhenden Amputationshund I.

\begin{tabular}{|c|c|c|c|}
\hline & $\begin{array}{l}\text { Trocken- } \\
\text { substanz } \\
\mathrm{g}\end{array}$ & $\begin{array}{l}\text { Äther- } \\
\text { extrakt } \\
\text { g }\end{array}$ & $\begin{array}{l}\text { Stickstoff } \\
\mathrm{g}\end{array}$ \\
\hline $\begin{array}{l}\text { Pferdefleisch }(2560 \mathrm{~g}) \text { 9.-16. Juni } 1906 \\
\text { einschliesslich } \\
\text { Schweineschmalz }(280 \mathrm{~g}) . \\
\end{array}$ & $\begin{array}{l}670,7 \\
278,0\end{array}$ & $\begin{array}{r}71,2 \\
277,3\end{array}$ & $\begin{array}{r}84,7 \\
0,7\end{array}$ \\
\hline Ausscheidung im Kot ........ & $\begin{array}{r}948,7 \\
66,0 \\
\end{array}$ & $\begin{array}{r}348,5 \\
6,0 \\
\end{array}$ & $\begin{array}{r}85,4 \\
4,6 \\
\end{array}$ \\
\hline 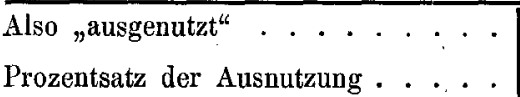 & $\begin{array}{r}\left.882,8^{1}\right) \\
93,0^{\%} \%\end{array}$ & $\begin{array}{l}342,5 \\
98,0 \%\end{array}$ & $\begin{array}{l}80,8 \\
\mathbf{9 4 , 6} \%\end{array}$ \\
\hline
\end{tabular}

Tabelle 14.

II. Ausnutzungsversuch am ruhenden Amputationshund I.

\begin{tabular}{|c|c|c|c|}
\hline & $\begin{array}{c}\text { Trocken- } \\
\text { substanz } \\
\mathrm{g}\end{array}$ & $\begin{array}{l}\text { Ather- } \\
\text { extrakt } \\
\mathrm{g}\end{array}$ & $\begin{array}{l}\text { Stickstoff } \\
\mathrm{g} \\
\end{array}$ \\
\hline $\begin{array}{l}\text { Pferdefleisch }(9570 \mathrm{~g})(10 .-31 . \text { Juli } 1906 \\
\text { einschliesslich) } \\
\text { Schweineschmalz }(330 \mathrm{~g}) \cdot \ldots \ldots \\
\end{array}$ & $\begin{array}{r}2863,3 \\
327,7 \\
\end{array}$ & $\begin{array}{l}645,0 \\
326,8 \\
\end{array}$ & $\begin{array}{r}331,1 \\
0,9 \\
\end{array}$ \\
\hline Ausscheidung im Kot. . . . . . . & $\begin{array}{r}3191,0 \\
131,2 \\
\end{array}$ & $\begin{array}{r}971,8 \\
16,4 \\
\end{array}$ & $\begin{array}{r}332,0 \\
11,0 \\
\end{array}$ \\
\hline $\begin{array}{l}\text { Also „ausgenutzt" }{ }^{\prime} \ldots \ldots \\
\text { Prozentsatz der Ausnutzung . . . . . . }\end{array}$ & \begin{tabular}{r|}
3059,8 \\
$\mathbf{9 6 , 0} \%$
\end{tabular} & $\begin{array}{r}955,4 \\
\mathbf{9 8 , 3} \%\end{array}$ & $\begin{aligned} 320,9 \\
96,7 \%\end{aligned}$ \\
\hline
\end{tabular}

Tabelle 15 .

Ausnutzungsversuch am arbeitenden Ampntationshund I.

\begin{tabular}{|c|c|c|c|}
\hline & $\begin{array}{c}\text { Trocken- } \\
\text { substanz } \\
\mathrm{g}\end{array}$ & $\begin{array}{c}\text { Ätlier- } \\
\text { extrakt } \\
\mathrm{g}\end{array}$ & $\begin{array}{c}\text { Stickstoff } \\
\mathrm{g}\end{array}$ \\
\hline 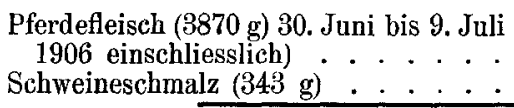 & $\begin{array}{r}1043,6 \\
340,6 \\
\end{array}$ & $\begin{array}{l}233,9 \\
339,7 \\
\end{array}$ & $\begin{array}{r}114,4 \\
0,9 \\
\end{array}$ \\
\hline Ausscheidung im Kot . . . . . . & $\begin{array}{r}1384,2 \\
49,4\end{array}$ & $\begin{array}{r}573,6 \\
5,5\end{array}$ & $\begin{array}{r}115,3 \\
4,2\end{array}$ \\
\hline 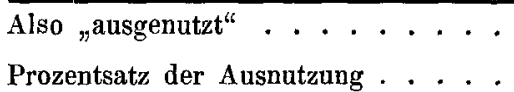 & $\begin{array}{r}1334,7 \\
96,4 \%\end{array}$ & $\begin{array}{r}568,1 \\
99,0 \%\end{array}$ & $\begin{aligned} 111,0 \\
96,3 \%\end{aligned}$ \\
\hline
\end{tabular}

1) Aus den Originalanalysenzahlen aufgerechnet.

Pflüger's Archiv für Physiologie. Bd. 133. 
Tabelle 16.

Ergebnisse der Ausnutzungsversuche am Amputationshund I.

\begin{tabular}{|c|c|c|c|}
\hline & $\begin{array}{c}\text { Trocken- } \\
\text { substanz } \\
\%\end{array}$ & $\begin{array}{c}\text { Äther- } \\
\text { extrakt } \\
\%\end{array}$ & $\begin{array}{c}\text { Stickstoff } \\
\%\end{array}$ \\
\hline $\begin{array}{l}\text { Ruheausnutzungsversuch I. } \\
\text { Ruheausnutzungsversuch II } \\
\text { Arbeitsausnutzungsversuch . }\end{array}$ & $\begin{array}{l}93 \\
96 \\
96\end{array}$ & $\begin{array}{l}98 \\
98 \\
99\end{array}$ & $\begin{array}{l}95 \\
97 \\
96\end{array}$ \\
\hline
\end{tabular}

Was aber die Zersetzung von Eiweiss angeht, so ist eine Differenz allerdings da (vgl. Tab. 17 und 18); denn einem mittleren Ruheharn-Stickstoffwert von $10,11 \mathrm{~g} \mathrm{~N}$ pro Tag steht ein Arbeitswert von $9,95 \mathrm{~g}$ Harnstickstoff gegenüber. Ist dieser Unterschied auch gering, so ist er doch bedeutungsvoll, weil die Ruheperiode sich an die Amputation anschliesst, d. h. einer Zeit angehört in der prozentual weniger tätiges Körpermaterial zersetzt wurde. Es ist ferner zu erwägen, dass dem Ruheversuch eine Periode abnorm gesteigerten Eiweisszerfalles voranging. An den beiden der Operation folgenden Tagen stieg der Harnstickstoff von dem Perjodenmittel von $9,95 \mathrm{~g} \mathrm{~N}$ auf $10,46 \mathrm{~g} \mathrm{~N}$ am ersten und 12,25 $\mathrm{g} \mathrm{N}$ am zweiten Tage nach der Amputation. Während der folgenden Tage dürfte der Stick-

Tabelle 17.

Stickstoffausscheidung während der Ruhe beim Amputationshund II.

\begin{tabular}{|c|c|c|c|c|c|}
\hline $\begin{array}{c}\text { Datum } \\
1907\end{array}$ & $\begin{array}{c}\text { Harn- } \\
\text { stick- } \\
\text { stoff } \\
\text { g }\end{array}$ & $\begin{array}{c}\text { Kot- } \\
\text { stick } \\
\text { stoff } \\
\text { g }\end{array}$ & $\mid \begin{array}{c}\text { Stickstoff in } \\
\text { Epidermis- } \\
\text { gebilden und } \\
\text { im Käfig- } \\
\text { sptulwassex } \\
\mathbf{g}\end{array}$ & $\begin{array}{c}\begin{array}{c}\text { Ins- } \\
\text { gesamt }\end{array} \\
\text { g }\end{array}$ & Bemerkungen \\
\hline 14.-15. April & 11,40 & - & - & - & \\
\hline $\begin{array}{l}15 .-16 . \\
16 .-17 . \\
17 .-18 . \\
18 .-19 . \\
19 .-20 . \\
20 .-21 .\end{array}$ & $\begin{array}{r}11,91 \\
9,85 \\
9,19 \\
9,12 \\
9,81 \\
9,75 \\
10,56 \\
10,17 \\
9,78\end{array}$ & $\begin{array}{l}0,47 \\
0,47 \\
0,47 \\
0,47 \\
0,47 \\
0,47 \\
0,47 \\
0,47 \\
0,47\end{array}$ & $\begin{array}{l}0,04 \\
0,04 \\
0,04 \\
0,04 \\
0,04 \\
0,04 \\
0,04 \\
0,04 \\
0,04\end{array}$ & $\begin{array}{r}12,42 \\
10,36 \\
9,70 \\
9,63 \\
10,32 \\
10,26 \\
11,07 \\
10,68 \\
10,29\end{array}$ & 19. April Brunst! \\
\hline $24-25$. & 11,00 & 0,47 & 0,04 & $11,51\{$ & $\begin{array}{l}\text { 25. A pril Blutverlust } \\
\text { durch die Vulva. }\end{array}$ \\
\hline $\begin{array}{l}\text { Mittel der Periode } \\
\quad(15 .-25 . \text { April })\end{array}$ & 10,11 & 0,47 & 0,04 & 10,62 & \\
\hline
\end{tabular}


stoffverlust noch grösser gewesen sein, da Durchfall bestand. Zudem war ja am neunten und zehnten Tage nach der Amputation die Bilanz bei einer Stickstoffausscheidung von 11,40 bzw. 11,91 g pro Tag noch leicht negativ. Dieser dem Ruheversuch vorangegangene nicht unerhebliche Stickstoffverlust des Körpers lässt den an sich geringen Mehrzerfall in der Rubeperiode als guten Beweis für die Förderung des Stickstoffansatzes durch die Arbeit erscheinen.

Tabelle 18.

Stickstoffausscheidung während der Arbeit beim Amputationshund II.

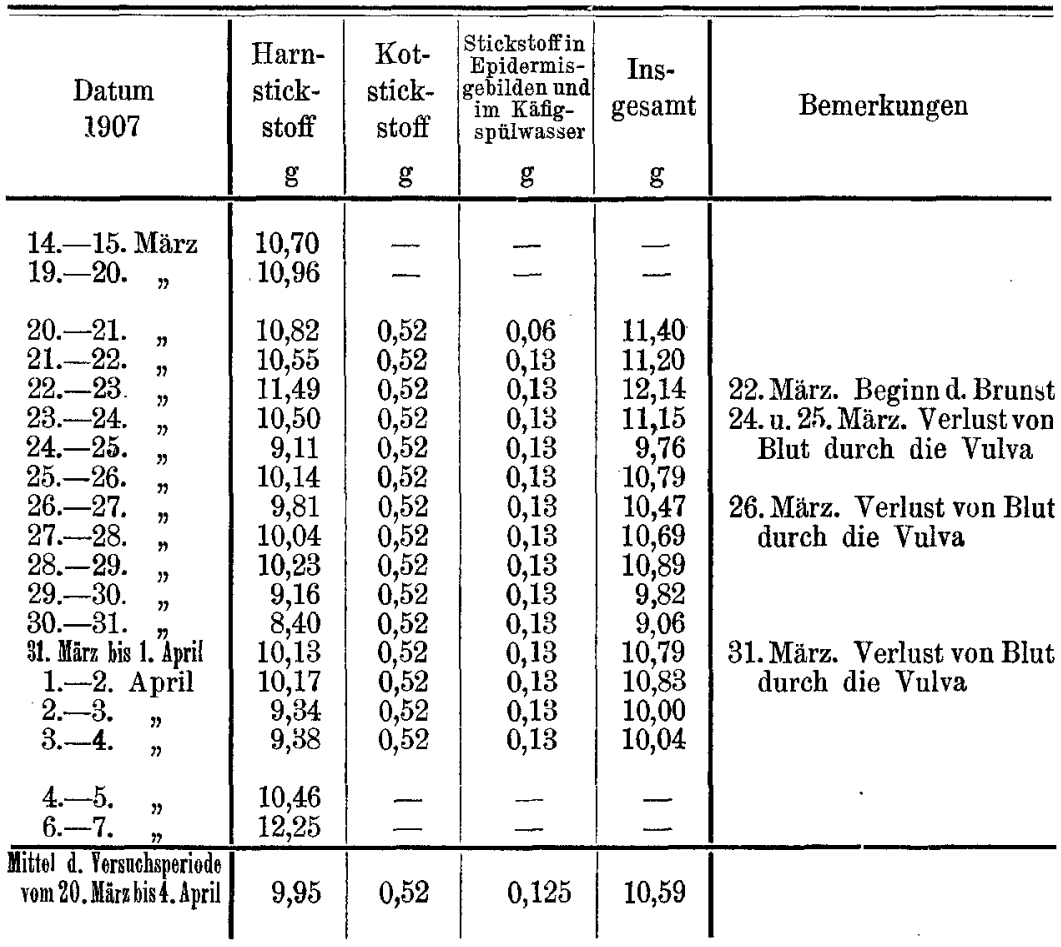

In den mitgeteilten Stickstoffausscheidungswerten fallen einige Unregelmässigkeiten auf. Analysenfehlern ist nicht schuld zu geben, da diese Zahlen mehrfach kontrolliert sind. Worauf sie beruben, ist schwer zu sagen. Zum Teil bestehen Beziehungen zum Eintreten der "Brunst". In die Arbeitsperiode fiel ihr Beginn am 22. März 1907. Die Hündin verlor sowobl an diesem Tage, wie am 24., 25., 26. und 31. März Blut aus der Vulva. Die Arbeit wurde in diesen Tagen, obwohl sie die Hündin jetzt sichtlich angriff, nicht unterbrochen. Dieser Periode geht ein Absinken der Stickstoffausscheidung 
parallel. In den nächsten, auf die ersten Verluste folgenden Tagen stieg die Stickstoffmenge wieder etwas an, um dann, als - wahrscheinlich infolge des unhygienischen Arbeitsvollzugs - die Blutung rezidivierte, wieder zu sinkeu. In die Ruheversuchszeit fiel dieselbe Komplikation am 19. April. Hier sank die Ausscheidungsgrösse des Stickstoffs ebenfalls, stieg aber bald trotz weiteren Fortbestandes der Brunst wieder leicht an.

Während der Arbeit machte anfänglich der Phosphorsäuregehalt der Exkrete die Stickstoffschwankungen mit, fiel aber dann, auch als der Stickstoff wieder anwuchs, weiter ab. In der Ruhezeit stieg der Phosphorsäuregehalt in den Ausscheidungen langsam an. (Über die Ursache des Anstiegs vgl. S. 447). Es erscheint deshalb nicht statthaft, aus meinen Versuchen auf einen Einfluss der Brunst auf die $\mathrm{P}_{2} \mathrm{O}_{5}$-Ausfuhr zu schliessen ${ }^{1}$ ). Es lässt sich a us den Daten nur das entnehmen, dass die Stickstoffausfuhr während der Brunst etwas niedrigere Werte annahm. Das stimmt ja auch mit den Ergebnissen der Untersuchungen anderer Autoren, insbesondere von Schrader und Schöndorff über die Menstruation ${ }^{2}$ ) überein. Die Beobachtung steht allerdings in Widerspruch mit den Feststellungen Hagemann's ${ }^{8}$ ), der eine Mehrzersetzung von Eiweiss während der Brunst konstatierte. Da aber in diesen Fällen die Brunstperiode durch die Begattung; und erste Schwangerschaft kompliziert war, sind die Daten $\mathrm{Hagemann}$ 's mit den unserigen nicht vergleichbar.

Um über die Quantität der Sekretion einigen Aufschluss zu gewinnen, habe ich am 22. und 23. April (Ruhe) eine Spülung von Uterus und Vagina vorgenommen. Die für den Stickstoff erhaltenen Zahlen sind so gering $(0,013$ bzw. $0,008 \mathrm{~g} \mathrm{~N})$, dass sie zeigen, dass der Blutverlust als solcher gänzlich vernachlässigt werden kann, und dass es sich hier nur um allgemeine Wirkungen der Brunst auf den Stoffumsatz handeln kann.

1) Schrader, Untersuchung über den Stoffwechsel während der Menstruation. Zeitschr. f. klin. Medizin Bd. 25 S. 72. 1894. - G. Ho ppe-Seyler, Brodersen u. Rudolph), Über den Blutverlust bei der Menstruation. Zeitschrift f. physiol. Chem. Bd. 42 S. 545. 1904.

2) Schöndorff, Öber den Einfluss der Schilddrüse auf den Stoffwechsel. Pflüger's Arch. Bd. 67 S. 395.1897.

3) O. Hagemann, Beitrag zur Kenntnis des Eiweissumsatzes im tierischen Organismus. Diss. Erlangen 1891. 
Der Berechnung des En e r gi i u m satzes sind beim Amputationshund II direkte Bestimmungen der Verbrennungswärme der Einund Ausgaben zugrunde gelegt worden. Sie gelten für die Ruheperiode vom 15. bis 24. April 1907 einsehliesslich und für die Arbeitszeit vom 20. März bis 3. April einschliesslich, umfassen also einen Zeitraum von $10 \mathrm{bzw}$. 15 Tagen.

In der Rubezeit (nach der Amputation) erhielt die Hündin täglich $350 \mathrm{~g}$ Pferdefleisch. Die kalorimetrische Untersuchung ergab pro $1 \mathrm{~g}$ Trockensubstanz im Mittel 5320,6 cal.; für Schmalz ${ }^{1}$ ) wurde pro $1 \mathrm{~g}$ ein mittlerer Brennwert von 9300,4 cal. gefunden. In 94,3 g Fleischtrockensubstanz täglich sind also 501,8 Cal. gereicht worden. Hinzu kommen 416,7 Cal. in Schmalz. Die gesamte Aufnahme machte also pro Tag 918,5 Cal. aus.

Von diesem Werte kommen in Abzug die in Harn und Kot abgegebenen Energiemengen.

Zur Bestimmung des Brennwertes wurde der Harn (Mischharn von je 3 Tagen) in Zelluloseblöckchen im Vakuum eingesogen und nach gründlichem Auswischen des Schälehens in der von Kroeker verbesserten Mahler'schen Bombe verbrannt. Bei der Verbrennung der Blöckchen bediente ich mich mit Vorteil der Praxis, den Draht mit einer feinen Nadel durch das Blöckchen zu ziehen. Ich kann diese Methode auf Grund meiner Erfahrungen nur empfehlen, da hierdurch Fehlbestimmungen, die auf mangelhaftem Kontakt beruhen, nicht mehr vorkommen können. Die Kontrolle am Stickstoffgehalt von beschickten Blöckchen garantierte die Richtigkeit der erhaltenen Verbrennungswerte. Die. Berechnung geschah nach der S t o h m a n n'schen Formel ${ }^{2}$ ) unter Berücksichtigung der Verbrennungswärme des verwendeten Eisendrahtes und der entstandenen Salpetersäure. Die Angabe von $\mathrm{Fries}^{3}$ ), dass die Mengen des eingelassenen käuflichen Sauerstoffs. Differenzen in den Resultaten bedingen, konnte ich für unsere Verhältnisse nicht bestätigen.

Mit der besprochenen Methodik wurden für den Ruheharn im Mittel mehrerer völlig übereinstimmender Verbrennungswerte 697,1 Cal. $=69,7$ Cal. pro Tag gefunden.

1) Das Schmalz wurde in Zelluloseblöckchen aufgesogen verbrannt.

2) Stohmann, Kleber u. Langbein, Methodik der Verbrennung usw. Journ. f. prakt. Chemie N. F. Bd: 39 S. 502.1889.

3) J. A. Fries, Investigations in the use of the bomb calorimeter. U. S. Dep. of Agricult. 1907 Nr. 94. S. A. 
Mit dem Kot wurden in derselben Periode 387,4 Cal. $=38,74$ Cal. pro 'Tag abgegeben.

Die Tagesbilanz stellt sich also für das ruhende Tier folgendermaassen dar:

$$
\begin{aligned}
& \text { Zufuhr . . . } 918,5 \text { Cal. (Fleisch }=-501,8 \text { Cal., } \\
& \text { Schmalz }=416,7 \text { Cal.) } \\
& \text { Verlust . . . } 108,4 \text { Cal. } \\
& \text { Differenz . . . } 810,1 \mathrm{Cal} .
\end{aligned}
$$

Für die Arbeits \%eit gelten folgende Zahlen:

Abgabe im Harn $=1026,3$ Cal. $=68,4$ Cal. pro Tag,

$$
n \quad \text { Kot }=464,0,=30,9, n \text { " }
$$

so dass also nur der Brennwert des Kotes von dem Rubewert abwich.

Die Gesamtausfuhr betrug 1490,3 Cal., d. s. pro Tag also 99,3 Cal.

Da die Zufuhr 1118,4 Cal. (501,8 Cal. im Fleisch, 616,6 Cal. im Schmalz) ausmachte, ist hicr die Rechnung für die Tagesbilanz:

$$
\text { 1118,4 Cal. }-99,3 \text { Cal. }=1019,1 \text { Cal. }
$$

Hiernach stellt sich der Verlust bei der Ruhe zu $12 \%$, bei der Arbeit der Hündin zu $9 \%$ heraus, so dass der physiologische Nutzeffekt bei der Arbeit $(91 \%)$ grösser war als in der Ruhe $(88 \%)$. Dieser Unterschied ist aber nicht als ein spezifischer zwischen Ruhe und Arbeit anzusehen, vielmehr beruht er im wesentlichen darauf, dass bei der Arbeit ein grösserer Prozentanteil des Energieverbrauchs durch das zu 98-99\% verwerthare Fett, bei der Ruhe durch das nur zu 70,5-72,9\% verwertbare Eiweiss bestritten wurde.

Zu der gleichen Schlussfolgerung wie die Bilanzrcchnuug führt die Ableitung des Nut $z$ wertes des gereichten Fleisches.

A. Ruhe. Täglicb wurden 94,3 g Fleischtrockensubstanz gereicht. Diese enthielt $10,17 \mathrm{~g}$, Fett ${ }$ und $11,70 \mathrm{~g}$ Stickstoff. Ia das Fleisch pro 1 g 5320,6 cal. lieferte, beträgt der Brennwert der Tagesportion 501,77 Cal. Rechnen wir hiervon den Brennwert des

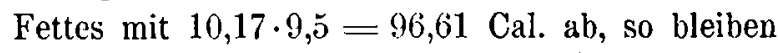

$$
501,77 \text { Cal. }-96,61 \text { Cal. }=405,16 \text { Cal. täglich }
$$

für das verabreichte Fleisch.

Nach den früheren Analysen (Tab. 6) kommen auf $100 \mathrm{~g}$ fettfreie Fleischtrockensubstanz im Mittel ca. 4,9 g Asche. Der Abzug beträgt also für 


$$
94,3 \mathrm{~g} \text { Fleisch }-10,2 \mathrm{~g} \text { Fett }=84,1 \mathrm{~g}
$$

fettfreies Fleisch 4,12 g Asche; d. h. $80,0 \mathrm{~g}$ fett- und aschefreies Trockenfleisch lieferten 405,16 Cal.

Es entspricht also $1 \mathrm{~g}$ fett- und aschefreie Fleischtrockensubstanz 5064,5 cal.

In $94,3 \mathrm{~g}$ trockenem Fleisch waren $11,7 \mathrm{~g}$. Stickstoff. $94,3 \mathrm{~g}$ Trockensubstanz entsprechen $80 \mathrm{~g}$ fett- und aschefreiem Trockenfleisch. Auf $1 \mathrm{~g}$ N kommen also $6,838 \mathrm{~g}$ fett- und aschefreie Fleischtrockensubstanz, die 34,64 Cal. Energiewert besitzen.

Pro Tag wurden $10,62 \mathrm{~g} \mathrm{~N}$ (Tab. 17) ausgeschieden. Demnach betrug die Verbrennungswärme des täglich umgesetzten Eiweisses

$$
10,62 \cdot 34,64=367,88 \mathrm{Cal} .
$$

$\mathrm{Nutzbar}$ waren davon

367,88 Kal.

- 108,44 (Harn- und Koteal.)

259,44 Cal.; d. s. 70,52\% der Energiezufuhr.

Der Nutzwert pro $1 \mathrm{~g} N$ der Fleischzufuhr ist hiernach 24,43 Calorien.

B. Arbeit. Da die Fleischzufuhr die gleiche war, gilt hier ebenfalls für die Zufuhr die obenstehende Rechnung. Im übrigen kommt noch folgendes in Betracht.

Die Ausfuhr von Stickstoff betrug täglich (Tab. 18) $10,59 \mathrm{~g} \mathrm{~N}$. Von der Verbrennungswärme des täglich umgesetzten Fleisehes $=$ 366,84 Cal. waren nutzbar:

\section{6,84}

- 99,30 (Harn- und Kotcalorien)

267,54 Cal. unter Ansatz von 30,9 Kotealorien pro Tag.

Die Energieverwertung bemisst sich alsozu $72,93 \%$.

Der Nutzwert pro $1 \mathrm{~g} \mathrm{~N}$ ist, da $10,59 \mathrm{~g} \mathrm{~N}$ umgesetzt wurden und 267,54 Nutzcalorien in Betracht kommen, $=25,26 \mathrm{Cal}$.

Der gegebene Kraftvorrat war also während der Arbeit besser verwertet worden ${ }^{1}$. Bei Pflüger's Versuchen wurde in der Arbeit mehr durch den Kot verloren, bei mir in der Ruhe.

1) Nach Pflüger: Ruhe. $1 \mathrm{~g} \mathrm{~N}$ des Fleisches 26,76 Cal. (l. c.Bd. 31 S. 78).

$$
\text { Arbeit. 1" " " } 25,98 \text {. }
$$


1 g fett- und aschefreie Fleischsubstanz (trocken) lieferte bei der Ruhe

$$
\frac{5064,5 \cdot 70,52}{100}=3,57 \mathrm{Cal} \text {. }
$$

bei der Arbeit $\frac{5064,5 \cdot 72,93}{100}=3,69 \mathrm{Cal}$, im letzteren Falle also für $1 \mathrm{~g}$ : $\quad 3,69$

\begin{tabular}{|c|}
\hline$-3,57$ \\
\hline 0.12 \\
\hline
\end{tabular}

Im Mittel der Frentzel-Schreuer'schen Ruheversuche (Abh. III) ${ }^{1}$ ) lag der Nutzwert für $1 \mathrm{~g}$ fett- und aschefreie Fleischtrockensubstanz bei reiner Fleischfütterung bei 4,22 Cal. (Nutzwert von $76,07 \%$ ), also nicht unerheblich über meinen Zahlen. Auf $117,3 \mathrm{~g} \mathrm{~N}$-Zufuhr kamen bei meinem Hunde in der Ruhe $4,7 \mathrm{~g} \mathrm{~N}$ im Kot, also $4 \%$; Frentzel und Schreuer fanden nur $2 \%$; es war bei meinem Hunde also doppelt so viel Stickstoff im Kot verloren worden als in den erwähnten Versuchen. Die schlechtere Nutzung des zugeführten Eiweisses, die in meinem Versuch beobachtet wurde, erklärt sich also aus der schlechteren Aufnahme im Darm.

Zur besseren Veranschaulichung der besprochenen Verhältnisse stelle ich die Analysen des Fleischkotes dieser Versuchsreihen mit den Angaben, welche von Pflüger (s. o.), Frentzel und Schreuer ${ }^{2}$ ), Prausnitz ${ }^{3}$ ) und Rubner ${ }^{4}$ ) darüber vorliegen, tabellarisch zusammen (Tab. 19). Wie man sieht, besitzt der Kot meines Versuchs durchaus die Charakteristika des gut verdauten Fleischkotes. Wir können deshalb mit Recht in den oben diskutierten Versuchsresultaten einen wünschenswerten Beitrag zur Frage des Nutzwertes des Fleisches sehen. Aus diesem Grunde habe ich hier auch noch die Zahlen, die am Amputationshund I gewonnen wurden, in der Tabelle beigefügt.

1) J. Frentzel u. M. Schreuer, Der Nutzwert des Fleisches, Arch. f. (Anat. u.) Phys. 1902 S. 297-306. (Abh. III.)

2) J. Frentzel u. M. Schreuer, Die Zusammensetzung und der Energiewert des Fleischkotes. Arch. f. (Anat. u.) Phys. 1903 S. $460-479$. (Abh. IV.)

3) W. Prausnitz, Die chemische Zusammensetzung des Kotes bei verschiedenartiger Ernährung. Zeitschr. f. Biol. Bd. 35 S. 335-354. 1897.

4) M. Rubner, Die Gesetze des Energieverbrauches bei der Ernährung. S. 34. Leipzig 1902. 
Untersuchungen über den Einfluss der Muskelarbeit auf die Organe etc. 433

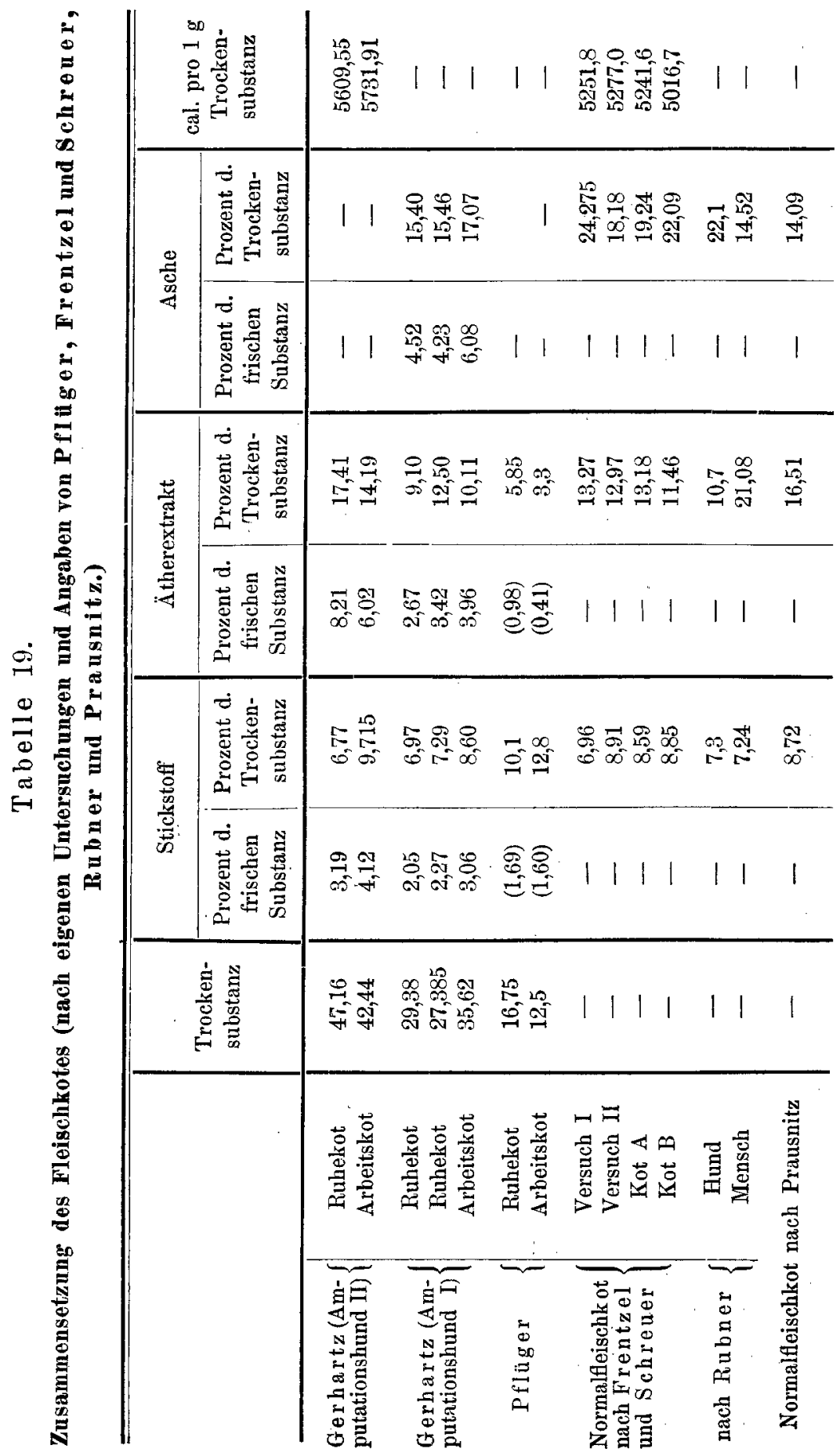


Aus schon oben erwähnten Daten lässt sich für $1 \mathrm{~g}$ Kot-N beim Amputationshund II in der Arbeitszeit ein Brennwert von $59,0 \mathrm{Cal}$, für aie $\mathrm{Ruhezeit}$ ein solcher von $82,9 \mathrm{Cal}$. berechnen. Die Zahlen sind wegen des wechselnden Fettgehaltes des Kotes schlecht vergleichbar. Ich führe deshalb für den fettfreie n Kot die Rechnung durch:

I. Ruhe. Pro Tag wurden im Kot ausgeschieden:

$$
\begin{array}{lll}
6,9 & \mathrm{~g} & \text { Trockenkot mit } \\
1,2 & \mathrm{~g} & \text { Ätherextrakt } \\
0,47 & \mathrm{~g} & \text { Stickstoff, }
\end{array}
$$

also $5,70 \mathrm{~g}$ fettfreie, aber aschehaltige Trockensubstanz. Insgesamt kam den $14,64 \mathrm{~g}$ täglichen frischen Kotes ein Brennwert von 38,74 Cal. zu.

Wir rechnen also für $5,70 \mathrm{~g}$ fettfreien Kot: 38,74 .Cal.

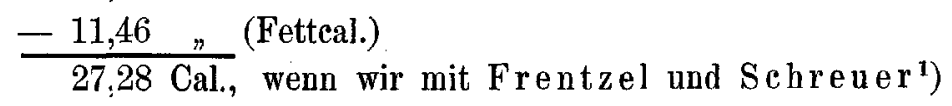
den Brennwert des Kotfettes zu 9,55 Cal. pro $1 \mathrm{~g}$ annehmen. $1 \mathrm{~g}$ dieses Kotes entsprechen nun $0,08 \mathrm{~g} \mathrm{~N}$ und auf der anderen Seite 4,79 Cal. Das gibt pro $1 \mathrm{~g} \mathrm{~N}$ in der fettfreien Kotsubstanz $59,9 \mathrm{Cal}$.

II. A r beit. Hier wurden täglich ausgeschieden:

$$
\begin{aligned}
& 5,40 \mathrm{~g} \text { Trockenkot mit } \\
& 0,77 \mathrm{~g} \text { Ätherextrakt } \\
& 0,52 \mathrm{~g} \text { Stickstoff, d. s. } 4,63 \mathrm{~g}
\end{aligned}
$$

fettfreie, aschehaltige Trockensubstanz. Der Brennwert der täglich ausgeführten Kotmenge (12,72 $\mathrm{g}$ frischer Kot) betrug 30,93 Cal.

$0,77 \mathrm{~g}{ }_{\text {Fett }}=7,35$ Cal. Es bleiben also für den fettfreien Kot $(4,63 g)$ 30,93 Cal.

$$
=\frac{7,35 \%}{23,58 \mathrm{Cal} .}
$$

Da nun auf $1 \mathrm{~g}$ fettfreien trocknen Kot $0,11 \mathrm{~g} \mathrm{~N}$ kommen, $1 \mathrm{~g}$ dieses Kotes aber 5,09 Cal. entspricht, so resultieren für $1 \mathrm{~g} \mathrm{~N}$ des fettreien Kotes 45,35 Cal.

Beide Zablen, die das „Mittel“ 52,6 Cal. repräsentieren, harmonieren durchaus mit früheren Befunden, so z. B. mit denen von

1) 1. c. Abh. IV S. 470 (S to hm ann 9,50 Cal. pro 1 g Neutralfett). 
Zuntz und seinen Mitarbeitern. Von diesen werden in der Höhenklimaarbeit Werte von 37,2 bis 71,1 Wärmeeinheiten pro Gramm N für fettfreien Kot genannt; das Mittel liegt also dort bei $53,35 \mathrm{Cal}$. Ich habe die Mittelwerte aus den Versuchen an je einer Versuchsperson berechnet und folgende recht naheliegende Zahlen erhalten: Waldenburg 51,2; Kolmer 58,2 ; Caspari 55,$9 ;$ Muller 58,2 ; Löwy 43,0; Zuntz 53,6 Cal. (Tab. IX a im Anhang der Höhenklimaarbeit 1. c.). Der früher von Frentzel und Schreuer (Abb. I) ${ }^{1}$ ) gefundene Mittelwert liegt allerdings etwas niedriger. Diese Autoren nennen pro $1 \mathrm{~g} \mathrm{~N}$ im Mittel von 9 Bestimmungen 48,91 Cal. unter Anrechnungvon 9500 cal. pro $1 \mathrm{~g}$ Kotfett (tatsächlich für $1 \mathrm{~g}$ Kotfett 9793,75 cal. gefunden, so dass $1 \mathrm{~g} \mathrm{~N}$ im fettfreien Kot 48,24 Cal.entsprach). Pflüger rechnete pro $1 \mathrm{~g} \mathrm{~N}$ des fettfreien Fleischkotes nur 28,2 Cal.

Es ist noch von Interesse, für den Harn die viel untersuchte Relation $\frac{\text { Calorien }}{\text { Stickstoff }}$ festzustellen.

In der ganzen Arbeitsperiode kommen auf 149,28 g $\mathrm{N}$ 1026,31 Cal., in der Ruheperiode auf 101,14 g N 697,01 Cal. Der calorische Quotient ist also in beiden Fällenderselbe, gleich 6,9. Fr ist identisch mit dem von Frentzel und Schreuer (l. c. Abh. III. S. 300 und 304) für den Fleischharn angegebenen.

In Energiebilanz, Stickstoffbilanz, den Daten für die Wasseraufnahme und Harnmengen sind die wichtigsten Unterlagen für eine Betrachtung des Wasserwechsels gegeben.

Nach den Bestimmungen von $\mathrm{Zuntz}$ und $\mathrm{Schumburg}$ (1. c.) entsprechen bei vorwiegender Fettverbrennung (wie hier) 4,686 cal.: 1 Liter Sauerstoff. Für den Hund berechnet sich nun auf 1 Liter Sauerstoff nach den von Porges und Pribram²) als Mittel von 25 Rubeversuchen angegebenen Zahlenwerten eine Lungenventilation von 21,2 Liter Atemluft; denn die Atemgrösse war pro Minute 1,35 Liter. Pro Minute wurden $63,6 \mathrm{ccm} \mathrm{O}_{2}$ auf-

1) J. Frentzel u. M. Schreuer, Der Nutzwert des Fleisches. Arch. f. (Auat. u.) Physiol. 1901 S. $293 \mathrm{ff}$. (Abh. I).

2) O. Porges u. E. Pribram, Über den respiratorischen Stoffwechsel nach ermüdender Arbeit. Biochem. Zeitschr. Bd. 3 S. 463.1907. 
genommen. Hier entspricht also 1 Liter Sauerstoff 21,2 Liter Atemluft. Auf der Tretbahn betrug die Atemgrösse pro Minute 8,53 Liter. Pro Minute wurden (S. $469 \mathrm{der}$ betr. Arbeit) $400 \mathrm{~cm} \mathrm{O}_{2}$ aufgenommen, so dass also 1 Liter $\mathrm{O}_{2}=21,32$ Liter Lungenventilation. Bei ruhiger Atmung änderte sich der Wert für die Atemluft also nicht merklich. Wir können also annehmen, dass 1 Cal. $\frac{21,26}{4,686}=4,54$ Liter Ventilation entspricht.

Für die Ruhezeit kommen 810,1 Nutzcalorien in Betracht; diesen entsprechen 3677,85 Liter Atemluft.

In der Arbeitszeit wurden pro Tag 1118,43 Cal. eingeführt; 99,35 Cal. gingen in Harn und Kot verloren. Im Organismus wurden also 1019,08 Cal. frei. Hiernach sind $\frac{1019,08 \cdot 21,16}{4,686}=$ $4623,51 \mathrm{Luft}$ respiriert worden.

Die in der Exspirationsluft ausgeführte Wassermenge betrug bei der gemessenen mittleren Körpertemperatur von $38,9^{\circ} \mathrm{C}$. unter der Voraussetzung vollständiger Sättigung $54,2 \mathrm{mg}$ pro Liter. In den 3677,85 Liter Atemluft der Ruheperiode (täglich) sind also $199,34 \mathrm{~g}$ Wasser ausgegeben worden. Die eingeatmete Luft enthielt im Mittel der Versuchsperiode im Liter $6,7 \mathrm{mg}$ Wasserdampf. In 3677,85 Liter Atemluft wurden also $24,64 \mathrm{~g}$ Wasser aufgenommen. Daraus berechnet sich, dass $199,34 \mathrm{~g}$

$$
\frac{-24,64 \mathrm{~g}}{174,70 \mathrm{~g}} \text { Wasser in der Atemluft }
$$

von 24 Stunden der ruhenden Hündin entzogen wurden.

Im ganzen haben wir also beim rubenden Hund einen Totalverlust von

$$
\begin{aligned}
301,77 \mathrm{~g} \text { Harn } \\
14,64 \mathrm{~g} \text { Kot } \\
\frac{174,70 \mathrm{~g} \text { Respirationswasser }}{\left.491,11 \mathrm{~g}^{\mathrm{1}}\right) .}
\end{aligned}
$$

Da pro Tag $350,0 \mathrm{~g}$ Fleisch $+44,8 \mathrm{~g}$ Schmalz $+157,8 \mathrm{~g}$ Trinkwasser, im ganzen also $552,6 \mathrm{~g}$ a u f g e nommen wurden, stellt sich die Tagesbilanz so, dass eine Retention von 552,6 $\mathrm{g}-491,1 \mathrm{~g}=$ $61,5 \mathrm{~g}$ sich ergibt.

1) Ausserdem Verlust durch das Überwiegen der $\mathrm{CO}_{2}$-Ausscheidung über die $\mathrm{O}_{2}$-Aufnahme, der aber nach meiner Berechnung hier nicht wesentlich in Betracht kommt. 
Das Anfangsgewicht war (am 15. April 1907) 10,640 kg, das Endgewicht (am 25. April, nach 10 tägiger Zufuhr) 11,120 kg. Die mittlere tägliche Gewichtszunahme machte also

$$
\begin{aligned}
& 11,120 \mathrm{~g} \\
- & 10,640 \mathrm{~g} \\
\hline 480 \mathrm{~g}: 10 & =48 \mathrm{~g} \text { aus. }
\end{aligned}
$$

Die detaillierte Berechnung ergab eine mittlere Tageszunahme von $61,5 \mathrm{~g}$, was eine Differenz von $61,5 \mathrm{~g}$

$$
\frac{-48,0 \mathrm{~g}}{13,5 \mathrm{~g} \text { ausmacht. Da es sich }}
$$

nur um eine Schätzungsberechnung handelte, ist das nicht zu verwundern. So z. B. ist schon die Harnmengenbestimmung keineswegs völlig exakt, da nur durch Spülen alle Harnreste aus der Blase entfernt werden können, die hier genannte Harnmenge aber den vor der Spülung erhaltenen Harn angibt. Die Detailzahlen sind also nun nach der Gewichtsbilanz zu korrigieren. Natürlich hat diese Korrektur da einzusetzen, wo direkte Bestimmungen fehlen. Am wahrscheinlichsten ist, dass der in der Exspiration erfolgte Wasserverlust zu gross angegeben ist. Korrigieren wir diesen Wert mit der tatsächlichen Zunahme, so finden wir

$$
\begin{array}{r}
174,7 \mathrm{~g} \\
-13,5 \mathrm{~g} \\
\hline 161,2 \mathrm{~g} \text { Exspirationswasser. - }
\end{array}
$$

Mit diesen Zahlen lässt sich die Wasserbilanz ziehen.

Die Hündin trank während der Ruhe täglich im Mittel 157,8 g Wasser. Ausser dieser Wassermenge stand dem Tier noch sowohl die in der Nahrung gegebene Flüssigkeitsmenge - im Fleisch 255,69 g Wasser - wie das bei der Verbrennung entstehende „Oxydationswasser" zur Verfügung. Von der elementaren Zusammensetzung eines Fleisches von $16,65 \% \mathrm{~N}$ finden sich nach $\mathrm{Zuntz}$ (Höhenklimaarbeit S. 102) nach Abrechnung der organischen

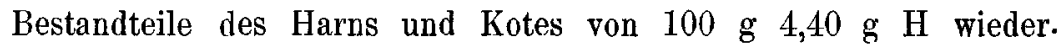
Demnach sind für die $11,73 \mathrm{~g} \mathrm{~N}$ des Eiweisses der Rubeperiode 3,10 g $\mathrm{H}$ anzusetzen, d. s. $27,90 \mathrm{~g}$ aus der Verbrennung des Wasserstoffes hervorgehendes Wasser. $100 \mathrm{~g}$ Fett enthalten $11,9 \mathrm{~g} \mathrm{H}$. Da hier ohne Abzug gerechnet wird, kommen auf die 54,95 g Fett der Ruheperiode $6,54 \mathrm{~g} \mathrm{H}$, d. s. $58,85 \mathrm{~g}$ Oxydationswasser. In Summa haben wir es also mit $27,90 \mathrm{~g}$ 
Die gesamte Wasserzufuhr setzt sich also zusammen aus: $\quad 255,69 \mathrm{~g}$ in der Nahrung zugeführtem Wasser, $157,80 \mathrm{~g}$ Trinkwasser, \begin{tabular}{l}
86.75 g Oxydationswasser, \\
\hline $\mathbf{5 0 0 , 2 4} \mathrm{g}$ Wasser.
\end{tabular}

Die Ausfuhr an Wasser addiert sich aus: $278,77 \mathrm{~g}$ Wasser im Harn, $7,74 \mathrm{~g} \quad " \quad$ Kot, $174,70 \mathrm{~g}$ Überschuss des Exspirationswassers über das Inspirationswasser

zu $\overline{461,21 \mathrm{~g}}$ Wasserausuhr.

Die Bilanz ist also positiv mit

$$
\begin{aligned}
& 500,24 \mathrm{~g} \\
- & 461,21 \mathrm{~g} \\
\hline \mathbf{3 9 , 0 3} \mathrm{g} & \text { Wasser täglicher Retention. }
\end{aligned}
$$

Zur Erklärung dieses Wassers haben wir uns zu erinnern, dass auch ein Stickstoftansatz stattgefunden hat (vgl. S. 426). Im Mittel der 10 Ruhetage haben wir gegenüber einer Resorption von 11,26 g N einen Verlust im Harn von 10,11, in den Epidermisgebilden (c. g. s.) von $0,04 \mathrm{~g} \mathrm{~N}$, d. i. im ganzen von $10,15 \mathrm{~g} \mathrm{~N}$, demnach einen täglichen Ansatz von

$$
\begin{aligned}
& 11,26 \mathrm{~g} \\
& -10,15 \mathrm{~g} \\
& \hline 1,11 \mathrm{~g} \mathrm{~N} .
\end{aligned}
$$

In der Muskulatur des Hundes wurden am Ende der Ruheperiode $74,38 \%$ Wasser und $3,39 \%$ Stickstoff gefunden. Daraus berechnen sich auf einen Ansatz von $1,11 \mathrm{~g} \mathrm{~N}: 24,35 \mathrm{~g}$ Wasser. Der Wert zeigt, dass das angesetzte Wasser sich aus dem Fleischansatz zur Genüge erklärt.

In der gleichen Weise lässt sich für das arbeitende Tier die Rechnung durchführen.

Nehmen wir einmal an, dass die Lungenventilation des auf der Tretbahn arbeitenden Tieres der des ruhenden entsprochen habe. Dann sind in der Arbeitsperiode pro Tag 4623,5 Liter Atemluft respiriert worden. Darin wurden $32,36 \mathrm{~g} \mathrm{H}_{2} \mathrm{O}$ aufgenommen. Da beim arbeitenden Hunde die Körpertemperatur wohl gut um $1^{\circ}$ bis $2^{\circ} \mathrm{C}$. höher angenommen werden kann, wird es den tatsächlichen Verhältnissen am nächsten kommen, wenn mit einer mittleren Körpertempcratur von $40^{\circ}$ C., d. h. mit einer Dampfmenge von $54,86 \mathrm{mg}$ pro 
Liter gerechnet wird, so dass in 4623,5 Liter Respirationsluft $253,64 \mathrm{~g}$ Wasser abgegeben sein mögen.

Vom Oxydationswasser treten aus dem verbrannten Fleischeiweiss (11,74 g N Zufuhr), wie vorher, 27,90 g Wasser, aus dem zugeführten „Fett“ (75,05 g) $8,93 \mathrm{H}=80,38 \mathrm{~g}$ Wasser, zusammen also $27,90 \mathrm{~g}$ $\frac{+80,38 \mathrm{~g}}{108,28 \mathrm{~g}}$ Wasser in die Berechnung ein.

Für die Gewichtsbilanz kommen also nach dem Gesagten folgende Daten in Betracht. Für die A ufnahme:

350 g Fleisch, 66,3 g Schmalz, d. s. im ganzen $695,9 \mathrm{~g}$.

Der tägliche Gesamtverlust machte aus:

$$
\begin{aligned}
339,0 & \text { g Harn, } \\
12,72 & \text { g Kot, } \\
221,28 & \text { g Überschuss des Exspirationswassers über das } \\
& \text { Inspirationswasser, } \\
\hline 573,0 \text { g. } &
\end{aligned}
$$

Das Aufgenommene übertraf also um

$$
\begin{aligned}
& 695,9 \mathrm{~g}, \\
&- 573,0 \mathrm{~g}, \\
& \hline 122,9 \mathrm{~g} \text { die Ausfuhr. }
\end{aligned}
$$

Nun betrug das mittlere Gewicht bei Beginn der Arbeitsperiode $11,350 \mathrm{~kg}$, am Ende dieses Versuchs (4. April) 11,410 kg, war also konstant geblieben bzw. um $60 \mathrm{~g}$ angestiegen. Die Differenzen in der Wasserabgabe sind nur zu klar; denn der arbeitende Hund scheidet ja viel mehr Wasser durch seine Speicheldrüsen und infolge der forcierten, hachelnden Atmung, bei der oft der $\mathrm{CO}_{2}$-Gehalt der Exspirationsluft auf $1 \%$ und darunter herabgeht, aus. Für diese Spezialfunktion stehen, da das Körpergewicht nur um $60 \mathrm{~g}$ pro Periode $=4,0$ g pro Tag zugenommen hat,

$$
\begin{aligned}
& 122,9 \mathrm{~g}, \\
& -4,0 \mathrm{~g}, \\
& \hline 118,9 \mathrm{~g} \text { an Wasser täglich zur Verfügung. }
\end{aligned}
$$

Die Wasserbilanz des arbeitenden Hundes ist hier. nach in folgender Weise zu formulieren: 


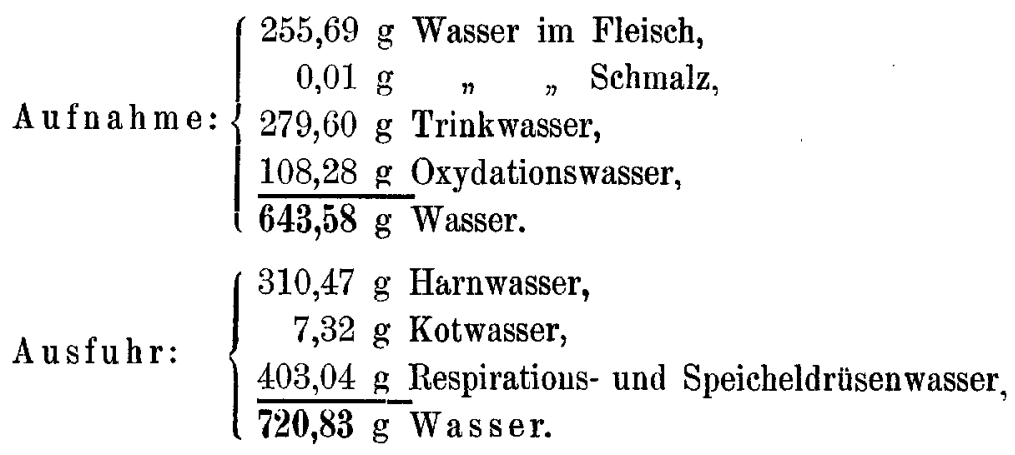

Die Bilanz ist $\mathrm{m}$ it $720,83 \mathrm{~g}$, $-643,58 \mathrm{~g}$,

$77,25 \mathrm{~g} \mathrm{~W}$ asser täglich negativ.

Es ist also zu einer erheblichen Verarmung an Wasser infolge der Arbeit gekommen.

Das wird noch augenfälliger, wenn in Betracht gezogen wird, dass zur Erzielung eines Fleischansatzes ein Mehr an Wasser gegenüber der Ruheperiode verwandt wurde. Die Differenz zwischen resorbiertem Stickstoff und der Summe von Harn- und Epidermisstickstoff macht

$$
\begin{array}{r}
11,21 \mathrm{~g} \mathrm{~N}, \\
-9,95 \mathrm{~g} \mathrm{~N}, \\
\hline 1,26 \mathrm{~g} \mathrm{~N} \text { pro Tag aus. Im Arbeits- }
\end{array}
$$

muskel (vgl. die Analysen im zweiten Teile der Abhandlung [Tabelle 52]) waren $73 \%$ Wasser und $3,50 \%$ Stickstoff. Auf einen Stickstoffansatz von $1,26 \mathrm{~g} \mathrm{~N}$ kommen also $25,84 \mathrm{~g}$ Wasser. Der Ansatz betrug während der Ruheperiode pro $\mathrm{Tag} 1,11 \mathrm{~g} \mathrm{~N}$, womit nur 24,35 g Wasser zurückgehalten wurden (vgl. S. 438).

Die oben genannten Zahlen sagen aus, dass die Differenz zwischen Ruhe- und Arbeitszeit-Wasser auf täglich

Ruhe $39,0 \mathrm{~g}$ Wasser +

Arbeit $77,3 \mathrm{~g}, \quad-$

d. i. auf $116,3 \mathrm{~g}$ W asser zu bemessen ist.

Von Interesse ist nun noch die Untersuchung der Beziehungen des Atemwassers zur Arbeitsleistung.

Eine Tour der Tretbahn, die in einem Winkel von $28,52 \%$ zur Ebene stand, entsprach $65,1 \mathrm{~cm}$ Horizontalkomponente und 
18,58 cm Steigung. Im Mittel der Arbeitszeit wurden 6020 Touren täglich geleistet. Das sind

3922,6 m Horizontalkomponente,

und 1119,0 m Steigung, woraus sich unter Zugrundelegung der in meiner früheren Arbeit über das Wachstum (l. c., siehe Anmerkung auf S. 406) angegebenen Daten für das mittlere Körpergewicht $11,37 \mathrm{~kg}$

ergeben, so dass sich die Ge-

$$
\begin{aligned}
& 75,133 \text { Cal. für den Horizontalanteil, } \\
& 89,825 " \Rightarrow \text { die Steigarbeit }
\end{aligned}
$$

samtleistung auf

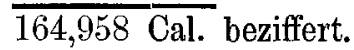

Wenn diese Mehrproduktion von Wärme durch Wasserverdunstung weggeschafft werden sollte, würden dazu $\frac{164,958}{0,535}=308 \mathrm{~g}$ Wasser notwendig gewesen sein. Bei der Arbeit wurden 403,1 g, bei der Ruhe 174,7 $\mathrm{g}$ Wasser exspiriert, also vom arbeitenden Tier $228,4 \mathrm{~g}$ Wasser mehr, was, zusammengehalten mit dem obigen Werte von $308 \mathrm{~g}$ Wasser, zeigt, dass der grösste Teil der durch die Arbeit produzierten Warme durch Wasserverdunstung, und nur etwa ein Viertel durch vermehrte Strablung und Leitung abgegeben wurde. Die vermehrte Abgabe durch Wärmestrahlung und Wärmeleitung wird leicht verständlich erstens durch die erhöhte Hauttemperatur des arbeitenden Tieres, zweitens dadurch, dass ein weit grösserer Teil der Haut der Berührung mit der kühlenden Luft ausgesetzt ist. Das ist beim Hunde, der in der Ruhe fast stets zusammengerollt ist, in noch stärkerem Maasse der Fall als beim Menschen.

Ehe ich zur Mitteilung der Ergebnisse der direkten Organinsbesondere Muskeluntersuchung, die namentlich für die zuletzt gegeschilderten Verhältnisse Aufklärung gibt, übergehe, soll untersucht werden, inwieweit sich ein Abbau oder Aufbau von Knochensubstanz aus den Mineralst of fausscheidungen des arbeitenden Tieres herleiten lässt.

Die Technik dieser Aschenanalysen sei in den nachstehenden Zeilen kurz besprochen. Alle Bestimmungen wurden, mit Ausnahme der Harnphosphorbestimmungen, an Mischproben, welche der ganzen jeweiligen Periode entsprachen, ausgeführt. Die Phosphorsäure des Harns 
wurde in äquivalenten Mengen Mischharn je dreier vorhergehender Tage bestimmt. Es wurde hier, wie bei der Kotanalysierung, nach der Neumann'schen Methode der Säuregemischveraschung verfahren.

Die übrigen Mineralstoffe wurden im Harn wie im Kot in je drei Portionen bestimmt (I. $\mathrm{Ca}+\mathrm{Mg}$; II. S; III. $\mathrm{K}+\mathrm{Na}$ ).

In der ersten, zur Bestimmung des Kalks und der Magnesia dienenden Probe wurde zunächst in der üblichen Weise durch öfteres vollständiges Abdampfen mit Salzsäure die Kieselsäure abgeschieden. Nachdem dann noch mit Eisenchlorid und Ammoniumazetat die Phosphate aus dem essigsauren Filtrat entfernt worden waren, wurde der Kalk mit Ammoniumoxalat gefällt. Das Calciumoxalat wurde nach etwa zwölfstündigem Stehen bei ca. $50^{\circ} \mathrm{C}$ aufs Filter gebracht, dort mit ammoniumoxalathaltigem Wasser gewaschen und im Platintiegel durch starkes Glühen in $\mathrm{CaO}$ übergeführt.

Zur Schwefelbestimmung wurde die Kohle nach Zusatz eines Gemisches von Soda und Salpeter geglüht, die Kieselsäure abgeschieden und im heissen Filtrat der Schwefel mit Baryumchlorid als Baryumsulfat gefällt.

Die Bestimmung der Alkalien wurde in der Weise vorbereitet, dass zunächt Schwefelsäure, Magnesia, Phosphorsäure und die Erdmetallphosphate durch Barytwasser (unter Zusatz von Eisenchlorid) entfernt wurden. Dem folgte die Eliminierung der Reste der Salze der Alkalierden (mit Ammoniumkarbonat). Die Lösung der Chloride von $\mathrm{K}$ und $\mathrm{Na}$ wurde mehrmals abgedampft und dann von den Ammonsalzen befreit. Nach der Wägung der gesamten Chloride wurde das Kalium als Kaliumplatinchlorid aus dem Gemisch abgeschieden und gewogen, das Natrium aus der Differenz bestimmt. Alle Analysenwerte sind, wie üblich, auf Oxyde berechnet worden.

Bei der Ausführung der Bestimmungen bin ich von Herrn Dr. Strigel, einem gewiegten Analytiker, in der liebenswürdigsten Weise unterstützt worden.

Die Ergebnisse der Mineralstoffbestimmungen sind in den Tabellen 20-25, spezifiziert sowohl hinsichtlich der Verteilung der Ausscheidungen auf Harn und Kot, wie zusammengefasst als mittlere tägliche Ausfuhrgrössen, zusammengestellt. (Tab. 20.)

Es wird zweckmässig sein, die einzelnen Aschenbestandteile zunächst gesondert zu betrachten. 

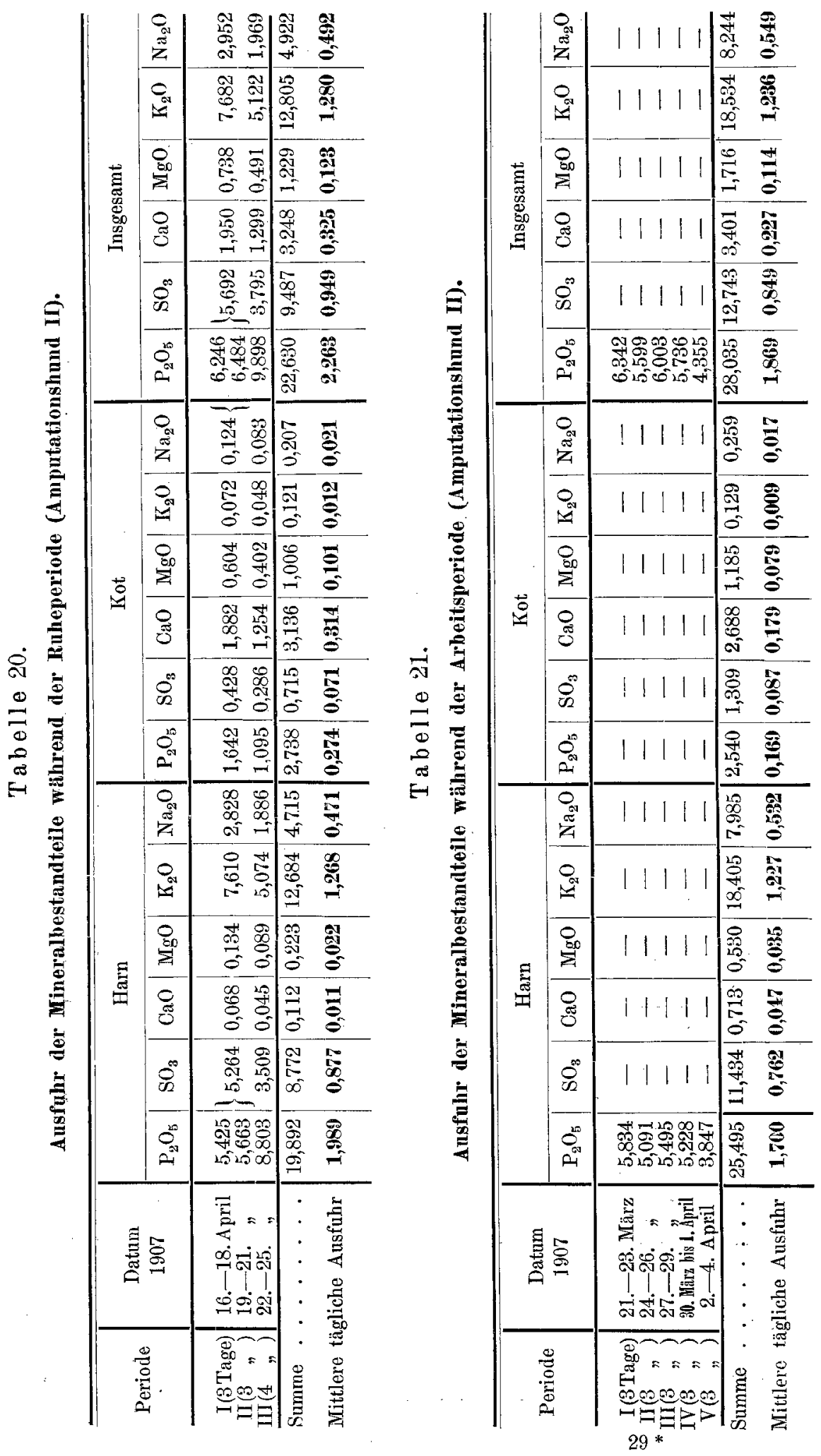
Tabelle 22.

Mittlere tägliche Mineralstoffausscheidung in der Ruhe- und Arbeitsperiode beim Amputationshund II.

\begin{tabular}{l|c|c}
\hline & $\begin{array}{c}\text { Rube } \\
\mathrm{g}\end{array}$ & $\begin{array}{c}\text { Arbeit } \\
\mathrm{g}\end{array}$ \\
\hline & 2,26 & 1,87 \\
$\mathrm{P}_{2} \mathrm{O}_{5}$ & 0,95 & 0,85 \\
$\mathrm{SO}_{3}$ & 0,32 & 0,23 \\
$\mathrm{CaO}$ & 0,12 & 0,11 \\
$\mathrm{MgO}$ & 1,28 & 1,24 \\
$\mathrm{~K}_{2} \mathrm{O}$ & 0,49 & 0,55 \\
$\mathrm{Na}_{2} \mathrm{O}$ & &
\end{tabular}

Tabelle 23.

Prozentuale Verteilung der Mineralstoffe in den Ausscheidungen in der Ruhe- und Arbeitsperiode beim Ampntationshund II.

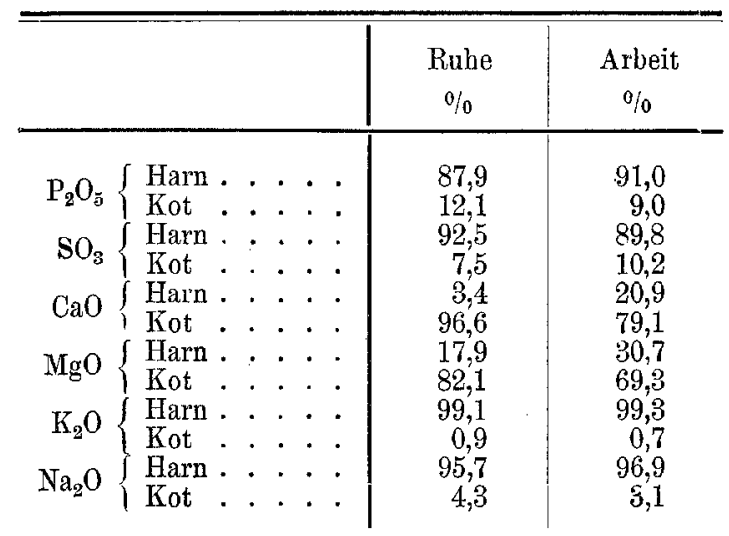

Tabelle 24.

Beziehungen der Stickstoff- zur Phosphorsäureausfuhr beim Amputationshand II.

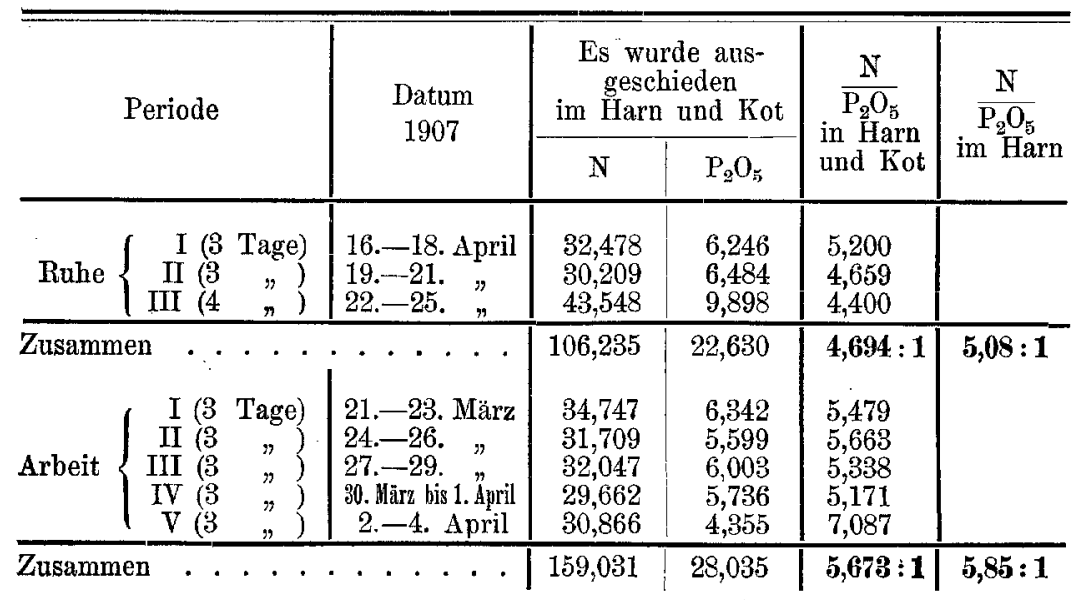


Untersuchungen über den Einfluss der Muskelarbeit auf die Organe etc. 445

Tabelle 25.

Mineralstoffbilanz im Ruhe- und Arbeitsversuch beim Amputationshund II.

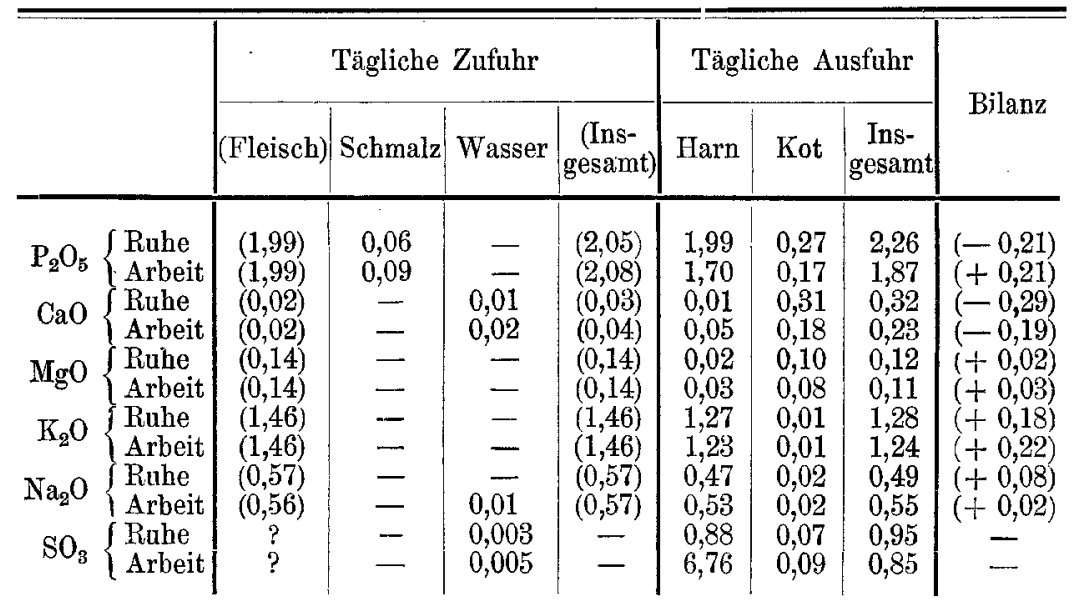

A. Schwefelsäure ${ }^{1}$ ). Das ruhende Tier schied pro Tag $0,1 \mathrm{~g} \mathrm{SO}_{3}$ mehr aus als das arbeitende. Da der Schwefel, soweit er im Körper angesetzt oder abgebaut wird, wesentlich nur in Form von Eiweiss in Betracht kommt, dürfte es von Interesse sein, die Beziehung der Stickstoff- zur Schwefelausscheidung zahlenmässig festzustellen. Das Tier hatte bei gleicher Kost 1,26 g N

$$
\frac{-1,11 \cdots n}{0,15 \mathrm{~g} \mathrm{~N} \text { bei der }}
$$

Arbeit mehr angesetzt. Es würde hierbei, da die Relation $\frac{N}{S}$ im Fleisch etwa $=\frac{15}{1}$ also $\frac{\mathrm{N}}{\mathrm{SO}_{3}}=\frac{15}{2,5}=\frac{6}{1}$ ist, eine Retention von $0,025 \mathrm{~g} \mathrm{SO}_{3} \mathrm{zu}$ erwarten gewesen sein. Die faktisch gefundene viermal grössere Retention (Tabelle 22) zu diskutieren, erscheint mir bei der Geringfügigkeit der Zahlen nicht zweckmässig. Ich verweise nur noch bezüglich der Verteilung auf Harn und Kot in beiden Perioden auf die Angaben der Tabelle 23.

B. Kalium. Bei der geringen Retention von Stickstoff (Vermehrung der Fleischsubstanz) ist auch eine geringgradige Retention von $\mathrm{K}_{2} \mathrm{O}$ - etwa $1 / 10$, bei Mehransatz von $0,15 \mathrm{~g} \mathrm{~N}$ also $0,015 \mathrm{~g} \mathrm{~K}_{2} \mathrm{O}$

1) C. Beck und H. Benedict, Über den Einfluss der Muskelarbeit auf die Schwefelausscheidung. Pflüger's Arch. Bd. 54 S. 27-61. 1893. (Dort Literatur.) 
- zu erwarten. Wir finden tatsächlich eine Differenz von $0,04 \mathrm{~g} \mathrm{~K}_{2} \mathrm{O}$. Bei der Schwierigkeit der Bestimmung ist das eine genügende Übereinstimmung.

C. Natrium. Das arbeitende Tier verlor $1 / 2 \mathrm{~g} \mathrm{Na}_{2} \mathrm{O}$ mehr als das ruhende, wobei jedoch die prozentuale Verteilung auf Harn und Kot gewahrt blieb. Es bewegt sich also das Natrium in entgegengesetzter Richtung wie alle anderen Mineralstoffe. Das ist wichtig. Das Natrium findet sich vorwiegend in Blut und Lymphe. Es wird somit wahrscheinlich, dass, während die Masse der Muskulatur infolge der Arbeit zugenommen hat, die Masse der natriumbaltigen Gewebsflüssigkeiten sich verminderte. Der relativ grosse Wasserverlust des arbeitenden Tieres dürfte also zum Teil als Abnahme der Na-haltigen zirkulierenden Flüssigkeiten zu deuten sein.

Für den Menschen liegt über das Verhältnis, das zwischen Natrium und Arbeitsleistung besteht, eine Mitteilung von $\mathrm{Munk}$ im Anschluss an die Marschversuche von Zuntz und Schumburg vor. Hier wurde an den Arbeitstagen die Natriummenge im Harn vermindert gefunden. Das bedeutet aber keinen Widerspruch gegen meine Befunde, erklärt sich vielmehr befriedigend aus dem hohen Chlornatriumgehalt des Schweisses, der in jenen Versuchen in Mengen von 1-3 Liter ausgesehieden wurde.

D. Magnesia. Die Verteilung der Ausfuhr in Harn und Kot ist dergestalt in den beiden Perioden verschieden, dass beim ruhenden Tier nahezu die Hälfte derjenigen Menge, welche in der Arbeitsperiode im Harn vorgefunden wurde, im Harn ausgeschieden wurde. Im allgemeinen geht die Magnesiaausscheidung der des Kalks parallel.

E. Kalk. Bei der Beurteilung der Kalkausfuhr ist die differierende Zufuhr im Trinkwasser zu berücksichtigen. Die Hündin nahm bei der Arbeit täglich $280 \mathrm{ccm}$, bei der Ruhe nur $158 \mathrm{ccm}$ auf. Das Berliner Leitungswasser enthielt nach einer Durchschnittsanalyse, die mir Herr Dr. Strigel freundlicherweise zur Verfügung gestellt hat, im Liter:

$$
\begin{aligned}
& \mathrm{CaO} \text {. . . . } 0,096 \mathrm{~g} \\
& \mathrm{MgO} \text {. . . . . } 0,01 \text { ” } \\
& \mathrm{K}_{2} \mathrm{O} \text {. . . . . 0,004, } \\
& \mathrm{Na}_{2} \mathrm{O} \text {. . . . . } 0,025 \text {, } \\
& \mathrm{SO}_{3} \text {. . . . . } 0,018 \text { " } \\
& \mathrm{Cl} \text {. . . . . 0,021, }
\end{aligned}
$$


Die Kalkzufuhr betrug also im Wasser:

bei der Ruhe $0,01 \mathrm{~g} \mathrm{CaO}$ täglich,

" Arbeit $0,02, \mathrm{CaO}$ "

Um diese Verhältnisse einigermaassen illustrieren zu können, habe ich die Bilanz durchgeführt (vgl. S. 415). Dieser Rechnung ist eine eigene Aschenanalyse des benutzteu Pferdefleisches untergelegt. Diese hatte ergeben:

$$
\begin{aligned}
& \mathrm{CaO} \text {. . . 0,02\% der Trockensubstanz } \\
& \mathrm{MgO} \text {. . . 0,15\%" " } \\
& \mathrm{P}_{2} \mathrm{O}_{5} \cdot \text {. . } 1,99 \% \text { " } \\
& \mathrm{K}_{2} \mathrm{O} \cdot \text {. . } 1,55 \% \text { " } \\
& \mathrm{Na}_{2} \mathrm{O} \cdot \cdot \cdot 0,605 \%, \\
& \frac{\mathrm{N}}{\mathrm{P}_{2} \mathrm{O}_{5}}=5,89 \text {. }
\end{aligned}
$$

Tabelle 25, welche die Bilanzen angibt, lässt das eine mit Gewissheit erkennen, dass die Kalkbilanz stets negativ gewesen ist, und dass trotz grösserer Zufuhr die Kalkausscheidung gegenüber der Ruhe recht erheblich, um mehr als ein Viertel des Ruhebetrages, herabgesetzt war.

Es kann daran gedacht werden, dass die Resorption des Knochenstumpfes des amputierten Beines Kalk frei gemacht hat. Das Gewicht des Femur meines Hundes betrug annähernd ca. $42 \mathrm{~g}$; der Knochen besass also einen Kalkgehalt von etwa $8,5 \mathrm{~g} \mathrm{CaO}$. Der Mehrverlust während der Ruheperiode betrug $0,09 \mathrm{~g} \mathrm{CaO}$ pro Tag, in den 10 Tagen der Periode also 0,9 g. Das sind $11 \%$ vom Kalkvorrat des ganzen Femur. Da nun von einem Amputationsstumpf stets Material resorbiert wird, erscheint es durchaus wahrscheinlich, dass die vermehrte Kalkansscheidung dem Knochenstumpf entstammt, und dass demgemäss in bezug auf die normale Knochenernährung keine Unterschiede zwisehen Ruhe und Arbeit nachweisbar sind.

F. Phosphorsäure. Die Differenz in der Ausscheidung betrug hier ungefähr 1/2 g zugunsten einer grösseren Ausfuhr im Kot des ruhenden Tieres. Hierbei kann es sich um zweierlei handeln, einmal um einen Zerfall von phosphorhaltigen Eiweissstoffen, dann aber um einen Abbau von Knochensubstanz. Dass das letztere stattgefunden hat, beweist der Kalkschwund. Da im Knochen Kalk und Phosphor im Verhältnis von $142 \mathrm{P}_{2} \mathrm{O}_{5}$ zu $168 \mathrm{CaO}$ stehen, war für 
die in Verlust gegangene $\mathrm{CaO}$-Menge von $0,09 \mathrm{~g}$ ein Verlust von 0,076 g $\mathrm{P}_{2} \mathrm{O}_{5}$ zu erwarten. Es dürfte also ausser dem Knochengewebe keine phosphorhaltige Substanz zerfallen sein.

Es versteht sich von selbst, dass die so geringen Differenzen im Knochenwachstum auf das Körpergewicht keinen Einfluss haben können.

\section{Teil. Die chemische Abänderung der inneren Organe infolge der Arbeitsleistung. ${ }^{1}$ )}

Bei der Muskelarbeit werden hochmolekulare Verbindungen zu kleineren Molekülen zersetzt. Diese letzteren sind osmotisch wirksam und verschieben infolgedessen die Wassergehaltsverhältnisse der Muskulatur. Das Wasser, welches sich bei diesen Prozessen beteiligt, kann unmittelbar nur aus dem Blute stammen. Es ergibt sich also, dass sich am Blute nach verrichteter Arbeit Änderungen in seiner Zusammensetzung ausbilden müssen. In der Tat sind durch die Untersuchung des Blutes solche Unterschiede nachgewiesen worden, so insbesondere bei den Versuchen von $\mathrm{Zuntz}$ und Sehumburg, wo gleich nach der Arbeit eine erhebliche Vermehrung der roten Blutkörperchen und eine Zunahme des spezifischen Gewichtes des Blutes konstatiert wurde. Es hat sich dabei gezeigt, dass bald reculiert wird; auch Rogozinski (l. c., Anm. 1 auf S. 404) fand bei einem täglich arbeitenden Hunde die physikalischen und chemischen Eigenschaften des Blutes einige Stunden nach der Arbeit nicht verändert. Die Versuche Rogozinski's wurden an 18 Tage, also längere Zeit hindurch arbeitenden Hunden angestellt, sind aber nach den oben (S. 404) gemachten Ausführungen nicht geeignet, die Frage, ob eine Abänderung des Blutes unter dem Einflusse der Leistung von Arbeit zustande kommt, zu erledigen. Die Beantwortung dieser Frage liegt in den Ergebnissen der an den schon oben beschriebenen Versuchstieren ${ }^{1}$ ) vorgenommenen Blutuntersuchungen.

Ich erinnere daran, dass der Arbeitshund II der Hunde gleichen Wurfes 37 Tage, Amputationshund II 23 Tage auf der Tretbahn arbeitete.

1) Erste kurze Notiz in Mediz. Klinik Jahrg. 6 S. 23. 1910. - Die vorliegende Arbeit war schon im März 1909 endgültig abgeschlossen. 
Das Blut wurde durch Aderlass bzw. Entbluten der seit 24 Stunden nüchternen Tiere gewonnen. Ein Teil wurde mit Quecksilber defibriniert, ein anderer in einem Messzylinder zur Serumgewinnung aufgefaugen. Die Bestimmungen sind in der üblichen Weise vorgenommen worden (spezifisches Gewicht pyknometrisch ermittelt). Ich möchte es nicht unterlassen, auf eine Fehlerquelle, welche bei der Defibrinierung mit Quecksilber sich einschleichen kann, hinzuweisen. Durch das Schütteln wird das Quecksilber so fein zerstäubt, dass es sich erst sehr spät zu Boden senkt und beim Pipettieren mit in die Pipette gerät. Die Stäubchen sind dann nicht zu sehen. Man wird erst darauf aufmerksam, wenn beim Trocknen des Blutes das Quecksilber sich wieder zusanmenballt und dann als feinste Kügelchen am Boden des verwendeten Gefässes vorgefunden wird. Ich kann aus diesem Grunde die Methodik für die Vorbereitung des Blutes zur chemischen Untersuchung nicht empfehlen. Hier sind Glasperlen besser.

Der Gehalt au Hämoglobin wurde mit dem Hüfner'schen Spektrophotometer bestimmt.

Die Ergebnisse der Untersuchungen sind aus den beiden Tabellen 26 und 27 ohne weiteres ersichtlich. Im ersteren Falle (Tab. 26) handelt es sich um Blut von verschiedenen Individuen desselben Wurfes, in dem anderen um Blut vom gleichen, einmal geruhten, das andere Mal arbeitenden Hund (Tab. 27).

Tabelle 26.

Ergebnis der Untersuchung des Blutes von Tieren gleichen Wurfes.

\begin{tabular}{|c|c|c|c|}
\hline & $\begin{array}{c}\text { Ruhe- } \\
\text { hund I } \\
0 \%\end{array}$ & $\begin{array}{c}\text { Arbeits- } \\
\text { hund II } \\
\%\end{array}$ & $\begin{array}{c}\text { Weib- } \\
\text { licher } \\
\text { Ruhe- } \\
\text { hund) } \\
\%\end{array}$ \\
\hline 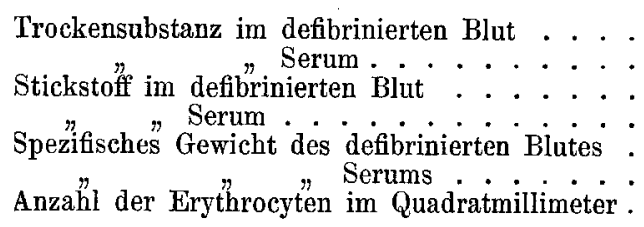 & $\begin{array}{c}19,74 \\
8,56 \\
2,15 \\
0,92 \\
1,055 \\
1,027 \\
6560000\end{array}$ & \begin{tabular}{|c|}
22,36 \\
9,03 \\
2,67 \\
1,07 \\
1,058 \\
1,029 \\
6856000
\end{tabular} & $\begin{array}{c}18,7 \\
5,7 \\
2,5 \\
0,7 \\
1,050 \\
1,020 \\
5700000\end{array}$ \\
\hline
\end{tabular}

1) Die Tiere waren $7 \frac{1}{2}$ Monate alt, als sie getötet wurden. 
Tabelle 27.

Ergebnis der Ontersuchungen bei einem erst arbeitenden, dann ruhenden Hund (Amputationshund II).

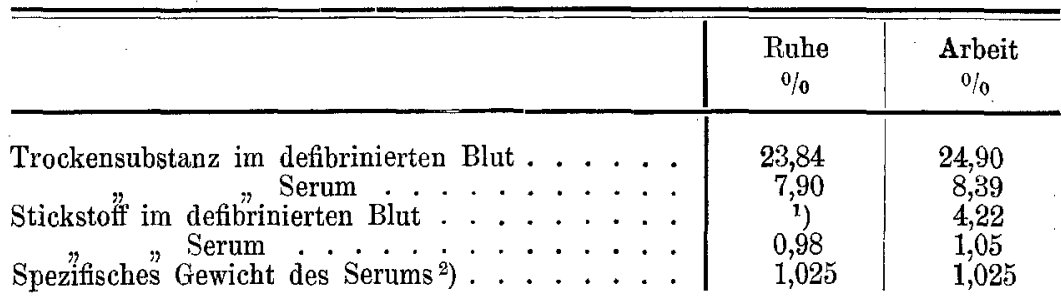

Die Unterschiede sind wohl genügend gross, um im Sinne einer Wasserverarmung des Blutes infolge lange dauernder Arbeitsleistung gedeutet werden zu können.

Bei der Ruhe wurden in $100 \mathrm{~g}$ Blut $19,85 \mathrm{~g}$ Hämoglobin gefunden, nach der Arbeit $21,98 \mathrm{~g}$. Es ist also eine geringe Vermehrung des Oxyhämoglobingehaltes des Blutes zutage getreten.

Bei der Untersuchung der übrigen inneren Organe lag es nahe, auch die absoluten Gewichte der Organe festzustellen, um einigermaassen zu einem Urteile darüber zu kommen, wie weit die Abänderung der chemischen Zusammensetzung einzelner Organe eine andere Verteilung der Stoffmasse des Körpers bedingt. Diese Organwägungen betreffen insgesamt den frisch entbluteten Körper. Wir wissen, dass das Körpergewicht kein gutes Bezugsmaass bei der Beurteilung der Organgewichte abgeben kann, einesteils wegen der wechselnden Anteilnahme des Magen- und Darminhaltes am Gewichte, der variierenden Organgewichte und Wassergehaltsdifferenzen, andererseits der bekannten Beziehungen zwischen Ernährungszustand und Organgewicht, z. B. Herzgewicht ${ }^{3}$ ), wegen. Die absoluten Gewichte sind deshalb in den nachstehenden die Er-

1) Kontrollzahl verloren gegangen; nur soviel ist sicher, dass der Ruhewert niedriger, als der Arbeitswert liegt.

2) Bestimmung des spez. Gewichts des defibrinierten Blutes durch Quecksilherbeimengung verdorben.

3) Schieffer, Über den Einfluss des Ernährungszustandes auf die Herzgrösse. Deutsch. Arch. f. klin. Med. Bd. 92 S. 54-63. 1907. 
Untersuchungen über den Einfluss der Muskelarbeit auf die Organe etc. 451

gebnisse der Organuntersuchung wiedergebenden Tabellen 28, 29 und 30 auch auf das Gehirngewicht bezogen.

Tabelle 28.

Absolute Organgewichte von Arbeits= und Ruhehunden desselben Wurfes.

\begin{tabular}{|c|c|c|c|c|}
\hline & \multicolumn{2}{|c|}{ I. gleiches Paar } & \multicolumn{2}{|c|}{$\begin{array}{l}\text { II. etwas differierendes } \\
\text { Paar }\end{array}$} \\
\hline & $\begin{array}{c}\text { Ruhehund I } \\
\mathrm{g}\end{array}$ & $\begin{array}{l}\text { Arbeits- } \\
\text { hund II } \\
\quad \mathrm{g}\end{array}$ & $\begin{array}{l}\text { Weiblicher } \\
\text { Ruhehund } \\
\mathrm{g}\end{array}$ & $\begin{array}{l}\text { Schwarzer } \\
\text { Arbeitshund } \\
\mathrm{g}\end{array}$ \\
\hline 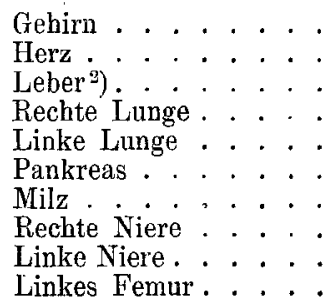 & 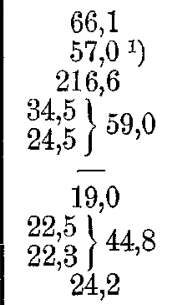 & $\begin{array}{r}61,3 \\
54,6 \\
222,4 \\
31,9 \\
23,7\} 55,6 \\
21,3 \\
17,5 \\
21,5\} 43,5 \\
22,0\} \\
20,2\end{array}$ & $\begin{array}{c}59,7 \\
39,1 \\
143,2 \\
26,5 \\
17,5\} 44,0 \\
14,3 \\
9,3 \\
\left.\begin{array}{c}16,8 \\
16,7\end{array}\right\} 33,5 \\
18,6\end{array}$ & $\begin{array}{c}58,7 \\
39,4 \\
197,3 \\
- \\
- \\
13,0 \\
6,2 \\
15,8\}_{15,2} 31,0 \\
16,0\end{array}$ \\
\hline Körpergewicht. . . . . & 6950 & 6670 & 4600 & 3950 \\
\hline
\end{tabular}

Tabelle 29.

Organgewichte von Arbeits: und Ruhehunden desselben Wurfes in Prozenten des Körpergewichts.

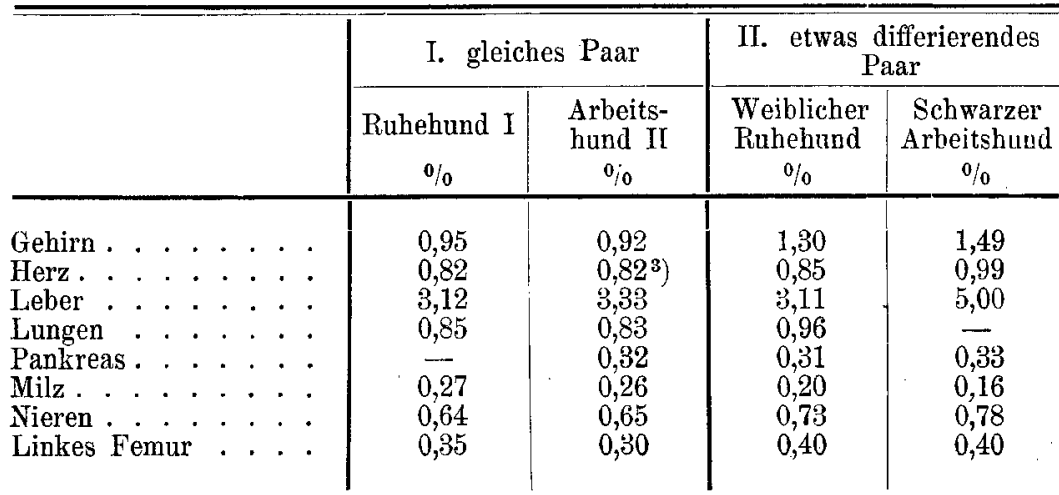

1) Enthielt Blutgerinnsel! Das Herz wurde nach Abpräparieren des epikardialen Fettes am Herzbeutelansatz losgetrennt und im Wägeglas gewogen.

2) Leber mit gallefreier Gallenblase.

3) Blutkoagulum! 
Tabelle 30 .

Organgewichte ron Axbeits- und Ruhehunden gleichen Wurfes in Prozenten des Gehirngewichtes.

\begin{tabular}{|c|c|c|c|c|}
\hline & \multicolumn{2}{|c|}{ I. gleiches Paar } & \multicolumn{2}{|c|}{$\begin{array}{c}\text { II. etwas differierendes } \\
\text { Paar }\end{array}$} \\
\hline & $\begin{array}{c}\text { Ruhehund I } \\
\%\end{array}$ & $\begin{array}{c}\text { Arbeits- } \\
\text { hund II } \\
\% / 0\end{array}$ & $\begin{array}{c}\text { Weiblicher } \\
\text { Rubehund } \\
\% \%\end{array}$ & $\begin{array}{c}\text { Schwarzer } \\
\text { Arbeitshund } \\
\% \%\end{array}$ \\
\hline 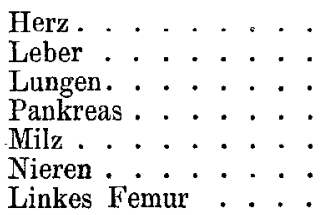 & $\begin{array}{r}86,23 \\
327,68 \\
89,26 \\
\overline{28,74} \\
67,78 \\
36,61\end{array}$ & $\begin{array}{r}89,07 \\
362,81 \\
90,70 \\
34,75 \\
28,55 \\
70,96 \\
32,95\end{array}$ & $\begin{array}{r}65,49 \\
239,87 \\
73,70 \\
23,95 \\
15,58 \\
56,11 \\
31,16\end{array}$ & $\begin{array}{r}67,12 \\
336,12 \\
-\overline{22,15} \\
10,56 \\
52,81 \\
27,26\end{array}$ \\
\hline
\end{tabular}

Es hat sich hierbei durchweg eine Gewichtszunahme von Herz und Leber bei den arbeitenden Tieren ergeben.

Wägungen von Herzen nach Ruhe und schwerer Arbeitsleistung sind wiederholt vorgenommen und ihre Ergebnisse in Vergleich gesetzt worden, so von Robinson, Bollinger, Bergmann, Parrot, Hirsch, Rogozinski, Külbs (l. c., Anm. 1 auf S. 399), Grober ${ }^{1}$ ) und Bruns. Was nun diese Sektionsbefunde angeht, so scheint es mir, dass die von den Autoren geübte Art der Berechnung keinen definitiven Beweis für eine Arbeitshypertrophie des Herzens abgibt; denn die genannten Wägungen betreffen weder das Herz entbluteter Organismen, noch ist die Herzmasse auf ein Organ bezogen, das geringeren Schwankungen unterworfen ist als Körpergewicht und Muskulatur. Wie fehlerhaft es sein kann, das Herzgewicht des Ruhe- und Arbeitstieres an den in Prozenten des Lebendgewichtes ausgedrückten Zahlen zu vergleichen, sofern man

1) J. Grober, Untersuchungen zur Arbeitshypertrophie des Herzens. Deutsch. Arch. f. klin. Med. Bd. 91 S. 502-517. 1907. - J. Grober, Über die Arbeitshypertrophie des Herzens und seiner Teile. Zentralbl. f. inn. Med. Bd. 28 S. 657-660. 1907. - 0. Bruns, Welche Faktoren bestimmen die Herzgrösse? Münch. med. Wochenschr. Bd. 56 S. 1003-1007. 1909. - Dort und bei Külbs weitere Literatur. Über orthodiagraphische Messungen vgl. u. a.: Schieffer, Über Herzvergrösserung infolge Radfahrens. Deutsch. Arch. f. klin. Med. Bd. 89 S. 604-625. 1906. - A. Selig, Sport und Herz. Med. Klin. Bd. 4 S. 448_451. 1908. Ältere Literatur bei den Genannten und bei O. Fraentze1, Die idiopathischen Herzvergrösserungen S. 112 ff. Berlin 1889. 
nicht für völlige Gleichheit der Tiere Sorge trägt, gibt auch Grober ${ }^{1}$ ) zu. Er schreibt: „Das Proportionalgewicht des Hundeherzens wird von $\mathrm{Külbs}$ für seine beiden Kontrollhunde auf 0,6 und 0,55 angegeben. Andere Daten von gesunden Hunden waren in der physiologischen und zoologischen Literatur nicht aufzufinden. Ich habe versucht, mehr Zahlen für das Proportionalgewicht des Hundeherzens zu erbalten. Im Laufe des letzten Jahres habe ich es bei allen Tieren, die im Laboratorium der Klinik zu anderen Untersuchungen verwendet worden waren, und an Tieren, die in den Tierställen spontan an Krankheiten starben, bestimmt. Aus diesen (sechs) Bestimmungen ergibt sich als Mittel 0,583, ein Wert, der mit denen von $K \ddot{u l b s}$ ganz gut übereinstimmt. Die einzelnen Zahlen bei den einzelnen Tieren aber weichen stark voneinander ab. . . . Die Zahl der von mir gewonnenen Bestimmungen ist unter solchen Verhältnissen zu klein, um einen entscheidenden Wert auf die daraus gewonnenen Durchschnittszahlen für die einzelnen Herzteile zu legen". Dass der Wert 0,583 nicht dem Mittel entsprechen und keine Vergleiche zulassen kann, geht schon aus den Messungen Rogozinski's, die Grober unbekannt geblieben sind, unzweifelhaft hervor. Ich habe seine Zahlen in Tabelle 31 zusammengestellt. Alle Zahlen liegen höher als $0,6 \%$. Das Gleiche ist bei meinen Zahlen in Tabelle 29 vorhanden. Da nun das Gewicht von Tieren desselben Wurfes auch bei gleicher Aufzucht stark variieren kann, ist es durchaus unstatthaft, sich auf diese Variable zu beziehen.

\section{Tabelle 31 .}

Herzgewichte (in Prozenten des Lebendgewichts) bei Ruhe- und Arbeitstieren nach den Untersuchungen von Rogozinski.

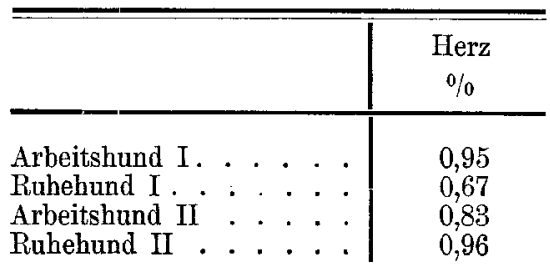

Es lässt sich überdies zeigen, dass die Zahlen Grober's nicht das beweisen, was er aus ihnen liest, die Herzhypertrophie des

1) J. Grober, Über die Beziehungen zwischen Körperarbeit und der Masse des Herzens und seiner Teile. Arch. f. exp. Path. u. Pharm. Bd. 59 S. 424-429. 1908. 
arbeitenden Tieres. Grober nennt nämlich folgende Zahlen für den Ausdruck:

$$
\begin{array}{r}
\frac{\text { Herzgewicht } \times 1000)}{\text { Körpergewicht }}: \text { I. für die Kontrolltiere }\left\{\begin{array}{l}
5,38 \\
5,91 \\
5,68 \\
7,00 !
\end{array}\right. \\
\text { (Mittel } 5,99) \\
\text { II. für das Arbeitstier } \quad \cdot \quad 6,20 \\
\text { III. " " Ruhetier . . } 5,52 .
\end{array}
$$

Der Mittelwert der Kontrolltiere liegt also recht $\mathrm{n}$ ahe unter der Zahl des Arbeitstieres, und bei den Kontrolltieren kommt ein Wert vor, der den des Arbeitstieres weit übersteigt.

Man hat aus theoretischen Gründen eine Definition der Herzhypertrophie aufgestellt, die dem Verfahren mancher Autoren, das Herzgewicht auf die Muskelmasse zu beziehen, die Grundlage geben soll. Der konstruierte Parallelismus zwischen peripherischer Muskulatur und Herz besteht aber nicht in dem Umfange, wie dazu erforderlich wäre. Die Definition, die eine Herzhypertrophie nur dann gelten lässt, wenn das Herz über das normale Verhältnis zur Muskelmasse des Körpers hinaus grösser geworden ist, ist unzweifelhaft zu eng gefasst und einseitig. Eine Herzhypertrophie ist, wie jede Hypertrophie eines Organs, in physikalisehem Sinne definiert, dann vorhanden, wenn das Organ aus der Proportionalität zu den übrigen Organen, die ihm entsprechend der aktiven Masse des Körpers, dessen Alter, Geschlecht und Ernährungszustand notorisch zulkommt, heraustritt. Da wir nun wissen, dass das Gewicht des Zentralnervensystems die grösste Konstanz besitzt, halte ich es für am ungezwungendsten und korrektesten, von diesem Gesichtspunkte aus die Beurteilung vorzunehmen, $d . h$. es ist notwendig, für das entscheidende Experiment gleich aufgezogene Tiere desselben Wurfes zu untersuchen, bei denen die auf das Gehirngewicht bezogenen Herzgewichte in Vergleich gesetzt werden.

Aus den Protokollen von Külbs ${ }^{1}$ ) (Tab. IV und V seiner Arbeit) ergibt sich nun in der Tat auch so eine eklatante Herzhypertrophie, wie es ja auch in dem einwandfreiesten Versuche Rogozinski's der Fall war.

1) Die Arbeit von Külbs war zur Zeit, als ich meine Versuche anstellte, noch nicht erschienen.. Rogozinski, dessen Untersuchungen zeitlich vor denen Külbs' lagen, bezog das Herzgewicht auch schon auf das Gehirngewicht. 
Die auf die genannte Weise bei den $7^{1 / 2}$ Monate alten Tieren zustande gekommenen Zablen der Tabelle 30 sprechen zwar im Sinne einer durch längerdauernde Arbeitsleistung entstandenen Gewichtszunahme, doch ist die Differenz gegenüber den Ruhetieren überraschend gering.

Das Gleiche gilt nun auch für die Leber. Ich erinnere daran, dass bereits $K u ̈ l b s$ eine Volums- und Gewichtszunahme der Leber des Arbeitstieres festgestellt hat (1. c., s. Anm. 1 auf S. 399). Er schreibt aber darüber: „Nach der Versuchsanordnung können Arbeit und Verdauung als an dieser Differenz sich unmittelbar beteiligende Faktoren ausgeschlossen werden (S. 301)." Wenn man die chemische Zusammensetzung der Leber (Tabelle 32) nach den Beobachtungen an der noch später zu erörternden chemischen Zusammensetzung der Arbeitsmuskulatur beurteilt, so ergeben sich auch keine weiteren Beweise hierfür.

$$
\text { Tabelle } 32 \text {. }
$$

Chemische Znsammensetzung ron Herzmuskulatur und Leber bei Arbeits* und Ruhehunden gleichen Wurfes.

\begin{tabular}{|c|c|c|c|c|}
\hline & \multicolumn{4}{|c|}{ Herzmuskulatur } \\
\hline & \multirow[b]{2}{*}{$\begin{array}{c}\text { Trocken- } \\
\text { substanz } \\
\text { (Proz.der } \\
\text { frischen } \\
\text { Substanz) } \\
0 / 0\end{array}$} & \multicolumn{2}{|c|}{ Stickstoff } & \multirow[b]{2}{*}{$\begin{array}{c}\text { Äther- } \\
\text { extrakt } \\
\text { (Proz.der } \\
\text { Trocken- } \\
\text { substanz) } \\
0 \%\end{array}$} \\
\hline & & $\begin{array}{c}\text { Proz. der } \\
\text { Trocken- } \\
\text { substanz } \\
\%\end{array}$ & $\begin{array}{c}\text { Proz. der } \\
\text { entfetteten } \\
\text { Trocken- } \\
\text { substanz } \\
\%\end{array}$ & \\
\hline I. $\underset{\text { Paar }}{\text { gleiches }}\left\{\begin{array}{l}\text { Ruhehund I. . . . . } \\
\text { Arbeitshund II . . }\end{array}\right.$ & $\begin{array}{l}22,45 \\
22,82\end{array}$ & $\begin{array}{l}13,71 \\
13,46\end{array}$ & $\overline{15,04}$ & $\overline{10,54}$ \\
\hline $\begin{array}{l}\text { II. etwas diffe- }\left\{\begin{array}{l}\text { Weiblicher Ruhehund } \\
\text { rierendesPaar }\{\text { Schwarzer Arbeitshund }\end{array}\right.\end{array}$ & $\begin{array}{l}28,43 \\
22,04\end{array}$ & $\begin{array}{l}13,14 \\
13,23\end{array}$ & $\begin{array}{l}15,36 \\
13,86\end{array}$ & $\begin{array}{r}14,47 \\
4,50\end{array}$ \\
\hline
\end{tabular}

\begin{tabular}{|c|c|c|c|c|}
\hline & \multicolumn{4}{|c|}{ Leber } \\
\hline & \multirow[b]{2}{*}{$\begin{array}{c}\text { Trocken- } \\
\text { substanz } \\
\text { (Proz.der } \\
\text { frischen } \\
\text { Substanz) } \\
\%\end{array}$} & \multicolumn{2}{|c|}{ Stickstoff } & \multirow[b]{2}{*}{$\begin{array}{c}\text { Äther- } \\
\text { extrakt } \\
\text { (Proz.der } \\
\text { Trocken- } \\
\text { substanz) } \\
\%\end{array}$} \\
\hline & & $\begin{array}{c}\text { Proz. der } \\
\text { Trocken- } \\
\text { substanz } \\
\%\end{array}$ & $\begin{array}{c}\text { Proz. der } \\
\text { entfetteten } \\
\text { Trocken- } \\
\text { substanz } \\
\%\end{array}$ & \\
\hline $\begin{array}{l}\text { I. gleiches } \\
\text { Paar }\end{array}\left\{\begin{array}{l}\text { Ruhehund I.. } \\
\text { Arbeitshund II } .\end{array}\right.$ & $\begin{array}{l}25,80 \\
30,20\end{array}$ & $\begin{array}{l}11,74 \\
10,92\end{array}$ & $\overline{12,17}$ & $\overline{10,27}$ \\
\hline 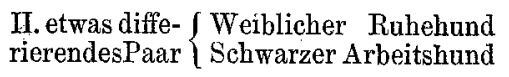 & $\begin{array}{l}29,52 \\
25,89\end{array}$ & $\begin{array}{l}12,04 \\
11,54\end{array}$ & $\begin{array}{l}13,90 \\
13,19\end{array}$ & $\begin{array}{l}13,37 \\
12,49\end{array}$ \\
\hline
\end{tabular}


Für das Herz trifft dasselbe zu; denn es zeigt sich bei einem Vergleich der hier (in Tab. 32) stehenden Zahlen für den Wasser-, Fett- und Stickstoffgehait ${ }^{1}$ ) mit denen in Tab. 40-43, 45, 46, 50 und 52, dass sich Herz- und peripherer Muskel in chemischer Hinsicht durchaus nieht analog verhalten. Die Analysen Danilewsky's (l. e. s. Anm. 3 auf S. 400 muskeltätige und muskelruhige Tierarten), die ich in Tabelle 33 zusammengestellt habe, sprechen in demselben Sinne. Sie sind aber nicht überzeugend, dà an die Möglichkeit gedacht werden musste, dass hier andere Arten Einflüsse in Betracht gekommen sind. Bence's (l. c. s. Anm. 1 auf S. 403) Untersuchungen decken sich in ihren Resultaten ebenfalls mit den meinigen: er fand auch während der Entstehung einer einseitigen Hypertrophie des Herzens den Stickstoff gleichmässig verteilt.

\section{Tabelle 33 .}

Vergleich der Trockensubstanz von Herz- und peripherer Iruskulatur bei rerschiedenen Tieren (Danilewsky's Analysen).

\begin{tabular}{|c|c|c|c|}
\hline & $\begin{array}{c}\text { Herzmuskulatur } \\
\text { (Trocken- } \\
\text { substanz) } \\
\%\end{array}$ & $\begin{array}{c}\text { Periphere } \\
\text { Muskulatur } \\
\text { (Trocken- } \\
\text { substanz) } \\
\% \%\end{array}$ & $\begin{array}{c}\text { Beziehung } \\
\text { zwischen Herz- } \\
\text { und peripherer } \\
\text { Muskulatur wie } \\
100:\end{array}$ \\
\hline 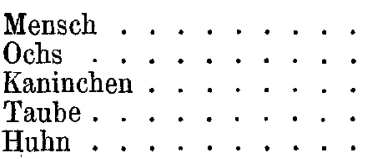 & $\begin{array}{l}20,85 \\
21,92 \\
20,60 \\
23,67 \\
22,10\end{array}$ & $\mid \begin{array}{c}21,48 \\
23,03 \text { (rote Musk.) } \\
25,81 \\
24,97\end{array}$ & $\begin{array}{l}108 \\
112 \\
109 \\
113\end{array}$ \\
\hline
\end{tabular}

Im übrigen beweisen meine Untersuchungen noch, dass die Angabe von Danilewsky, dass die Herzmuskelsubstanz, die doch dauernd Arbeit leistet, wasserreicher ist als die periphere Muskulatur, zutrifft. Sie besitzt auch weniger Stickstoff. Die Veränderungen, welche die peripherische Muskulatur zeigte, sind also beim Herzmuskel unter denselben Untersuchungsbedingungen nicht vorhanden. Das kann daran liegen, dass im ersteren Falle die Untersuchung erst einige Zeit nach der Leistung der Arbeit vorgenommen wurde, während das Herz bis zum Moment des Todes arbeitete. Es würde also das Herz in Parallele stehen z. B. zu den tetanisierten Muskeln Ranke's, bei denen ebenfalls der Wassergehalt erhöht war. Ich behalte mir eine aufklärende Untersuchung vor.

1) Hinsichtlich der befolgten Methodik vgl. die späteren Ausfübrungen, wo von den Muskelanalysen die Rede ist. 


\section{Untersuchung der peripherisehen Muskulatur.}

Es stand zu erwarten, dass sich die Unterschiede zwischen "Ruhe-" und „Arbeitsorganismus" am deutlichsten an der peripherischen Muskulatur zu erkennen geben würden. Meine diesbezüglichen Untersuchungen umfassen sowohl die Bestimmung der absoluten Masse wie die der chemischen Zusammensetzung der Muskeln.

Tabelle 34 .

Muskeluntersuchungen Rogozinsky's.

\begin{tabular}{|c|c|c|c|c|}
\hline \multirow{2}{*}{$\begin{array}{c}\text { Prozente } \\
\text { der frischen Substanz }\end{array}$} & \multicolumn{2}{|c|}{ Versuch I } & \multicolumn{2}{|c|}{ Versuch II } \\
\hline & $\underset{\%}{\text { Ruhe }}$ & $\begin{array}{c}\text { Arbeit } \\
\% \%\end{array}$ & $\begin{array}{c}\text { Ruhe } \\
\% \%\end{array}$ & $\begin{array}{c}\text { Arbeit } \\
\%\end{array}$ \\
\hline 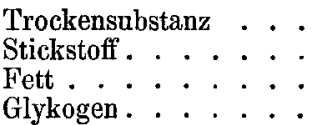 & $\begin{array}{r}23,90 \\
2,77 \\
5,86 \\
0,46\end{array}$ & $\begin{array}{r}28,25 \\
3,52 \\
5,40 \\
0,43\end{array}$ & $\begin{array}{r}26,89 \\
3,57 \\
3,00 \\
0,60\end{array}$ & $\begin{array}{r}26,84 \\
3,25 \\
4,81 \\
0,70\end{array}$ \\
\hline
\end{tabular}

Ich habe zu erwähnen, dass Rogozinski (l. c. s. Anm. 1 auf S. 404) in seinen beiden Versuchsreiben völlig differente Zahlen für die beiden physiologischen Zustände erhalten hatte, wie Tabelle 34, die seine Resultate (S. 218 und 224 seiner Arbeit) wiedergibt, ersehen lässt. Diese Unterschiede in den Ergebnissen, die sich auch auf die Daten der absoluten Muskelmasse beziehen, sind von Rogozinski dahin gedeutet worden, dass im Versuch II „durch Individuum und Rasse bedingte Schwankungen" den Effekt der Muskelarbeit überkompensiert haben. Man muss diese Deutung entschieden für die wahrscheinlichste halten, obwohl überraschenders weise manchmal die Organwägungen bei ganz verschiedenen Hunden einander. sehr nahestehende Resultate ergeben (Tab. 35). Es musaber immer daran gedacht werden, dass individuelle und Rasseunterschiede sich für einen direkten Vergleich der Tiere in der Regel als zu gross erweisen.

Der Weg zu eindeutigen Ergebnissen ist also gewiesen: es ist, wie schon oben betont wurde, notwendig, Geschwistertiere, die in gleicher Weise lange Zeit hindurch herangezogen worden sind, in Vergleich zu setzen, und womöglich auch die hier noch vorhandenen individuellen Schwankungen zu umgehen. 
Tabelle 35.

Beispiele für die gelegentliche Konstanz der Organgewichte bei verschiedenartigen Hunden.

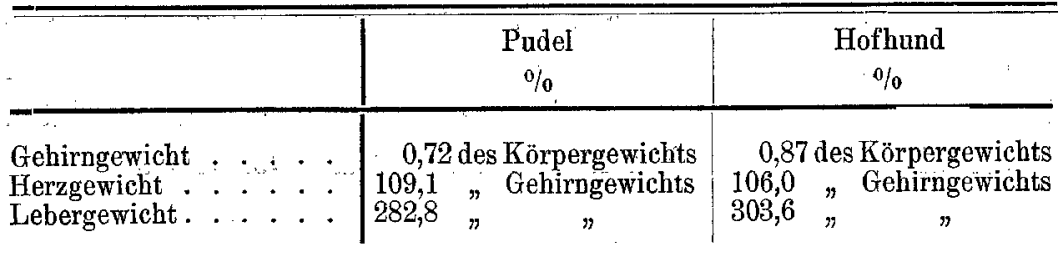

Bezüglich der Details der so angestellten Versuche verweise ich auf die Ausführungen auf S. $406 \mathrm{ff}$. Die Arbeitstiere batten vor ihrem Tode, wie hier wiederholt sei, : über einen Monat regelmässig Ärbeit geleistet. 24 Stunden vor dem Tode (Entblutung aus der Art. femor.; ausser bei dem schwarzen Arbeitshund, der an Staupe zugrunde ging, aber sehr bald nach dem Tode seziert wurde) erhielten sie keine Nahrung, weil mit der Möglichkeit, dass nicht vollendete Resorption des Futters den Wassergehalt der Organe beeinflusse, gerechnet werden musste. Ausserdem war die zuletzt gereichte Nahrung, um den grossen Einfluss des Glykogens auf den Wassergehalt auszuschalten, arm an Kohlehydraten.

Die Muskeln wurden nach der Entblutung der Hunde so schnell als möglich von ihrer Ansatzstelle losgelöst, von Bindegewebe, soweit es das oberste Prinzip, es zu keiner Verdunstung von Wasser kommen zu lassen, zuliess; befreit und in vorher tarierte, im Exsikkator getrocknete Gläser eingefüllt. Nach der Wägung wurden sie über Schwefelsäure im Vakuum bei etwa $60^{\circ} \mathrm{C}$. getrocknet, sobald tunlich, im Mörser grob zerstossen, wieder getrocknet und so weiter verarbeitet, bis die Substanz in feinste Pulverform gebracht war. Sie wurde hierauf im Wassertrỏckenschrank bei etwa $90^{\circ} \mathrm{C}$. bis zur Konstanz der dritten Dezimale weiter getrocknet.

Ursprünglich war die Absicht gewesen, die Muskeln frisch auf ibren Stickstoffgebalt hin zu untersuchen. Nachdem aber die Untersuchung von Muskulatur vor und nach dem Erhitzen auf ungefähr $90^{\circ} \mathrm{C}$. dargetan hatte, dass keine Stickstoffverluste zu befurchten sind, wenn in dieser Weise verfahren wird, unterblieb die Verarbeitung der frischen Substanz zur Kjeldahlbestimmung, und es wurde die gesamte Muskelsubstanz getrocknet und lufttrocken weiter untersucht. Die Analysierung wurde, wie schon oben angegeben, vorgenommen, d. h. der Fettgehalt durch mindestens 24 stündige 
Extraktion im Soxhlet'schen Apparate mit wasserfreiem Äther, Behandlung mit salzsaurem Alkohol, Trocknen, nochmalige Ätherextraktion, bestimmt. Auf Glykogengehalt wurde nicht untersucht, da die Glykogenarmut arbeitender. Tiere genügend sichergestellt ist.

Ich gehe nun zu den Ergebnissen der Untersuchungen über und verweise zunächst auf die Tabellen $36-43$, die die Hunde des gleichen Wurfes betreffen.

Tabelle 36.

Absolute Gewichte von Muskeln des ersten, gleichen Paares.

\begin{tabular}{c|c|c}
\hline & $\begin{array}{c}\text { Ruhehund I } \\
\end{array}$ & $\begin{array}{c}\text { Arbeitshund II } \\
\text { g }\end{array}$ \\
\hline Musculus extensor digitalis longus . . & 5,92 & $\mathrm{~g}$ \\
$\% \quad$ rectus femoris . . . . . & 10,69 & 5,30 \\
$" \quad$ sartorius . . . . . . & 5,26 & 12,50 \\
& & 6,06
\end{tabular}

Tabelle 37.

Absolute Gewichte von Muskeln des zweiten, etwas differierenden Paares.

\begin{tabular}{|c|c|c|}
\hline & $\begin{array}{l}\text { Weiblicher } \\
\text { Ruhehund } \\
\qquad \mathrm{g}\end{array}$ & $\begin{array}{l}\text { Schwarzer } \\
\text { Arbeitshund } \\
\mathrm{g}\end{array}$ \\
\hline 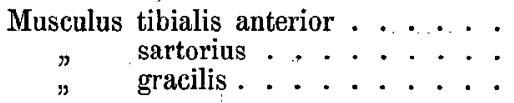 & $\begin{array}{l}2,91 \\
3,12 \\
1,47\end{array}$ & $\begin{array}{l}3,19 \\
4,75 \\
1,46\end{array}$ \\
\hline
\end{tabular}

Tabelle 38.

Prozentuale Gewichte von Muskeln des ersten Paares.

\begin{tabular}{|c|c|c|c|c|}
\hline & \multicolumn{2}{|c|}{$\begin{array}{c}\text { Prozente } \\
\text { des Körpergewichts }\end{array}$} & \multicolumn{2}{|c|}{$\begin{array}{c}\text { Prozente } \\
\text { des Gehirngewichts }\end{array}$} \\
\hline & $\begin{array}{l}\text { Ruhe- } \\
\text { hund I } \\
\text { \% }\end{array}$ & $\begin{array}{l}\text { Arbeits- } \\
\text { hund II } \\
\% \%\end{array}$ & $\begin{array}{l}\text { Ruhe- } \\
\text { hi nd I } \\
\% \%\end{array}$ & $\begin{array}{l}\text { Arbeits- } \\
\text { hund II } \\
\quad \%\end{array}$ \\
\hline $\begin{array}{c}\text { Musculus extensor digitalis longus } \\
\Rightarrow \quad \text { rectus femoris . . } \\
" \quad \text { sartorius. . . . . }\end{array}$ & $\begin{array}{l}0,090 \\
0,162 \\
0,080\end{array}$ & $\begin{array}{l}0,079 \\
0,187 \\
0,099\end{array}$ & $\begin{array}{r}8,96 \\
16,17 \\
7,95\end{array}$ & $\begin{array}{r}8,65 \\
20,39 \\
9,89\end{array}$ \\
\hline 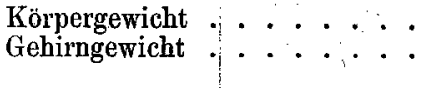 & $\begin{array}{ll}6,95 \mathrm{~kg} \\
66,1 \mathrm{~g}\end{array}$ & $\begin{array}{l}6,67 \mathrm{~kg} \\
61,3 \mathrm{~g}\end{array}$ & & \\
\hline
\end{tabular}

Mit einer einzigen Ausnahme (Tab. 36 und 38) liest man in den Tabellen, dass die Muskeln des unter dem Einflusse der Arbeitsleistung gestandenen Tieres die des Ruhetieres an Gewicht ubertreffen. In einem Falle (Tab. 37 
bzw. 39, Musculus gracilis) war das Gewicht unter den verschiedenen physiologischen Bedingungen gleich. Angesichts der Schwierigkeit, den Musc. extens. digit. long. schnell und in genau konstantem Umfange bei zeitlich weit auseinander liegenden Präparationen von seinem Bindegewebe zu isolieren, dürfte diese Ausnahme wenig besagen.

$$
\text { Tabelle } 39 .
$$

Prozentuale Gewichte ron Muskeln des zweiten Paares.

\begin{tabular}{|c|c|c|c|c|}
\hline & \multicolumn{2}{|c|}{$\begin{array}{c}\text { Prozente } \\
\text { des Körpergewichts }\end{array}$} & \multicolumn{2}{|c|}{$\begin{array}{c}\text { Prozente } \\
\text { des Gehirngewichts }\end{array}$} \\
\hline & $\begin{array}{c}\text { Weiblicher } \\
\text { Ruhehund } \\
\%\end{array}$ & \begin{tabular}{|c|} 
Schwarzer \\
Arbeitshund \\
$\%$
\end{tabular} & $\begin{array}{c}\text { Weiblicher } \\
\text { Ruhehund } \\
\%\end{array}$ & $\begin{array}{c}\text { Schwarzer } \\
\text { Arbeitshund } \\
0_{0}^{\prime}\end{array}$ \\
\hline $\begin{array}{c}\text { Musculis tibialis anterior . } \\
\Rightarrow \quad \text { sartorius ...... } \\
" \quad \text { gracilis . . . . . }\end{array}$ & $\begin{array}{l}0,063 \\
0,068 \\
0,082\end{array}$ & $\begin{array}{l}0,081 \\
0,120 \\
0,037\end{array}$ & $\begin{array}{l}4,88 \\
5,23 \\
2,46\end{array}$ & $\begin{array}{l}5,44 \\
8,10 \\
2,48\end{array}$ \\
\hline 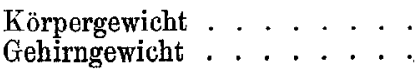 & $\begin{array}{ll}4,60 \mathrm{~kg} \\
59,7 \mathrm{~g}\end{array}$ & $\begin{array}{l}3,95 \mathrm{~kg} \\
58,7 \mathrm{~g}\end{array}$ & & \\
\hline
\end{tabular}

Tabelle 40.

Trockensubstanzgehalt von Muskeln des ersten, gleichen Paares. (Prozente der frischen Substanz.)

\begin{tabular}{|c|c|c|}
\hline & $\begin{array}{c}\text { Ruhehund - I } \\
\% \%\end{array}$ & $\begin{array}{l}\text { Arbeitshund II } \\
\% \%\end{array}$ \\
\hline 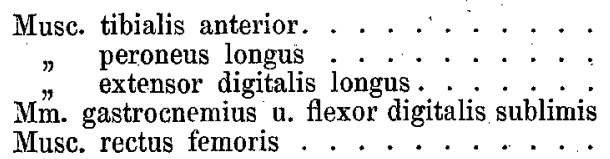 & $\begin{array}{l}23,13 \\
22,11 \\
24,49 \\
24,64 \\
22,92\end{array}$ & $\begin{array}{l}26,51 \\
24,49 \\
26,23 \\
27,24 \\
25,20\end{array}$ \\
\hline
\end{tabular}

Tabelle 41 .

Trockensubstanzgehalt von Muskeln des zweiten, etwas differierenden Paares.

(Prozente der frischen Substanz.)

\begin{tabular}{|c|c|c|}
\hline & $\begin{array}{c}\text { Weiblicher } \\
\text { Ruhehund } \\
\% \%\end{array}$ & $\begin{array}{c}\text { Schwarzer } \\
\text { Arbeitshund } \\
\% \%\end{array}$ \\
\hline $\begin{array}{l}\text { Musc. tibialis anterior. } \\
\text { Meroneus longus gastrocnemius u. flexor digitalis sublimis } \\
\text { Musc. sartorius. } \\
\text { Gemisch beliebig gewählter sonstiger Muskeln }\end{array}$ & $\begin{array}{l}25,95 \\
27,56 \\
26,23 \\
25,45 \\
24,84 \\
24,87\end{array}$ & $\begin{array}{l}26,57 \\
27,16 \\
26,82 \\
27,57 \\
26,49 \\
26,08\end{array}$ \\
\hline
\end{tabular}


Untersuchungen über den Einfluss der. Múskelarbeit auf die Organe etc. 461

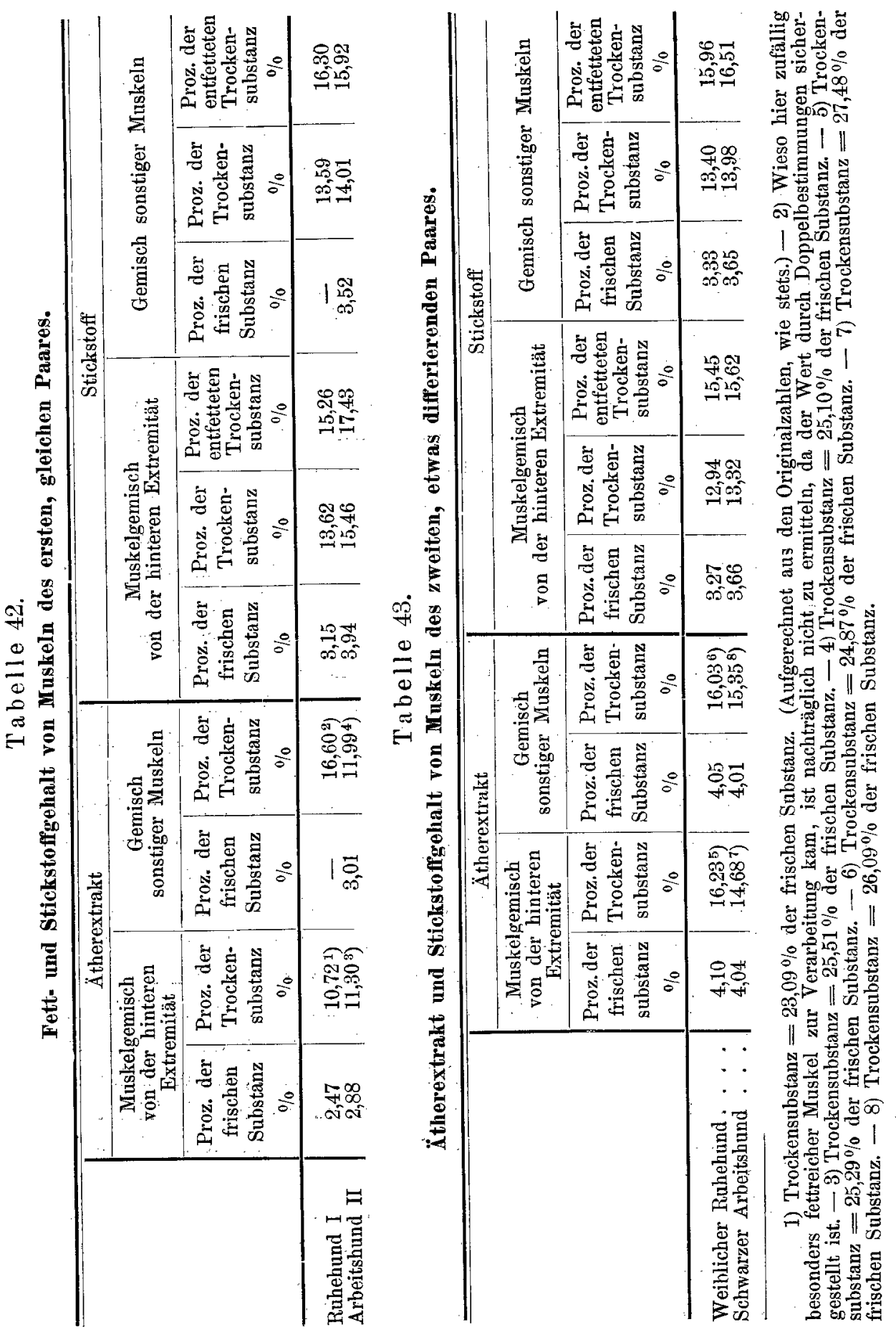


Ebenso eindeutig sind die Frgebnisse der Trockensubstanzbestimmung: durchweg, zum Teil erheblicher Wasserverlust der Arbeitsmuskulatur, wenn man von einer Ausnahme in Tabelle 41 (Musc. peroneus long.), die ohne Zweifel in ähnlichen Fehlern der Methodik, wie im vorigen Falle, ihren Grund hat, absehen will.

Unter den Zahlen, welche die übrige Zusammensetzung zum Ausdruck bringen, findet sich jedoch eine grössere Differenz vom Gros der Bestimmungen in Tabelle 42 (Extremitätenmuskel 10,72\% Rohfett, Muskelgemisch 16,6\% der Trockensubstanz Fett!). Dennoch kann als ausreichend gesichertes Ergehnis der bisherigen Untersuchungen an den vier Hunden desselben Wurfes angenommen werden, dass die Arbeitsleistung zu einer Vermehrung des Muskelstickstoffes und in der Regel auch zueiner Verminderung des Fettes führt.

Die Erfahrungen, welche während der Beobachtung der Entwicklung der vier Hunde gesammelt wurden, lebrten, ein wie grosser Einfluss durch die Individualität auch bei Geschwistertieren in den Stoffumsatz hereingebracht wird. Zur Kontrolle der bereits beschriebenen Resultate, andererseits um manche Erfahrungen von den fruheren Untersuchungen her der Sache zu gute kommen zu lassen, wurde ein weiteres Material in der Weise gewonnen, dass Hunden, die gearbeitet batten, ein Bein amputiert wurhe und dann die nach der Operation durch den Wegfall der Tretbahnarbeit, den Verband, die Unbequemlichkeit und wohl auch Schmerzen aufgezwungene Ruhe zur Ausbildung der Ruhecharakteristika des anderen Beines benutzt wurde. Über die hierfür in Betracht kommenden Tiere ("Amputationshund" I und II) ist bercits früher näbere Mitteilung gemacht worden. Am Tage vor der Amputation des einen Beines leisteten die Tiere morgens nur die Hälfte des sonst üblichen Arbeitsquantums, um die Nachwirkung, die ja unter Umständen bei ermülender Arbeit nicht unerheblich sein konnte, zu eliminieren. In den letzten 24 Stunden vor der Operation fasteten die Tiere.

Der "A mputationshund I" (Foxterrier) wurde am 10. Juli 1906 vor der Amputation durch Iujektion von Kokain in den Nerv. ischiad. und Schleich'sche Infiltrationsanästhesie anästhesiert. Es wurde dann nach dem Anlegen der Esmarch'schen Binde lege artis die rechte Extremität in der Mitte des Oberschenkels mit grosser Schnelligkeit abgeset $/$, dabei dafür Sorge getragen, dass das 
amputierte Bein bis zuir Präparation der Muskeln vor Verdunstung von Wasser geschützt blieb. Die Präparation selbst vollzog, sich unter den schon namhaft gemachten Kautelen. Das Tier überstand die Operation sehr gut; weder war das Allgemeinbefinden sichtlich gestört, noch stieg die Temperatur über die Norm. Schon bald nach der Operation frass der Hund das ihm gereichte Futter bis auf den letzten Rest auf. Näherte man sich dem Käfig, so stand er auf und zeigte wie früher Interesse. Nach 8 Tagen wurde der Verband gewechselt; die Fäden wurden entfernt; die sekretfreie Wunde zeigte gute Granulationen. Es wurde aber innerhalb der Wunde an einer Stelle ein Knochenvorsprung bemerkt, der infolge : der Retraktion der Muskulatur vorgekommen war. Er sollte am anderen Tage entfernt werden. Mittlerweile hatte aber der Hund, dessen Maulkorb sich gelöst hatte, in einem unbewachten Augenblick den Verband entfernt; er wurde dabei betroffen, wie er den Knochenvorsprung abknabberte. Ich liess nun den Verband vollständig weg. Der Hund beleckte seine Wunde weiter, bis sie in kurzem vollständig geschlossen war.

Am 25. Tage nach der Operation erkrankte der Hund, der bis dahin stets vortrefflichen Appetit gezeigt hatte, an einem schweren Darmkatarrh mit Erbrechen und flüssigen, zum Teil blutigen und schleimigen Entleerungen. Am folgenden Tage hielt derselbe Zustand noch an. Ohne Zweifel handelte es sich hier um die toxische, von Pflüger beschriebene Wirkung von Pferdefleisch. Es war anzunehmen, dass bei dem Tier, wenn es in diesem Zustande getötet worden wäre, eine pathologische Wasserverarmung die Ergebnisse der Muskeluntersuchung getrübt hätte. Es wurde deshalb einen Tag hindurch kein Futter gereicht. Am darauf folgenden Tage wurde, nachdem die Fäces schon wieder völlig konsistent waren, das frühere sterilisierte Futter weiter gereicht. Die Durchfälle wiederholten sich nicht. Am 8. August 1906, also 29 Tage nach der Operation und nach einer ebenso langen Muskelruhe, wurde der Hund durch Einspritzung einer Spritze Chloroform ins linke Herz getötet. Der Tod trat im Moment ein.

Da das Körpergewicht des Hundes vor dem Tode etwas abgesunken war (vgl. Tab. 5), so ist es nicht einwandfrei, wenn die Gewichte der einzelnen Muskeln auf das Körpergewicht bezogen werden. Der reduzierte Fettgehalt des geruhten Tieres bedingt auch eine Komplikation in der Beurteilung der Ergebnisse der 
Muskeluntersuchung; dieser Umstand hat jedoch nicht verhindern können, dass die Muskelsubstanz, wie die Berechnung auf fett- und aschefreie Substanz ergibt, ibren Stickstoffbestand gewahrt hat, so dass auch diese Versuchsreihe, Erge b n iss e (Tab. 44-46) gefördert hat, die durchaus mit den früher bekanntgegebenen in Harmonie stehen. - Ich erinnere noch daran, dass auch in den Versuchen von Rogozinski ebenso wie hier der Aschengehalt der Ruhemuskeln erhöht gefunden wurde.

\section{Tabelle 44.}

Absolute Gewichte ron Mnskeln des Amputationshundes I.

\begin{tabular}{c|c|c|c}
\hline & $\begin{array}{c}\text { Ruhe- } \\
\text { muskel } \\
\mathrm{g}\end{array}$ & $\begin{array}{c}\text { Arbeits- } \\
\text { muskel } \\
\mathrm{g}\end{array}$ & $\begin{array}{c}\text { Gewichts- } \\
\text { differenz } \\
\mathrm{g}\end{array}$ \\
\hline Musc. tibialis anterior . . . . . . . & 13,96 & 14,33 & $+0,4$ \\
Musc. flexor digitalis profundus . . . & 12,77 & 18,36 & $+5,6$ \\
Mm. gastrocnemius u. flexor digitalis & 29,57 & 33,19 & $+3,6$
\end{tabular}

Tabelle 45.

Trockensubstanzgehalt ron Muskeln des Amputationshundes I.

\begin{tabular}{|c|c|c|}
\hline & $\underset{\% / \%}{\text { Ruhemuskel }}$ & $\begin{array}{c}\text { Arbeitsmuskel } \\
\% \%\end{array}$ \\
\hline 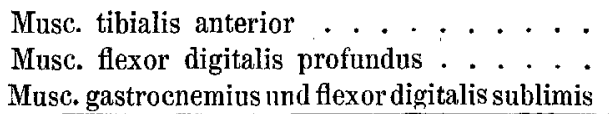 & $\begin{array}{l}25,64 \\
25,45 \\
25,53\end{array}$ & $\begin{array}{l}26,69 \\
30,63 \\
26,78\end{array}$ \\
\hline Mittel: . . . . . . . . & 25,54 & $27 ; 83$ \\
\hline
\end{tabular}

Tabelle 46.

Fett-, Stickstoff- und Aschegehalt von Muskeln des Amputationshundes I.

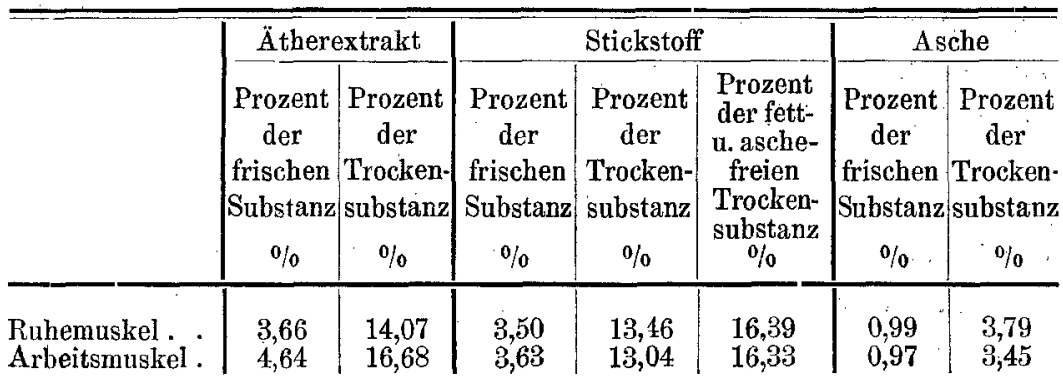


Ein zweiter Hund ( Amputationshund" II, vgl. S. 414) wurde am 5. April 1907, nachdem tags vorher etwa um dieselbe Tageszeit das letzte Futter gereicht worden war, operiert. Das Tier wog $11,36 \mathrm{~kg}$.

Auch diesmal wurde von einer Allgemeinnarkose abgesehen. Fis wurde in der Weise anästhesiert, dass $25 \mathrm{ccm}$ einer $0,5 \%$ igen Novokain-Suprareninlösung teils direkt in den Nerv. ischiar. injiziert, teils zur intrakutanen Infiltrationsanästhesie nach dem Verfahren von Reclus unter Zuhilfenahne. der elastischen Abschnürung verwandt wurden. Der Suprareninzusatz sollte zur Verzögerung der toxischen Wirkung des Kokains dienen.

Vor der Amputation wurde die Art. femoral. geöffnet, um Blut zur Analyse zu erhalten.

Die Absetzung der linken Extremität geschah wiederum im Schaftteil des Femur, und zwar wurde diesmal, da sich in dem früheren Falle der Zirkelschnitt nicht bewährt hatte, vorteilhaft ein breiter vorderer und ein schmälerer hinterer Ilautlappen gebildet und recht weit nach der Basis zu heraufpräpariert. Die Wunde wurde mit steriler Gaze bedeckt, mit einer Binde umwickelt und zum Schluss mit einer aus elastischem Gewebe hestehenden Kappe, die durch Schnüre am Tier sicheren Halt fand, bedeckt. So sass diesmal der Verband sehr sicher. Am fünften Tage nach der Operation wurde er gelöst. Die Wunde sah ausgezeichnet aus; sie heilte prima intentione ab. Die Temperatur stieg nach der Operation nie über die Norm: Das Maximum betrug $39,15^{\circ} \mathrm{C}$. in der Vagina am Abend des zweiten Tages nach der Operation. An den folgenden Tagen waren die Morgentemperaturen $38.8^{\circ} ; 38,9^{\circ} ; 39,1^{\circ} ; 38,7^{\circ} \mathrm{C}$., stets in der Vagina in derselben Tiefe bestimmt. Die Operation hatte das Allgemeinbefinden auch dieses Hundes so wenig mitgenommen, dass er, wie der frühere, sein Futter am Nachmittage des Operationstages mit dem alten Behagen verzehrte. Am zweiten Tage, von der Operation an gerechnet, wurde diarrhöischer Kot entleert. Da bis dahin, der Billigkeit wegen, 30 Tage hindurch Pferdefleisch grereicht worden war, dürte es sich auch hier wieder zweifelsohne un Pferdefleischtoxine gebandelt haben, wofür auch spricht, dass Diätwechsel sofort Änderung brachte.

Der Hund wog am Tage der Amputation $11,60 \mathrm{~kg}$, nach 21 Tagen Ruhe (amputiert) 10,83 kg; es hatte also eine Gewichtsabnahme stattgefunden. Nun sind aber die genannten Gewichts- 
Tabelle 17.

Absolute Gewichte von Muskeln des Amputationshundes II.

\begin{tabular}{|c|c|c|}
\hline & $\begin{array}{c}\text { Ruhe } \\
\text { (rechtes Bein) } \\
g \\
\end{array}$ & $\begin{array}{c}\text { Arbeit } \\
\text { (linkes Bein) } \\
\mathrm{g}\end{array}$ \\
\hline $\begin{array}{l}\text { Musc. tibialis auterior } \\
\text { Musc. peroneus longus } \\
\text { Musc. Gexor digitalis profundus } \\
\text { Musc. extensor digitalis longus. } \\
\text { Husc. gastrocnemius med. u. lat.. } \\
\text { Musc. peroneus tertius } \\
\text { Gesamte übrige Unterschenkelmuskulatur }\end{array}$ & $\begin{array}{r}9,11 \\
3,24 \\
12,73 \\
7,65 \\
46,43 \\
1,49 \\
5,38 \\
\end{array}$ & $\begin{array}{r}8,29 \\
3,05 \\
12,50 \\
7,11 \\
44,73 \\
1,59 \\
5,35 \\
\end{array}$ \\
\hline Insgesamt $\ldots \ldots \ldots \ldots$ & 86,03 & 82,62 \\
\hline
\end{tabular}

Tabelle 48.

Gewicht ron Muskeln des Amputationshundes II.

(Prozent des Körpergewichtes).

\begin{tabular}{|c|c|c|}
\hline & $\begin{array}{c}\text { Ruhe } \\
\text { Gewicht korri- } \\
\text { giert }=11,127 \mathrm{~kg} \\
\text { (rechtes Bein) } \\
\% \%\end{array}$ & $\begin{array}{c}\text { Arbeit } \\
\text { (linkes Bein) } \\
\%\end{array}$ \\
\hline $\begin{array}{l}\text { Musc. tibialis anterior. } \\
\text { Musc. peroneus longus } \\
\text { Musc. flexor digitalis profundus } \\
\text { Musc. extensor digitalis longus. }\end{array}$ & $\begin{array}{l}0,082 \\
0,029 \\
0,114 \\
0,069 \\
0,417 \\
0,013 \\
0,048\end{array}$ & $\begin{array}{l}0,073 \\
0,027 \\
0,110 \\
0,063 \\
0,394 \\
0.014 \\
0,047 \\
\end{array}$ \\
\hline Insgesamt . . . . . . . . . . & 0,773 & 0,727 \\
\hline
\end{tabular}

Tabelle 4.9 .

Gewicht ron Muskeln des Imputationshuudes II.

(Prozent des Gehirngewichts $[80,1 \mathrm{~g}]$.)

\begin{tabular}{|c|c|c|c|}
\hline & & $\begin{array}{c}\text { Ruhe } \\
\text { (rechtes Bein) } \\
0 / 0\end{array}$ & $\begin{array}{c}\text { Arbeit } \\
\text { (linkes Bein) } \\
0 / 0\end{array}$ \\
\hline $\begin{array}{l}\text { Musc. tibialis anterior } . \cdot \cdot \\
\text { Musc. peroneus longus } \cdot \text {. } \\
\text { Musc. flexor digitalis profundus } \\
\text { Musc. extensor digitalis longus } \\
\text { Mm. gastrocnemius med. u. lat. } \\
\text { Musc. peroneus tertius . . } \\
\text { Gesamte übrige Unterschenkelmus }\end{array}$ & 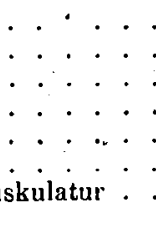 & $\begin{array}{r}11,37 \\
4,04 \\
15,89 \\
9,55 \\
57,97 \\
1,86 \\
6,71\end{array}$ & $\begin{array}{r}10,35 \\
8,80 \\
15,60 \\
8,88 \\
55,84 \\
1,98 \\
6,68\end{array}$ \\
\hline
\end{tabular}


zahlen nicht ohne weiteres kommensurabel, da das letztere Gewicht um den amputierten Schenkel zù gering gewogen ist. Dessen Gewicht betrug $300 \mathrm{~g}$, das Blut; das bei der Operation verloren ging ( $110 \mathrm{cem}), 117 \mathrm{~g}$, so dass also das Tier gleich nach der Operation 10,94 kg gewogen hätte. Diesem Gewicht entspricht das tatsächliche Ruhegewicht $10,83 \mathrm{~kg}$, einem Schenkel von $300 \mathrm{~g}$ Gewicht also ein solcher von 297 g. Hätte der Hund also bei der Ruhe noch sein linkes Bein besessen, so - kann man annehmen wäre sein Ruhegewicht $10,830+297=11,127 \mathrm{~kg}$ gewesen. Auf dieses Gewicht sind die Muskelgewichtszahlen (Tab. 47) in Tabelle 48 berechnet worden. Eigentlich ist auch dies nicht ganz korrekt; denn, wie ein Blick auf Kurve III lehrt, nahm das Körpergewicht vor dem Tode nach längerdauernder Konstanz stetig und so stark zu, dass die Muskeln mit dieser Zunahme nicht Schritt halten konnten. Richtiger wäre demnach schon die Beziehung auf das mittlere Ruhegewicht. Aber auch diese Berechnung ändert ebensowenig wie die Aufrechnung auf das konstante Gehirngewicht (Tab. 49) etwas daran, dass in diesem Versuch sämtliche untersuchten Muskeln das merkwürdige Phänomen darbieten, dass die Rubemuskeln sebwerer sind als die Arbeitsmuskeln. Diese Tatsache ist um so auffälliger, als die Ergebnisse der chemischen Untersuchung wiederum mit den früheren harmonieren und eklatant den Einfluss der Arbeit im Sinne einer Erhöhung der Trockensubstanz (Tab. 50 und 51) erkennen lassen. Die Zahlen für den Stickstoffgehalt

Tabelle 50.

Trockensubstanzgehalt von Muskeln des Amputationshundes II. (Prozent der frischen Substanz.)

\begin{tabular}{|c|c|c|}
\hline & $\begin{array}{c}\text { Ruhe } \\
\text { (rechtes Bein) } \\
0 / 0\end{array}$ & $\begin{array}{c}\text { Arbeit } \\
\text { (linkes Bein) } \\
\quad \%\end{array}$ \\
\hline $\begin{array}{l}\text { Musc. tibialis anterior } \\
\text { Musc. peroneus longus } \\
\text { Musc. flexor digitalis profundus } \\
\text { Musc. extensor digitalis longus } \\
\text { Mm. gastrocnemius med. n. lat. } \\
\text { Musc. peroneus tertius } \\
\text { Gesamte äbrige Untersehenkelmuskulatur . }\end{array}$ & $\begin{array}{l}25,52 \\
26,55 \\
25,92 \\
25,38 \\
25,52 \\
28,00 \\
25,40\end{array}$ & $\begin{array}{l}27,99 \\
29,00 \\
26,68 \\
27,01 \\
27,15 \\
29,18 \\
26,67\end{array}$ \\
\hline Insgesamt . . . . . . . . . & 25,62 & 27,00 \\
\hline
\end{tabular}


sind gleich; die Werte für die Menge des vorhandenen Ätberextraktes demonstrieren deutlich die grössere Fettarmut der Arbeitsmuskeln (Tab. 52).

Tabelle 51 .

Gewicht der trockenen Muskel voun Amputationshund II.

\begin{tabular}{|c|c|c|}
\hline & $\begin{array}{c}\text { Ruhe } \\
\text { (rechtes Bein) } \\
\mathrm{g}\end{array}$ & $\begin{array}{c}\text { Arbeit } \\
\text { (linkes Bein) } \\
\mathrm{g}\end{array}$ \\
\hline $\begin{array}{l}\text { Musc. tibialis anterior } \\
\text { Musc. peroneus longus } \\
\text { Musc. flexor digitalis profundus } \\
\text { Musc. extensor digitalis longus. }\end{array}$ & $\begin{array}{r}2,32 \\
0,86 \\
3,30 \\
1,94 \\
11,85 \\
0,42 \\
1,37 \\
\end{array}$ & $\begin{array}{r}2,32 \\
0,88 \\
3.33 \\
1,92 \\
11,94 \\
0,46 \\
1,45 \\
\end{array}$ \\
\hline Insgesamt $\ldots \ldots \ldots \ldots$ & 22,06 & 22,32 \\
\hline
\end{tabular}

Tabelle 52.

Ätherextrakt- und Stickstoffgehalt der Unterschenkelmuskel des A mpatationshundes II.

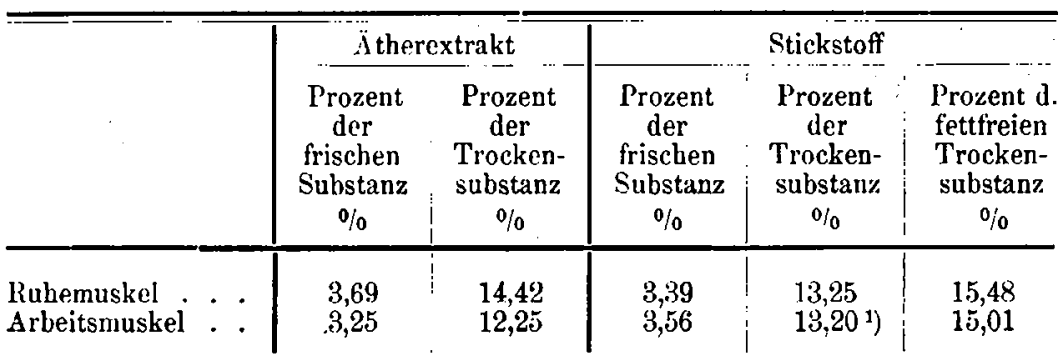

Die Menge des erst nach dem Digerieren mit Salzsäurealkohol aus dem Muskel mit Äther Extrahierbaren war in diesem Falle bei der Arbeit ebenso gross wie bei der Ruhe. Die kürzeste Extraktion dauerte 25 Stunden, so dass die Zahlen ohne Fehler vergleichbar sind (Tab. 54).

Die Ergebnisse der früheren Untersuchungen zeigen diese Konstanz der zweiten Extraktion nicht, sondern weisen durchweg ein relatives Überwiegen der zweiten Extraktion bei der Arbeit auf,

1) Von drei angesetzten Bestimmungen verunglückte eine, so dass nur zwei übrig blieben. Davon wies die eine einen Trockensubstanzgehalt ron 13,20 (Tab. 52) nach, die andere einen erheblich höheren von 13,30\% N der Trockensubstanz $=15,12 \%$ der fettfreien Trockensubstanz. 
Untersuchungen über den Einfluss der Muskelarbeit auf die Organe etc. 469

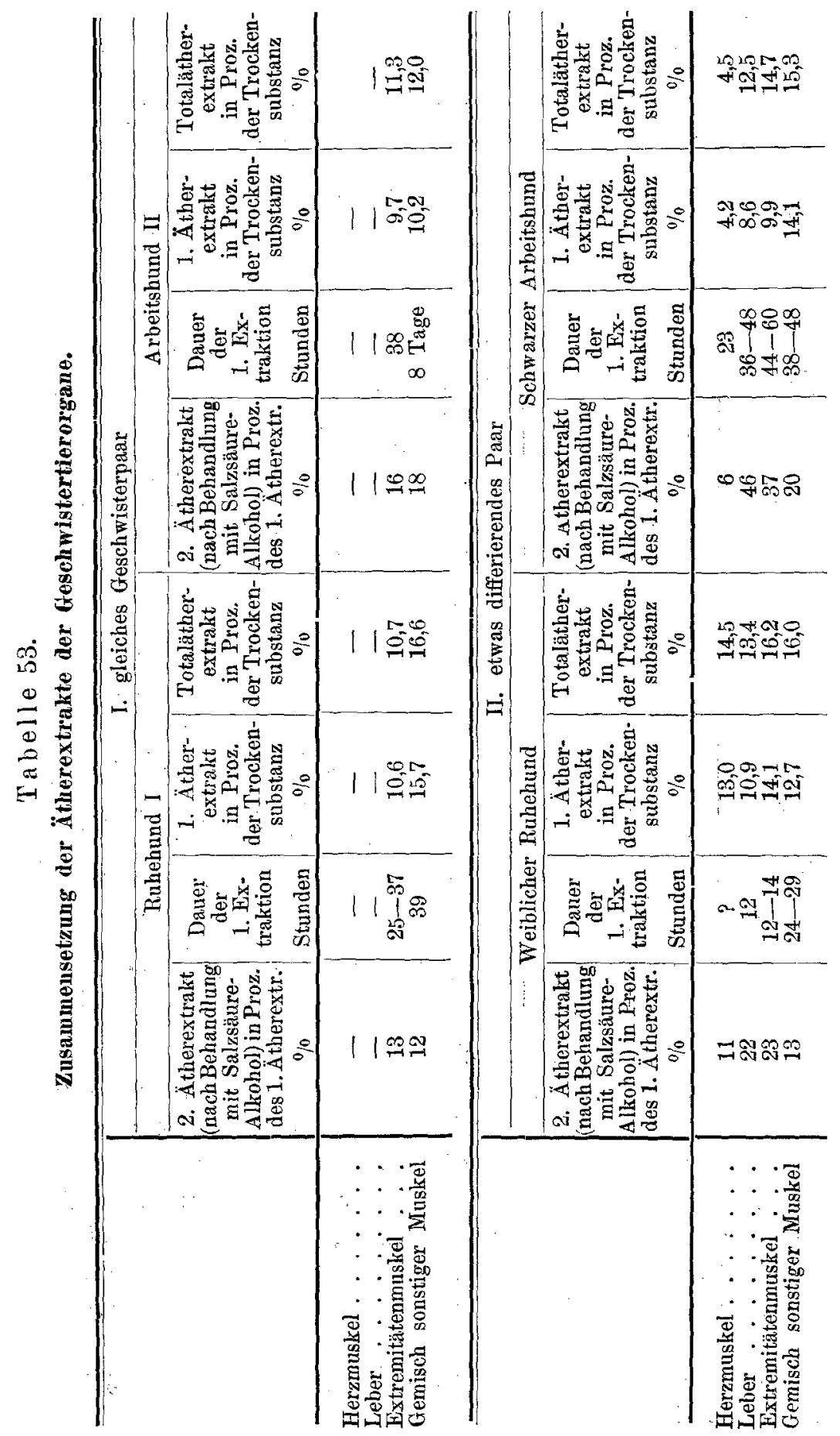


auch, wo infolge der längerdaueruden ersten Extraktion ein kleinerer zweiter Anteil zu erwarten gewesen wäre (Tab. 53). Allein die Herzmuskulatur weicht. von diesem Verhalten ab. Hier ist es aber sehr zweifelhaft, ob die Zahlen der Tabelle überhaupt vergleichbar sind.

Tabelle 54.

Zusammensetzung der Ätherextrakte der Extremitätenmuskeln der Amputationshnnde.

\begin{tabular}{|c|c|c|c|c|c|c|c|}
\hline \multicolumn{8}{|c|}{ Amputationshund $\mathrm{I}$. } \\
\hline \multicolumn{4}{|c|}{ Ruhe } & \multicolumn{4}{|c|}{ Arbeit } \\
\hline $\begin{array}{c}\text { 2. Äther- } \\
\text { extrakt(nach } \\
\text { Behandlung } \\
\text { mit Salzsäure- } \\
\text { Alkohol (in \% } \\
\text { des } 1 . \text { Äther- } \\
\text { extraktes } \\
\% \%\end{array}$ & $\begin{array}{c}\text { Dauer } \\
\text { der } \\
\text { 1. Ex- } \\
\text { traktion } \\
\text { (Stdn.) }\end{array}$ & $\begin{array}{c}\text { 1. Äther- } \\
\text { extrakt } \\
\text { in \% der } \\
\text { Trocken- } \\
\text { substanz } \\
\%\end{array}$ & $\begin{array}{c}\text { Total- } \\
\text { äther- } \\
\text { extrakt } \\
\text { in } \% \text { der } \\
\text { Trocken- } \\
\text { substanz } \\
\quad \%\end{array}$ & $\begin{array}{c}\text { 2. Ather- } \\
\text { extrakt(nach } \\
\text { Behandlung } \\
\text { mitSalzsäure- } \\
\text { Alkohol)in } \% \\
\text { des 1. Äther- } \\
\text { extrakts } \\
\%\end{array}$ & $\begin{array}{c}\text { Daper } \\
\text { der } \\
\text { 1. Ex- } \\
\text { traktion } \\
\text { (Stdn.) }\end{array}$ & $\begin{array}{c}\text { 1. Ather- } \\
\text { extrakt } \\
\text { in } \% \text { der } \\
\text { Trocken- } \\
\text { substanz } \\
\% \%\end{array}$ & $\begin{array}{c}\text { Total- } \\
\text { äther- } \\
\text { extrakt } \\
\text { in } \% \text { der } \\
\text { Trocken- } \\
\text { substanz } \\
\%\end{array}$ \\
\hline 8 & $\left(\begin{array}{c}? \\
\text { (über 25) }\end{array}\right)$ & 13,0 & 14,1 & 14 & 34 & 14,2 & 16,7 \\
\hline \multicolumn{8}{|c|}{ Amputationshund II. } \\
\hline \multicolumn{4}{|c|}{ - Ruhe } & \multicolumn{4}{|c|}{ Arbeit } \\
\hline $\begin{array}{c}\text { 2. Äther- } \\
\text { extrakt(nach } \\
\text { Behandlung } \\
\text { mit Salzsänre- } \\
\text { Alkohol) in \% } \\
\text { des } 1 . \text { Äther- } \\
\text { extraktes } \\
\% \%\end{array}$ & $\begin{array}{c}\text { Dauer } \\
\text { der } \\
1: \text { Ex- } \\
\text { traktion } \\
\text { (Stdn.) }\end{array}$ & $\begin{array}{c}\text { 1. Äther- } \\
\text { extrakt } \\
\text { in } \% \text { der } \\
\text { Trocken- } \\
\text { substanz } \\
\%\end{array}$ & $\begin{array}{c}\text { Total- } \\
\text { äther- } \\
\text { extrakt } \\
\text { in \% der } \\
\text { Trocken- } \\
\text { substanz } \\
\% \%\end{array}$ & $\begin{array}{c}\text { \%. Äther- } \\
\text { extrakt(nach } \\
\text { Behandlung } \\
\text { mit Salzsäuer- } \\
\text { Alkohol)in } \% \\
\text { des 1. Äther- } \\
\text { extraktes } \\
\%\end{array}$ & $\begin{array}{c}\text { Dauer } \\
\text { der } \\
\text { 1. Ex- } \\
\text { traktion } \\
\text { (Stdn.) } \\
\%\end{array}$ & $\begin{array}{c}\text { 1. Äther- } \\
\text { extrakt } \\
\text { in } \% \text { der } \\
\text { Trocken- } \\
\text { substanz } \\
\%\end{array}$ & $\begin{array}{c}\text { Total- } \\
\text { äther- } \\
\text { extrakt } \\
\text { in \% der } \\
\text { Trocken- } \\
\text { substanz } \\
\%\end{array}$ \\
\hline 10 & 42 & 12,9 & 14,4 & 10 & 25 & 10,8 & 12,25 \\
\hline
\end{tabular}

Die Verhältnisse (vgl. Tab. 53-55) liegen also für die peripherische Muskulatur so, dass die Muskelarbeit vor allem (eine Ausnahme) zu einer Verminderung des leicht aus dem Muskel extrahierbaren eigentlichen Fettes füht, der Gehalt an schwer mit Äther extrahierbarem regelmässig - von einem Falle, wo er gleich blieb, abgesehen - zunimmt. N. Zuntz ?) hat darauf aufmerksam gemacht, dass das erste Extrakt das zwischen den Muskelfasern gelegene Fett repräsentiert, das

1) Zuntz, Über die Fette des Fleisches. Arch. f. (Anat. u.) Physiol. 1897 S. 149-150. 
zweite (erhebliche Mengen freier Säuren) aber das der quergestreiften Muskelfaser selbst entstanmende "Fett" darstellt. Bogdanow fand unter Leitung von Zuntz, „dass diese schwer extrahierbaren, in der kontraktilen Substanz selbst verteilten Fette zur Tätigkeit derselben in inniger Beziehung stehen“, und dass sie „bei der Arbeit verbraucht, aber durch Neuzufuhr vom Blute her rasch wieder ersetzt zu werden" scheinen. $\mathrm{Zuntz}$ demonstrierte als Beleg hierfür in der Berliner physiologischen Gesellschaft „drei korrespondierende, mit Osmiumlösung behandelte Muskelproben von Fröschen. Die Farbe der drei in genau gleicher Weise bereiteten Präparate variierte von hellem Gelbbraun bis zu Schwarzbraun. Die hellste Farbe zeigten die Muskeln, welche nach Aufhebung des Blutkreislaufs bis zur Erschöpfung , tetanisiert waren, am dunkelsten waren jene, welche nach zweitägiger Curarelähmung bei gut erhaltener Zirkulation ausgeschnitten wurden. In der Mitte stand die Färbung der nach langer Tetanisierung bei erhaltenem Blutkreislauf präparierten Muskeln“. Meine Befunde bestätigen durchaus diese Anschaungen uber die Bedeutung der zweiten Ätherextrakte für die Arbeitsleistung. Sie zeigen, dass sie dabei gelegentlich sogar erheblich zunehmen, sei es dass überkompensiert wird oder neue Stoffe eintreten.

Tabelle 55 .

Ïtherextrakte bei Ruhe- und Arbeitsmuskeln.

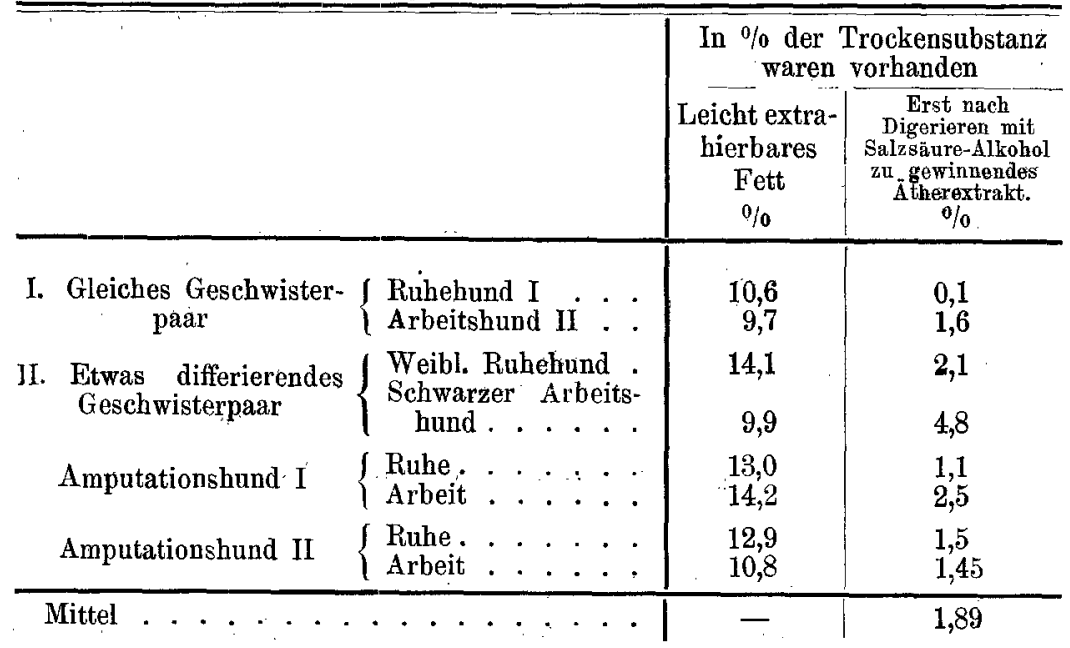

Ich vermute nach diesen Erfahrungen, dass das sekundäre Ätherextrakt überhaupt für den normalen Ablauf der Lebensfunktionen eine 
grosse Bedeutung besitzt. Eine Stütze für diese Ansicht finde ich in Beobachtungen von $\mathrm{Schulz}^{1}$ ), der verhungerte Hunde anf ihren Fettgehalt untersucht hat. In den Tabellen dieses Autors findet man nun wohl grosse Differenzen im Gehalt an leicht extrahierbarem Fett bei seinen Hunden, aber ausserdem eine Konstanz des. Prozentsatzes an erst durch die Verdauungsmethode erschliessbarem "Fett" und sogar einen Prozentsatz, der etwas über dem von mir an normalen Tieren gefundenen Mittel liegt.

Das höhere Gewicht der Ruhemuskeln des Amputationshundes II bedarf noch einer aufklärenden Untersuchung. Ich erinnere daran, dass der Einfluss der Arbeit am linken, der der Ruhe am rechten Unterschenkel studiert wurde: Beim Amputationshund I, bei dem das arbeitende Bein schwerer war, war dieses das rechte. Liegt in diesem Momente die Ursache?

Über die topographischen Unterschiede in der peripherischen Muskulatur desselben Individuums.

Dass Unterschiede zwischen rechter und linker Muskulatur beim Menschen vorhanden sind, ist jedermann geläufig. Dass sie beim Vierfüsser sich geltend machen, ist von vornherein mit Rücksicht darauf, dass hier alles das, was der Erscheinung beim Menschen als Erklärung untergelegt wird, fehlt, unwahrscheinlich. Ist es der Fall, so wirft es ein aufklärendes Licht nicht zum mindesten auf die Genese der Unterschiede beim Mensehen.

Meines Wissens enthält die Literatur keine Angaben über die hier auftretenden Fragestellungen. Das Einzige, was mir bekannt geworden ist, ist eine Mitteilung von C. v. Voit ${ }^{2}$ ), in der sich genaue Maasse der Organe eines gesunden. wohlgenährten und eines hungernden Hundes finden. Unter diesen Zahlen ist bei dem $15,4 \mathrm{~kg}$ schweren ersteren Hund folgende Angabe gemacht:

rech te hintere Extremität $=280,2 \mathrm{~g}(=11,75 \%$ des Körpergew. $)$, linke $" \quad=241,9 \mathrm{~g}(=10,14 \% " n)$.

1) Fr. N. Schulz, Über die Verteilung von Fett und Eiweiss beim mageren Tier, zugleich ein Beitrag zur Methode der Fettbestimmung. Pflüger's Ärch. Bd. 66 S. 145-167. 1897.

2) C. Voit, Gewichte der Organe eines wohlgenährten und eines hungernden Hunles: Zeitschr. f. Biol. Bd. 30 S. 510 ff. 1894. 
Auf den rechten Unterschenkel kamen $85,6 \mathrm{~g}$, auf den linken 77,5 g. Beim Fuss waren die Unterschiede ebenfalls sehr gross; die Oberschenkel wiesen eine nur geringe Differenz auf.

Die Muskeln des rechten Unterschenkels wogen zusammen $173,5 \mathrm{~g}$, die des linken 195,5 g. Weitere Differenzierung fehlt.

Beim Hungerhund fand v. Voit noch geringere Unterschiede. Ich habe seine Zahlen in der Tabelle 56 zusammengestellt.

$$
\text { Tabelle } 56 \text {. }
$$

Extremititengewichte des Hundes nach C. von Voit. (Hunger.)

\begin{tabular}{|c|c|c|}
\hline & $\begin{array}{l}\text { Rechts } \\
\mathbf{g}\end{array}$ & $\begin{array}{l}\text { Links } \\
\mathrm{g}\end{array}$ \\
\hline 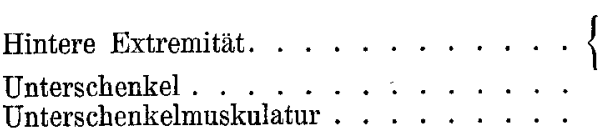 & $\mid \begin{array}{c}361,4=11,44 \% \\
\text { des Körpergew. } \\
114,0 \\
145,5\end{array}$ & $\begin{array}{c}359,5=11,37 \% \\
\text { des Körpergew. } \\
110,5 \\
147,0\end{array}$ \\
\hline
\end{tabular}

Diese Ergebnisse v. Voit's: grösseres Gewicht der rechten Extremität ohne Mitbeteiligung der Muskulatur, konnten zur Aufklärung der beobachteten Differenz nicht genügen. Es sind deshalb eigene Untersuchungen angestellt worden.

Drei gesunde Hunde wurden vor dem Tode einige Zeit hindurch mit überwiegenden Mengen Pferdefleisch, einer kleinen Zulage Schweineschmalz und sehr wenig Reis gefüttert, so dass also den früheren Versuchen völlig gleiche Verhältnisse geschaffen waren. Zwei Hunde waren junge Hofhunde von gleichem Gewicht $(7,6$ und $7,7 \mathrm{~kg}$, ठ), der dritte Hund war ein Jagdhund, der 19,4 kg wog. Diese Tiere sind im folgenden mit Hund VII, VIII und IX bezeichnet. Die übrigen Verhältnisse waren den oben beschriebenen analog; z. B. wurden auch diese Hunde durch Entbluten getötet.

Den Tabellen, welche die Untersuchungen der Muskulatur wiedergeben, ist noch eine die inneren Organe betreffende Notiz (Tab. 57) beigefügt. Es ergibt sich aus den Aufstellungen (Tab. 58 59 und 60), dass beim Vierfüsser in der Ruhe rechte und linke Seite, sowohl was das absolute Gewicht der Muskeln als ihren Wassergehalt angeht, sich gleich verhalten. Bei Hund VIII waren die entsprechenden Zahlen:

rechte bintere Extremität $25,69 \%$ Trockensubstanz,

linke $\Rightarrow \quad 25,12 \%$

Pflüger's Arehiv für Physiologie. Bd. 133. 
Tabelle 57.

Absolute und prozentuale Organgewichte rom Hund VII. (Körpergewicht 7,6 kg).

\begin{tabular}{l|c|c|c}
\hline \hline & $\begin{array}{c}\text { Absolutes } \\
\text { Gewicht } \\
\mathrm{g}\end{array}$ & $\begin{array}{c}\text { Prozent des } \\
\text { Körpergewichts } \\
\text { \% }\end{array}$ & $\begin{array}{c}\text { Prozent des } \\
\text { Gehirngewichts } \\
\%\end{array}$ \\
\hline Gehirn. . . . . . & 66,5 & 0,87 & 100 \\
Herz 1 . . . . . & 70,8 & 0,93 & 106,0 \\
Leber. . . . . . & 202,0 & 2,66 & 303,6 \\
Lunge. . . . . . & 130,2 & 1,71 & 195,7 \\
Pankreas . . . . . & 18,1 & 0,24 & 27,2 \\
Milz. . . . . . & 13,9 & 0,18 & 20,9 \\
Nieren \{rechts . . & $14,8\} 30,1$ & $0,19\} 0,40$ & $22,2\} 45,2$ \\
& $15,3\}$ & $0,20\}$ & $23,0\}$
\end{tabular}

Tabelle 58.

Vergleichende Zusammenstellung der Muskelgewichte vom Hund VII.

\begin{tabular}{|c|c|c|c|}
\hline & $\begin{array}{c}\text { Rechts } \\
\mathrm{g}\end{array}$ & $\begin{array}{c}\text { Links } \\
\mathrm{g}\end{array}$ & \\
\hline \multirow[t]{2}{*}{ 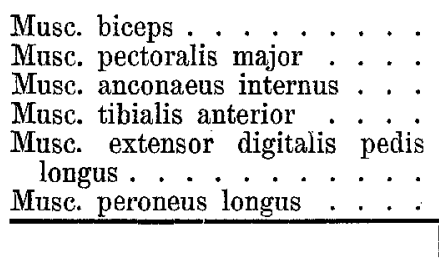 } & $\begin{array}{r}9,19 \\
18,24 \\
7,30 \\
9,07\end{array}$ & $\begin{array}{r}9,54 \\
18,72 \\
6,89 \\
8,72\end{array}$ & $\begin{array}{l}\text { Muskel der } \\
\text { vorderen } \\
\text { Extremität } \\
\text { Muskel der } \\
\text { hinteren } \\
\text { Extremität }\end{array}$ \\
\hline & 51,75 & 51,99 & \\
\hline
\end{tabular}

Tabelle 59 .

Trockensubstanzgehalt der Muskeln rom Hund VII.

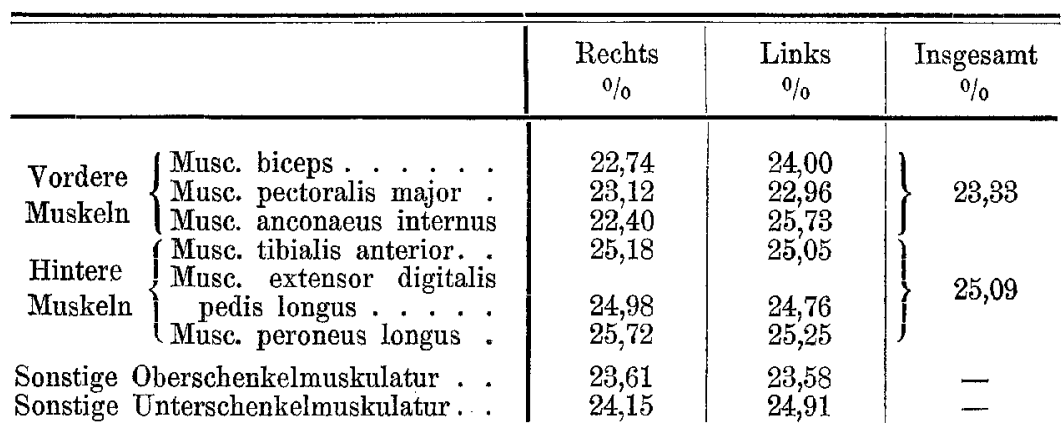

1) Am Herzbeutelansatz losgetrennt.

2) Schulz, l. c. (s. Anm. S. 472) fand bei einem verhungerten gesunden Hund von $24 \mathrm{~kg}$ Gewicht das Herz zu 102,6\% des Gehirngewichts, aber zu 1,3\% des Körpergewichts. Also auch hier zeigt sich der grössere Vorzug des ersteren Modus der Berechnung. 
Tabelle 60 .

Trockensubstanzgehalt der Muskeln vom Hund VII.

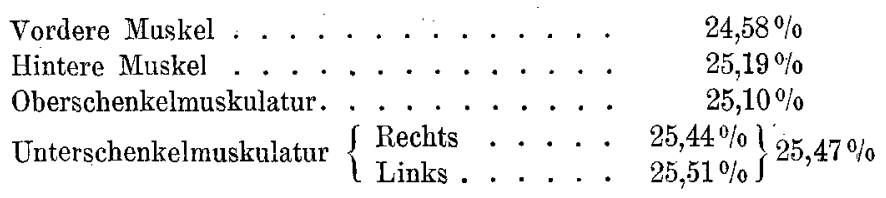

Weiterhin hat sich aber die interessante Tatsache ergeben, dass die vorderen Extremitätenmuskeln die hinteren an Wassergehalt übertreffen, desgleichen die Oberschenkel wasserreicher sind als die Unterschenkel.

Die hier gemachten Beobachtungen decken sich nun durehaus mit meinen früheren Erfahrungen. Beim Amputationshund I lagen beim Ruhemuskel die Trockensubstanzwerte der hinteren unteren Extremität bei etwa 25, $5 \%$, eher höher, für den Pector. maj. wurden dagegen nur 21,7\%, für die Bauchmuskeln 22,6\% Trockensubstanz gefunden.

Nur bei den vier Geschwistertieren sind solche Unterschiede nicht hervorgetreten. Es ist demnach wahrscheinlich, dass das Alter hier eine Rolle spielt, in der Art, dass erst langdauernde Einflüsse die genannte Verteilung des Wassers bedingen. Werden doch in der Tat die Muskeln der vorderen Extremität beim Hunde weniger intensiv benutzt als die der hinteren; denn beim Laufen haben die Hinterbeine der Vierfüsser die Aufgabe, den Rumpf nach vorn zu bringen. Dazu muss die hintere Extremität verlängert werden durch Funktion der Muskeln, welche die Winkelstellung der Beine fixieren. Die Vorderbeine dagegen tragen nur den Körper; sie vollführen hiermit eine viel geringere Arbeit.

Die Erkenntnis der Gesetzmässigkeiten, die hier zugrunde liegen, wird erleichtert durch eine Zusammenstellung der Unterschiede, die im Gewicht der frischen und trockenen Substanz zwischen Ruheund Arbeitsmuskeln bestehen (vgl. Tab. 61). Die Differenzen, die sich hier finden, illustrieren deutlich genug, dass die Beuger und Strecker in erster Reihe unter dem Einflusse der Arbeit an Wasser verarmen.

Da sich aus dieser ganzen Untersuchung als hier wichtigstes Ergebnis herausgestellt hat, dass eine Differenz sowohl der Gewichte wie im Wassergehalt $z$ wischen der Muskulatur der rechten und linken Körperseite beim hier als Versuchsobjekt dienenden Vierfüsser nicht 


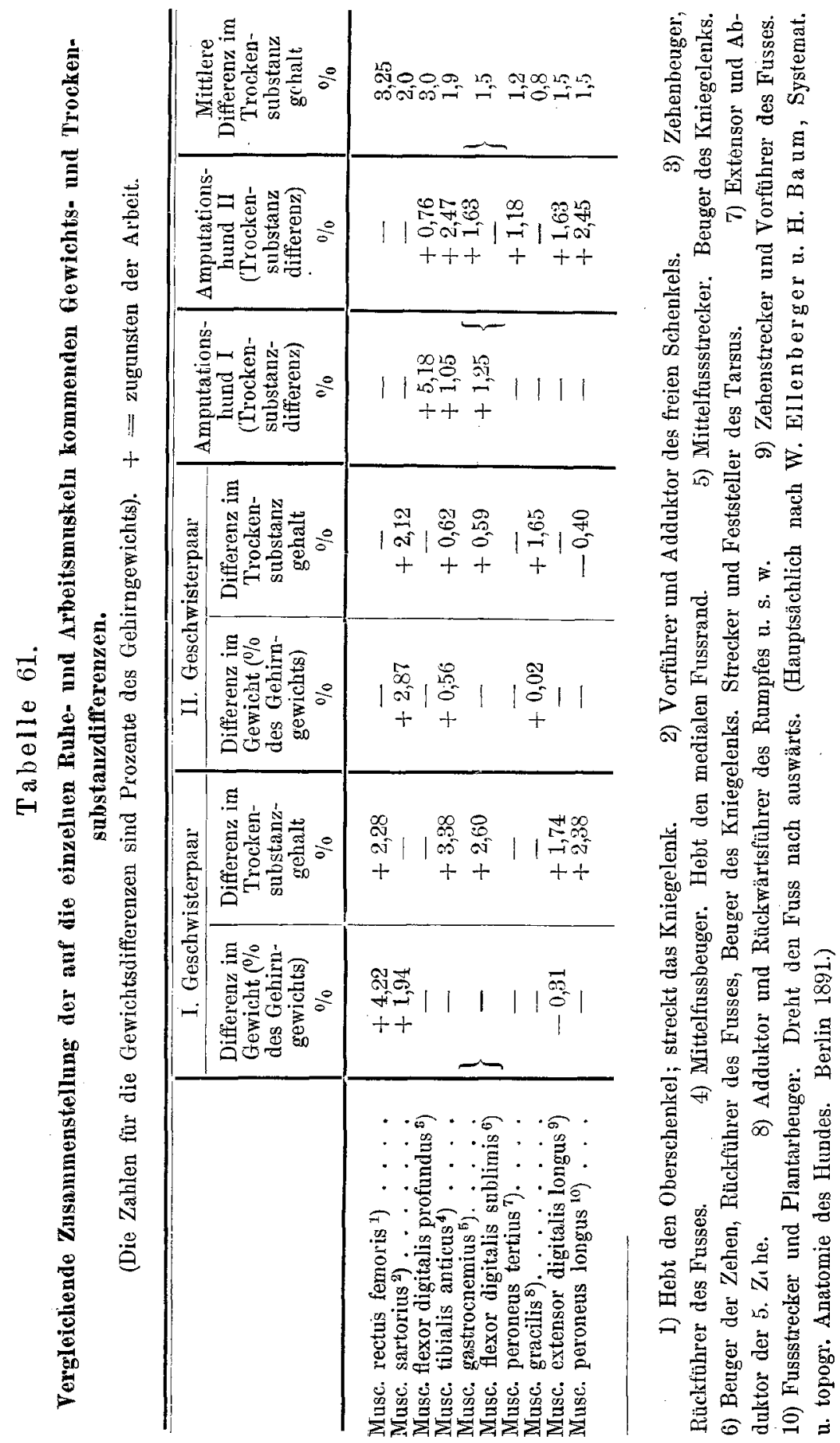


die Regel ist, ist es notwendig, die Erklärung für die im letzten Versuch beim Amputationshund II beobachtete Abweichung von den sonstigen Frfahrungen in anderer Richtung zu suchen, in einer Wasserverarmung der arbeitenden Muskeln von so hohem Grade, dass die Zunahme der Trockensubstanz im Gewicht des frischen Muskels nicht zum Vorsehein gek ommen ist.

Das lässt sich näher zeigen. $100 \mathrm{~g}$ Ruhemuskel hatten bei der Analyse 25,62 $\mathrm{g}$ Trockensubstanz ergeben. Es blieben also $74,4 \mathrm{~g}$ Wasser. Nun wogen $86,03 \mathrm{~g}$ Ruhemuskel nach der Arbeit $82,62 \mathrm{~g} ; 100 \mathrm{~g}$ Ruhemuskel würden also $96,03 \mathrm{~g}$ Arbeitsmuskel entsprechen. $100 \mathrm{~g}$ Arbeitsmuskel enthielten (Tab. 50) 27\% Trockensubstanz, 96,03 g Muskel also 25,93 g Trockensubstanz. Es waren also nun $96,03-25,93=70,10 \mathrm{~g}$ Wasser im Arbeitsmuskel vorhanden. Demnach gingen infolge der Arbeit

$$
\begin{aligned}
& 74,4 \mathrm{~g} \text { Wasser 25,93 g Trockensubstanz, } \\
& -\frac{70,1 \mathrm{~g}}{4,3 \mathrm{~g}} \text { Wasser verloren, und nur }-\frac{25,62 \mathrm{~g}}{0,31 \mathrm{~g}} \text { Trockensubstanz }
\end{aligned}
$$

kamen bei der Arbeit hinzu. Es trat also eine Gewichtsdifferenz von $4,0 \mathrm{~g}$ auf $100 \mathrm{~g}$ infolge Wasserverlustes ein (vgl. die graphische Darstellung auf S. 478).

Die Beobachtung lehrt, dass die übliche Anschauung, die Gewichtsvermehrung charakterisiere die Arbeitshypertrophie der Muskulatur, der Korrektur bedarf. Nicht sie ist das Wesentliche, sondern die konstantere Abänderung in der chemischen Zusammensetzung.

An der Hand der weiteren Analysenresultate von Amputationshund II lassen sich einige Erwägungen anstellen, welehe die Art der bei der Arbeit stattgehabten Äderungender Zusammensetzung noch näher beleuchten.

Ich habe eben angegeben, dass aus $100 \mathrm{~g}$ Ruhemuskel mit 25,62 $\mathrm{g}$ Trockensubstanz: 96,03 $\mathrm{g}$ Arbeitsmuskel mit 25,93 $\mathrm{g}$ 'Trockensubstanz geworden sind, also 0,31 $\mathrm{g}$ Trockensubstanz hinzugekommen sind. Um über die Art dieser Trockensubstanzzunahme Aufschluss zu erhalten, ist die Kenntnis der Extraktivstoffmenge der Muskel notwendig. Ich habe deshalb sowohl das Ruhe- wie das Arbeitsfleisch mit Wasser ausgelaugt und die Extrakte näher untersucht. Um hier den Zusammenhang nicht zu zerreissen, gehe ich später auf Technik und Ergebnisse dieser Untersuchungen näher ein und führe jetzt schon mit den hier notwendigen Analysenzahlen die 
Graphische Darstellung des Einflusses der Arbeit auf die periphere Muskulatur.

Amputationshund II.

Amputationshund I.

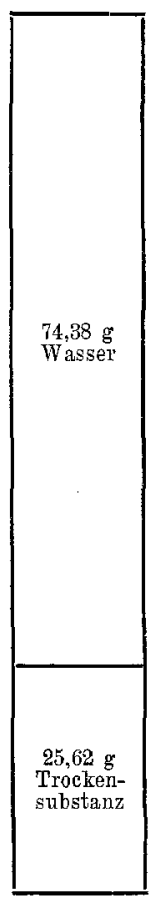

Ruhemuskel $100,00 \mathrm{~g}$

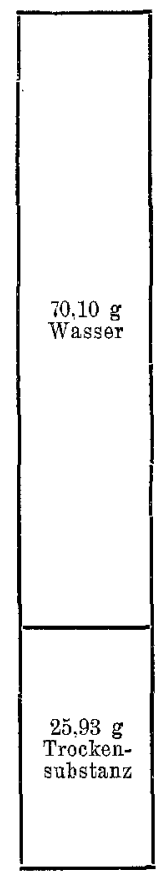

Arbeitsmuskel
$96,03 \mathrm{~g}$

Rechnung durch. Damit ergeben sich für die Ruhe- und Arbeitsmuskulatur die absoluten Werte für die Konstituenten, die in Tabelle 62 (S. 479) angegeben sind.

Wie man sieht, bestehen

$100 \mathrm{~g}$ Ruhemuskel aus $\left\{\begin{array}{lll}3,69 \cdot \mathrm{g} & \text { Rohfett, } \\ 3,62 \mathrm{~g} & \text { Extrakt, } \\ \frac{0,18 \mathrm{~g}}{7,49 \mathrm{~g}} & \text { Asche, }\end{array}\right.$

und einem Rest von . . 25,62 g Trockensubstanz,

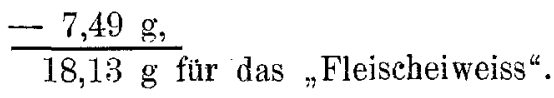


Untersuchungen über den Einfluss der Muskelarbeit auf die Organe etc. 479

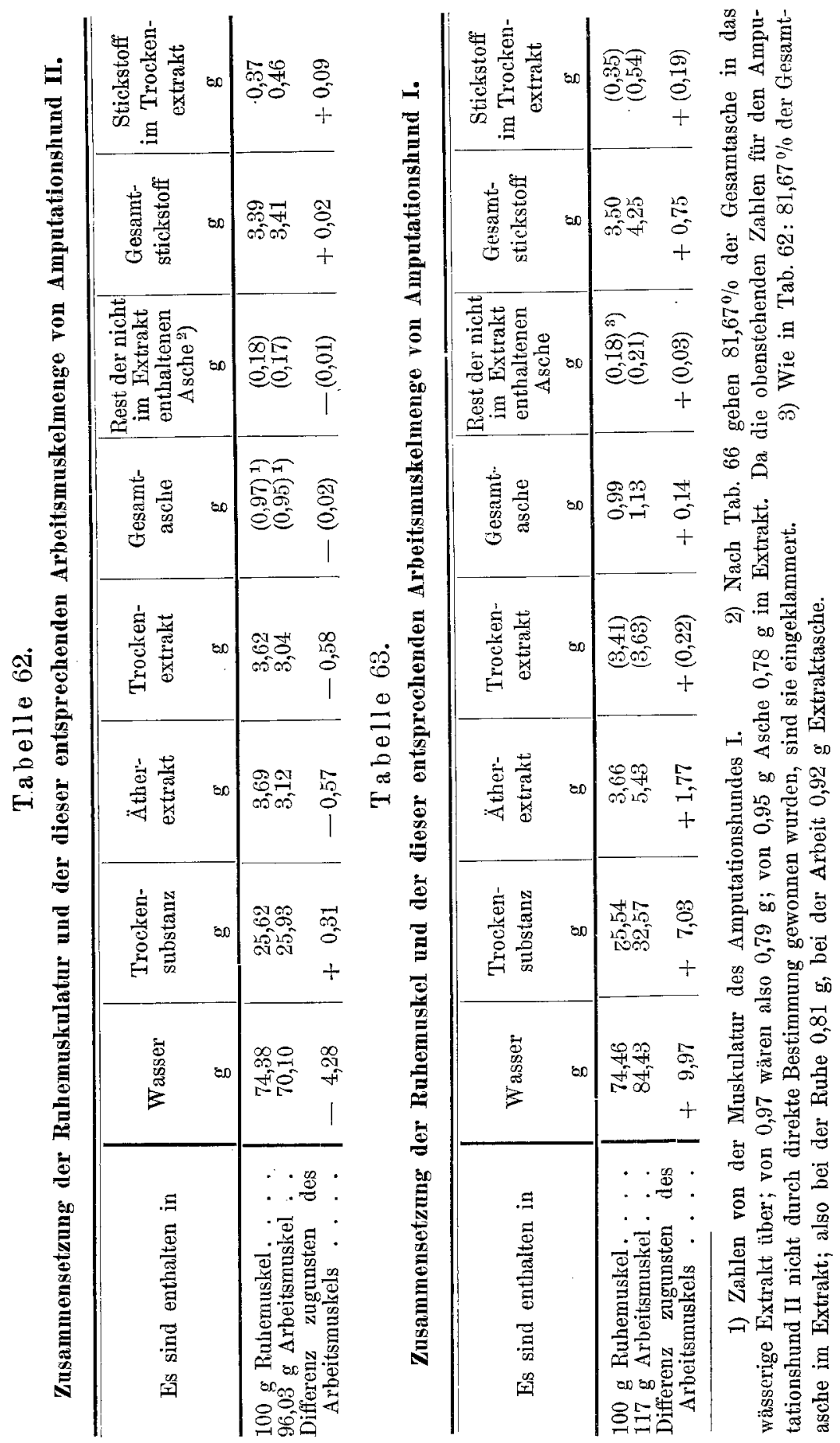


Beim Arbeitsmuskel nennt die Tabelle

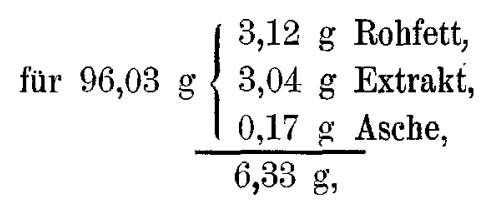

d. h.

$25,93 \mathrm{~g}$ Trockensubstanz,

$$
\frac{-6,33 \mathrm{~g},}{19,6 \mathrm{~g}} \text { fett-, extrakt- und aschefreies Fleisch. }
$$

Die eigentliche Fleischfasersubstanz hat also nach dieser Berechnung bei der Arbeit zugenommen.

Die Differenz beträgt

$$
\begin{array}{r}
19,60 \mathrm{~g}, \\
-18,13 \mathrm{~g}, \\
\hline 1,47 \mathrm{~g}=8,1 \% \text { des Ruhewertes. }
\end{array}
$$

Da nun in $100 \mathrm{~g}$ fett-, extrakt- und aschefreier Muskelsubstanz nach einer Berechnung, die weiter unten zur Sprache kommen wird, $15,257 \mathrm{~g} \mathrm{~N}$ sind, hätten in $1,47 \mathrm{~g}$ „Fleischfaser“ zum mindesten $0,22 \mathrm{~g} \mathrm{~N}$ mehr in den Muskel kommen müssen. Hier versagen die Analysen; denn da nur $0,02 \mathrm{~g} \mathrm{~N}$ im Arbeitsmuskel mehr waren, musste der übrige Stickstoff aus dem Extrakt herübergenommen, oder ein an Stickstoff sehr viel ärmeres Eiweiss angelagert worden sein. Das erstere war nicht der Fall, da im Gegenteil der Trockenextrakt des Arbeitsmuskels $0,09 \mathrm{~g}$ i mehr besass; das letztere ist im höchsten Grade unwahrscheinlich, obwohl, wie wir später sehen werden, eine geringgradige Reduktion des Stickstoffgehaltes des "Eiweisses" bei der Arbeit konstant statthat. Die plausibelste Erklärung ist wohl die, dass für eine so detaillierte Berechnung sich die Analysenfehler zu sehr summieren, zumal ja mit zwei auf fremdes Material gestützten Zahlen gerechnet werden musste. Was aus der Rechnung als wesentliches und sicheres Resultat sich hier ergeben hat, ist, dass der Arbeitsmuskel überhaupt an stickst offhaltiger Substanz gewonnen hat.

Es seien noch einige Beziehungen festgestellt. Wie wir aus den Tabellen ersehen, entsprachen bei der Ruhe: 18,13 g „Fleisehfaser $=\quad 3,39 \mathrm{~g}$ Gesamtstickstoff, $\frac{-0,37 \mathrm{~g} \text { Extrakt-Gesamtstickstoff, }}{3,02 \mathrm{~g} \mathrm{~N}}$ 
bei der Arbeit: 19,60 g extrakt-, fett- und aschefreie Muskelsubstanz $=\quad 3,41 \mathrm{~g}$ Gesamtstickstoff,

$$
\begin{aligned}
& -0,46 \mathrm{~g} \\
& 2,95 \mathrm{~g} \\
& \mathrm{~N}
\end{aligned}
$$

Auf $100 \mathrm{~g}$ fett-, extrakt- und aschefreie Fleischsubstanz kammen also bei der

Ruhe: $\mathbf{1 6 , 6 6} \mathrm{g}$ Stickstoff,

Arbeit: $15,05 \mathrm{~g}$

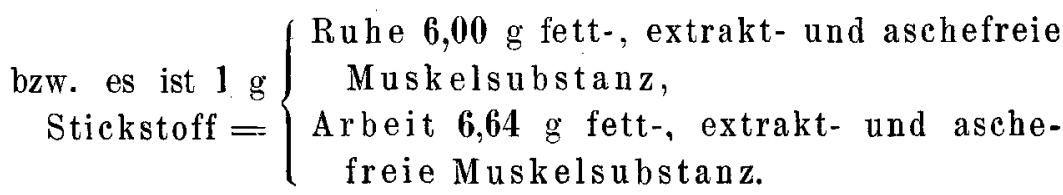

Beim Amputationshund I entsprachen $56,30 \mathrm{~g}$ Unterschenkelmuskulatur des ruhenden Hundes $65,88 \mathrm{~g}$ Arbeitsmuskulatur (totale Unterschenkelmuskulatur). Auf $100 \mathrm{~g}$ frische Substanz des Ruhemuskels entfallen also $117,0 \mathrm{~g}$ Arbeitsmuskel. Die Trockensubstanz machte im ersteren Falle (Tab. 45) 25,54\%, in letzteren $27,83 \%$ aus. Die absoluten Werte sind also für $100 \mathrm{~g}$ Ruhemuskel 25,54 g, für $117 \mathrm{~g}$ Arbeitsmuskel 32,57 g Trockensubstanz. Der Arbeitsmuskel hat also

$$
\begin{aligned}
& 84,43 \mathrm{~g} \text { Wasser } \\
&-74,46 \mathrm{~g} \\
& \hline 9,97 \mathrm{~g} \text { Wasser mehr erhalten. In der- }
\end{aligned}
$$

selben Weise sind die Zahlen für die übrigen Konstituenten berechnet worden. Sie finden sich in der Tabelle 63 (S. 479) zusammengestellt. In dieser Aufstellung sind die Extraktzahlen nach den Analysen an der Muskulatur des Amputationshundes II (fettfreie Trockensubstanz) eingesetzt. Dort enthalten (Tab. 64, s. u.) $100 \mathrm{~g}$ fettfreie Muskeltrockensubstanz $15,58 \mathrm{~g}$ Trockenextrakt und $1,58 \mathrm{~g}$ Gesamt-Extraktstickstoff. Auf $21,88 \mathrm{~g}$ fettfreie Trockensubstanz, wie hier, kommen demnach $3,41 \mathrm{~g}$ Trockenextrakt und $0,35 \mathrm{~g}$ Gesamtstickstoff im Extrakt. - Im Arbeitsmuskel (Tab. 65, s. u.) entsprechen $100 \mathrm{~g}$ fettfreier Muskeltrockensubstanz 13,37 g ''rockenextrakt und 2,01 g Gesamt-Extraktstickstoff; d. s. für die $27,14 \mathrm{~g}$ fettfreie Trockensubstanz des Amputationshundes I 3,63 g Trockenextrakt und 0,54 g Extrakt-Stickstoff. 
Auf Grund dieser Zahlen ergibt sich, dass der

\begin{aligned} & Ruhemuskel $\begin{aligned} 25,54 \mathrm{~g} \\ -\quad 7,25 \mathrm{~g}\end{aligned}\left\{\begin{array}{l}3,66 \mathrm{~g} \text { Rohfett } \\ 3,41 \mathrm{~g} \cdot \text { - Extrakt } \\ \frac{0,18 \mathrm{~g} \text { Asche }}{7,25 \mathrm{~g}}\end{array}\right. \\ &$\cline { 2 - 2 } $\mathbf{1 8 , 2 9 \mathrm { g }}$ fett-, extrakt- und aschefreie \end{aligned} Muskeltrockensubstanz enthielt, der

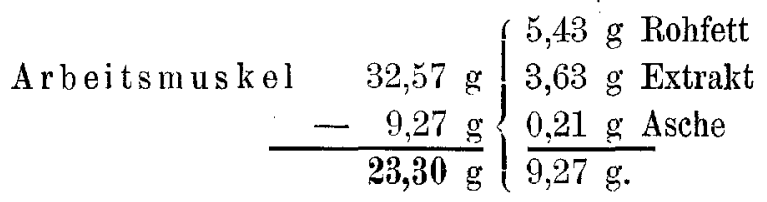

Die dafür geltenden Stickstoffzahlen sind:

Ruhe: $\left\{\begin{array}{r}3,50 \mathrm{~g} \text { Gesamt-N } \\ -0,35 \mathrm{~g} \text { Extrakt-N } \\ \hline 3,15 \mathrm{~g} \mathrm{~N},\end{array} \quad\right.$ Arbeit: $\left\{\begin{array}{r}4,25 \mathrm{~g} \text { Gesamt-N } \\ -0,54 \mathrm{~g} \text { Extrakt-N } \\ \hline 3,71 \mathrm{~g} \mathrm{~N} ;\end{array}\right.$ d. h. es kommen auf $100 \mathrm{~g}$ extrakt-, fett-und aschefreie Fleischtrockensubstanz bei der Ruhe 17,22 g N, bei der Arbeit nur $15,92 \mathrm{~g} \mathrm{~N}$, bzw. $1 \mathrm{~g} \mathrm{~N}$ entspricht bei dem Ruhemuskel 5,81, bei dem Arbeitsmuskel dagegen 6,28 g fett-, extrakt-und aschefreier Fleischsubstanz. Also auch diesmal entfällt auf die von Extrakten und Asche befreite Muskelsubstanz des Arbeitstieres ein geringerer Stickstoffgehalt als auf die des Ruhetieres.

Die Differenz der absoluten "Fleischfaser"werte macht $23,30 \mathrm{~g}$

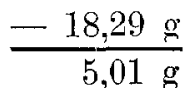

$5,01 \mathrm{~g}$ aus. Es hat also eine Zunahme um $27,4 \%$ des Ruhewertes stattgefunden.

Ehe es möglich ist, näher diese Verhältnisse zu diskutieren, muss auf die Extrakte selbst eingegangen werden. Verdienen sie doch auch im Hinblick auf die allgemeine Anschauung, dass die Arbeit zu einer Anbäufung stickstoffreicher wasserlöslicher Abbauprodukte führe, Interesse.

Die Extraktuntersuchung geschah an der Muskulatur von Amputationshund II, bei dem allerdings der Stickstoff in der Arbeitsmuskulatur nicht reichlicher, eher spärlicher vertreten war als in der Ruhemuskulatur. Das ist nicht das Häufigere; indessen wird 
die Untersuchung der Stickstoffverhältnisse der Extrakte auch hier von Nutzen sein müssen.

Die Extrakte wurden so gewonnen, dass das lufttrockene Muskelfleisch, dessen Gehalt an absoluter Trockensubstanz und Stickstoff bekannt war, zunächst ungefähr 14 Tage hindurch - so lange, bis das Wasser farblos über dem Fleisch stand - mit Wasser von Zimmertemperatur (Thymolzusatz) ausgelaugt wurde. Es wurde oft geschüttelt, um den Prozess zu beschleunigen. Das Auslaugewasser - vgl. das Schema - wurde nachdem auf dem Wasserbade erhitzt; in gleicher Weise wurde mit dem ausgelaugten Fleisch verfahren, von beiden Koagulis abfiltriert und im ausgewaschenen Rückstande zur Kontrolle der Gesamtstickstoff bestimmt. Die vereinigten Filtrate wurden auf dem Wasserbade bis zur Trockne eingedampft, der Rückstand mit kaltem Wasser aufgenommen, mitsamt den unlöslich gewordenen Resten (feinen Häutchen) in ein geeichtes Kölbchen übergespült und bis zur Marke aufgefüllt. Im Filtrat dem endgültigen Wasserextrakte der Ruhe- und Arbeitsmuskeln wurde auf Trockensubstanz, Stickstoff, "Reinprotein" und Brennwert untersucht. Ich hielt mich also im wesentlichen an die Methodik von Frentzel und Schreuer (Abh. III S. 284, 1. c. S. 432).

\section{Schema der Extraktdarstellung.}

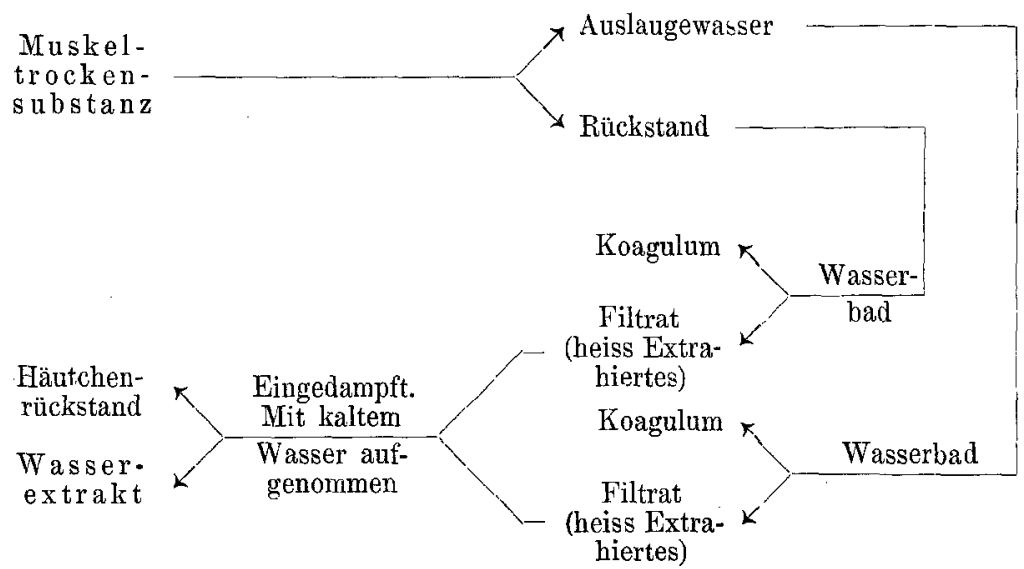

Die Bestimmung des Trockenextraktes wurde so vorgenommen, dass das letżte Filtrat, in Porzellanschälchen mit ausgeglihhtem Seesand vermischt, auf dem Wasserbade langsam unter Vermeidung von Krustenbildung getrocknet wurde. Die endgültige Trocknung 
wurde im Wassertrockensehrank bei etwas unter $100^{\circ} \mathrm{C}$. bewerkstelligt.

Bei der Ermittelung des Reinproteins wurde im Prinzip nach der Vorschrift Stutzer's ${ }^{1}$ ) verfahren: Das Extrakt wurde im Becherglase mit etwa der doppelten Menge Wasser versetzt und erhitzt; kurz vor dem Sieden wurden $25 \mathrm{ccm}$ Kupfersulfatlösung (60:1000) zugefügt, beim Aufkochen unter Umrühren allmählich $25 \mathrm{ccm}$ Natronlauge $(12,8: 1000)$ eingetropft. Die Lösungen waren so bemessen, dass die Mischung neutral reagierte. Nach dem Erkalten wurde von dem Niederschlage abfiltriert, dieser letztere mit lauwarmem Wasser, Alkohol, Äther ausgewaschen und getrocknet, zuletzt im Rückstande der Stickstoff (nach Kjeldahl) bestimmt.

Der in Form von Nichteiweiss-Verbindungen vorhandene Stickstoff wurde aus der Differenz des Protein-N vom Gesamt-N berechnet.

Das Extrakt wurde auf Zelluloseblöckchen verbrannt.

Aschenbestimmungen konnten der relativ geringen Extraktmenge wegen nicbt ausgeführt werden. Ich habe deshalb an anderweitigem Hundemuskelfleisch (Hund VII, VIII und IX) eine Kontrolle vorgenommen. Es wird weiter unten davon die Rede sein.

Tabelle 64.

Zusammensetzung des Ruhemuskelextraktes ron Amputationshund II.

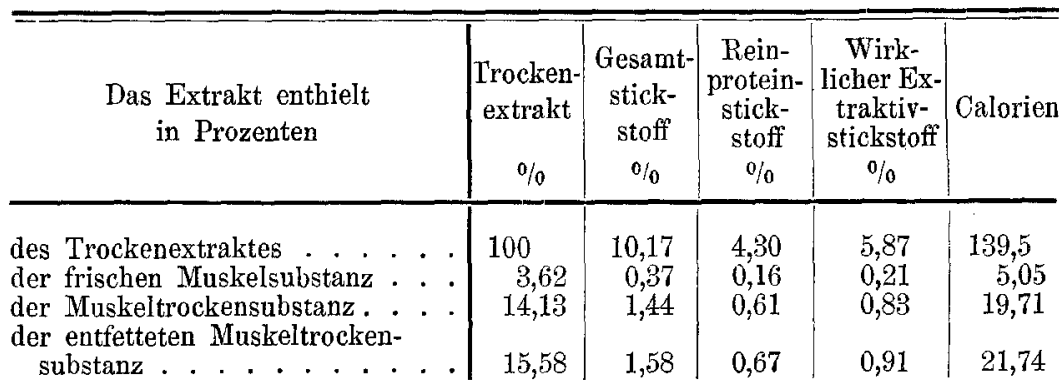

Die Ergebnisse der Extraktuntersuchungen sind in den Tabellen 64 und 65 zusammengestellt. Am hervorstechendsten ist die Abnahme der Extraktivstoffe in Arbeitsmuskel. Der Verlust im Arbeitsextrakt bezieht sich nicht auf die stickstoffhaltigen Substanzen; denn das Trockenextrakt des Ruhemuskels besitzt 10,2\%,

1) A. Stutzer, Untersuchungen über die Verdaulichkeit und die quantitative Bestimmung der Eiweissstoffe. Journ. fo Landw. Bd. 29 S. 473-492. 1881. 
Untersuchungen über den Einfluss der Muskelarbeit auf die Organe etc. 485

Tabelle 65.

Zusammensetzung des Arbeitsmuskelextraktes rom Amputationshund II.

\begin{tabular}{|c|c|c|c|c|c|}
\hline $\begin{array}{l}\text { Das Extrakt enthielt } \\
\text { in Prozenten }\end{array}$ & $\begin{array}{c}\text { Trocken- } \\
\text { extrakt } \\
\%\end{array}$ & $\begin{array}{c}\text { Gesamt- } \\
\text { stick- } \\
\text { stoff } \\
\%\end{array}$ & $\begin{array}{c}\text { Rein- } \\
\text { protein- } \\
\text { stick- } \\
\text { stoff } \\
\% / 0\end{array}$ & $\begin{array}{c}\text { Wirk- } \\
\text { licher Ex- } \\
\text { traktiv- } \\
\text { stickstoff } \\
\%\end{array}$ & $\begin{array}{c}\text { Calorien } \\
\%\end{array}$ \\
\hline \multirow[t]{2}{*}{$\begin{array}{l}\text { des Trockenextraktes } \\
\text { der frischen Muskelsubstanz . . } \\
\text { der Muskeltrockensubstanz } \\
\text { der entfetteten Muskeltrocken- } \\
\text { substanz. . . . . . . . . . }\end{array}$} & $\begin{array}{l}100 \\
8,17 \\
11,78\end{array}$ & $\begin{array}{r}15,05 \\
0,48 \\
1,77\end{array}$ & $\begin{array}{l}4,41 \\
0,14 \\
0,52\end{array}$ & $\begin{array}{r}10,64 \\
0,34 \\
1,25\end{array}$ & $\begin{array}{r}131,8 \\
4,18 \\
15,47\end{array}$ \\
\hline & 13,37 & 2,01 & 0,59 & 1,42 & 17,63 \\
\hline
\end{tabular}

das des Arbeitsmuskels 15,1\% Gesamtstickstoff, bzw. 5,9\% und 10,6\% Extraktivstickstoff. Da nun der Gesamtstickstoff der trocknen Muskulatur sich gleichblieh (vgl. Tab. 52), ging die Arbeit bei dem Amputationshund II mit einem Verluste von dem Anteile, den das Muskeleiweiss an der Zusammensetzung der Trockensubstanz nimmt, einher, oder - mit anderen Worten - die stickstoffhaltigen Extraktivstoffe nahmen bei der Arbeit unverhältnismässig mehr zu, wie das ja auch aus der Relation

Rubeextrakt

(trocken):

$\frac{\text { Extrakt-Gesamt-N }}{\text { Wirklichem Extraktiv-N }}=\frac{10,17}{5,87}=\frac{100}{57,7}$, und

$\begin{gathered}\text { Arbeitsextrakt } \\ (\text { trocken): }\end{gathered} \quad \begin{gathered}\text { Wirtrakt-Gesamt-N } \\ \text { Wirkhem Extraktiv-N }\end{gathered}=\frac{15,05}{10,64}=\frac{100}{70,7}$

bzw. aus der von Frentzel und Schreuer als fast konstant angegebenen Beziehung:

hervorgeht.

$$
\frac{\text { Muskel-Gesamt-N }}{\text { Wirklichem Extraktiv-N }}=\left\{\begin{array}{c}
\text { Ruh e }: \frac{13,25}{0,83}=\frac{100}{6,26}, \\
\text { A rbeit: } \frac{13,20}{1,25}=\frac{100}{9,47}
\end{array}\right.
$$

Die Verhältnisse können - unter Einsetzung des an anderem Material gefundenen Aschengehaltes (s. u. Tab. 66) - noch in anderer Weise illustriert werden.

In $100 \mathrm{~g}$ Ruhe-Trockenextrakt waren $4,30 \mathrm{~g} \mathrm{~N}$ als Eiweissstickstoff (Stutzer) vorhanden. Auf $1 \mathrm{~g} \mathrm{~N}$ kamen laut früherer Berechnung $6,00 \mathrm{~g}$ fett-, extrakt- und aschefreie Muskelsubstan\%. Unter Benutzung dieses Wertes würden den $4,30 \mathrm{~g} \mathrm{~N} 25,8 \mathrm{~g}$ Eiweiss entsprechen, so dass ein Rest von $74,20 \mathrm{~g}$ für stickstoffhaltige Extraktivstoffe, die nicht Reinprotein sind, bleibt. Ziehen wir davon 
die Aschenbestandteile mit 27,43 g (Tab. 66) ab, so bleibt für die aschefreie, stickstoffhaltige Nichteiweiss-Extraktsubstanz der Wert $74,20-27,43=46,77$ mit einem N-Gehalt von $5,87 \mathrm{~g} \mathrm{~N}$, d. s. $12,4 \%$ Stickstoff.

Im Arbeitstrockenextrakt $(4,41 \cdot 6,64=29,28 \mathrm{~g}$ "Eiweiss") entsprechen $43,29 \mathrm{~g}$ stickstoffhaltiger Nichteiweissrest $10,64 \mathrm{~g} \mathrm{~N}$. $100 \mathrm{~g}$ aschefreie, stickstoffbaltige eiweissfreie Extraktsubstanz enthalten also im Arbeitsmuskel 24,6 g Stickstoff, d. h. doppelt so viel, als für den Ruhemuskel gefunden wurde.

Überraschend niedrig ist die Verbrennungswärme des Extraktes, besonders, wenn man bedenkt, dass darin auch Glykogen enthalten sein dürfte. Es fällt namentlich auf, wenn man die Verbrennungswärme berechnet, welche das „Eiweiss" allein geben würde. Ein Grund zu der Annahme einer falschen Bestimmung des Brennwertes liegt nicht vor, da mehrere ganz unabhängig gewonnene Extrakte dieselben Resultate geben. (Vgl. weiter unten, s. Anm. 2 S. 494).

Es hatte sich oben herausgestellt, dass unter dem Einflusse der Arbeit aus $100 \mathrm{~g}$ Ruhemuskel beim Amputationshund II $96,03 \mathrm{~g}$ werden; ferner ging schon aus der Tabelle 62 hervor, dass der Gesamtstickstoff sich gleich blieb, und nur der Stickstoff im Extrakt zunahm. Differenzieren wir noch den letzteren laut Tabelle 64 und 65 in Reiuprotein- $\mathrm{N}$ und wirklichen Extraktiv-Stickstoff, so stehen sich gegenüber:

$100 \mathrm{~g}$ Ruhemuskel mit $0,16 \mathrm{~g}$ Reinprotein-N und $0,21 \mathrm{~g}$ Extraktiv-N,

$96,03 \mathrm{~g}$ Arbeitsmuskel mit $0,13 \mathrm{~g}$ Reinprotein-N und $0,33 \mathrm{~g}$ Extraktiv-N.

Daraus folgt, dass der Extraktiv-Stickst off (eiweissfrei) allein, und zwar um $0,12 \%$ des frischen Ruhemuskels, in 0 lge der Arbeit zugenommen hat, die Relation Gesamtstickstoff: wirklichem Extraktiv-Stickstoff also keine Konstante ist.

Es ergibt sich nun aber in der Beziehung des Proteins zum Wassergehalte der Muskeln eine bemerkenswert regelmässige Zahlengrösse.

In $100 \mathrm{~g}$ Ruhemuskel sind (Tab. 62 und 64) 74,38 g Wasser, $3,39 \mathrm{~g}$ Gesamtstickstoff und $0,21 \mathrm{~g}$ wirklicher Extraktivstickstoff vorhanden gewesen, also $3,39-0,21=3,18 \mathrm{~g}$ Protein-Stickstoff. 
Für $100 \mathrm{~g}$ Arbeitsmuskel sind die entsprechenden Zahlen: $73 \mathrm{~g}$ Wasser; 3,56 $\mathrm{g}$ Gesamt-Stickstoff und $0,34 \mathrm{~g}$ wirklicher ExtraktivStickstoff. Hier sind also $3,56-0,34=3,22 \mathrm{~g}$ "Eiweiss"-N vorhanden.

Nach diesen Daten ist also die Beziehung

$$
\begin{aligned}
& \frac{\text { „Protein"-Stickstoff }}{\text { Wasser }} \text { für den } \\
& \text { Ruhemuskel }=\frac{1}{23,4} \text {, für den } \\
& \text { Arbeitsmuskel }=\frac{1}{22,6} .
\end{aligned}
$$

Sie ist also - die minimale Differenz kann auf eine Glykogenabnahme zu beziehen sein - innerhalb der Fehlergrenzen konstant. Diese Relationen zeigen nun auch wiederum, dass die, wie schon lange bekannt, während der Arbeit stattfindende Wasseranreicherung der Muskeln in der nachfolgenden Ruhe zwar in das Gegenteil umgeschlagen ist, aber doch nur in äusserst geringem Maase, so dass der geübte Muskel wohl wasserärmer ist als der dauernd ruhende, immerhin nur in einem geringen Prozentsatz.

Die Beobachtung der relativen Konstanz des Verhältnisses des wichtigsten Konstituens der Trockensubstanz zum Wasser des Muskels spricht dafür, dass das Wasser im Muskel kein Reserve- ${ }^{1}$ ) und Luxusstoff ${ }^{2}$ ) ist. Anderenfalls würde wobl eine Regulation von der Ausdehnung, wie sie hier beobachtet wurde, nicht einsetzen. Ich neige deshalb der Auffassung zu, dass das im Muskel vorhandene Wasser Quellungswasser ist und sich nicht wie in einer gewöhnlichen Lösung darin befindet.

Die interessanten Beziehungen zwischen den einzelnen Bestandteilen der Muskeln, die im Verlaufe meiner bisherigen Untersuchungen aufgedeckt worden waren, riefen den Wunsch nach einer Vervollständigung der Extraktuntersuchungen wach. Ich habe deshalb an dem grossen Materiale, das von Hund VII, VIII und IX stammte, in der nachstehend geschilderten Weise weiter gearbeitet.

1) W. Engels, Die Bedeutung der Gewebe als Wasserdepots. Arch. f. exp. Path. u. Pharm. Bd. 51 s. 346. 1904.

2) A. Magnus-Levy in v. Noorden's Handb. d. Pathol. d. Stoffw., 2. Aufl, S. 448. Berlin 1906. 
Zur Herstellung eines wässerigen Extraktes wurden $33,742 \mathrm{~g}$ absolut trockene Muskelsubstanz in einer LehmannVöltz' schen ${ }^{1}$ ) Kugelmühlenflasche mit destilliertem Wasser versetzt und 47 Stunden gemahlen. Um Fäulnisprozesse völlig auszuschliessen, waren einige Tropfen Chloroform und die nötige Menge Thymol zugesetzt worden. Nachher blieb das Extrakt mit der extrahierten Substanz in einem Kolben in der Kälte solange stehen, bis sich der Rückstand von der intensiv gelbgefärbten Fleischlösung abgesetzt hatte. Die sauer reagierende wässerige Lösung wurde dann dekantiert, in einer Schale ohne Zusatz von Säure 5 Minuten gekocht und dann durch gewogenes Filter filtriert. Darnach wurde der Muskelrest wiederum mit Wasser versetzt, das erhaltene, noch intensiv gelbgefärbte Auslaugewasser wieder, wie vorher beschrieben, behandelt und so fortgefahren, bis das zugesetzte Wasser auch nach gutem Durchschütteln des Kolbens farblos blieb. Das bisher Extrahierte wurde nun in einer Porzellanschale auf dem Wasserbad auf geringes Volumen eingedampft, der Inhalt durch ein gewogenes Filter filtriert. Das trübe, durch Filtrieren nicht weiter zu klärende gelb gefärbte Filtrat wurde beiseite gestellt, das Filter samt Rückstand im Trockenschrank bei $70-73^{\circ} \mathrm{C}$, zuletzt kurze Zeit bei $95^{\circ} \mathrm{C}$. getrocknet und gewogen, um eine Kontrolle zu baben. Nachdem wurde der Rückstand quantitativ - mechanisch und zuletzt durch Abspritzen mit heissem Wasser - vom Filter in ein Wägeglas zur weiteren Verarbeitung gebracht.

Aus diesem $\mathrm{Rückstande} \mathrm{wurden,} \mathrm{im} \mathrm{Mittel} \mathrm{zweier} \mathrm{gut} \mathrm{überein-}$ stimmender Bestimmungen, 8,67\% seiner Trockensubstanz Rohfett mit Petroläther im Soxhlet'schen Apparat extrahiert. Das sind $7,49 \%$ der ursprünglichen Muskeltrockensubstanz und, da die frischen Muskeln 25,17\% Trockensubstanz besassen, 1,885\% der frischen Muskelsubstanz.

Ich habe den so ermittelten Fettgehalt mit dem in der ursprünglichen Muskelsubstanz bestimmten verglichen. Zu diesem Zwecke war die letztere mit Äther, der erst durch Chlorcalcium, dann noch mit Natriumsulfat von Wasser befreit worden war, 19 Stunden im Soxhlet'schen Extraktionsapparat (Modifikation

1) C. Lehmann, Über eine neue Fettbestimmungsmethode. (Vorl. Mitt.) Pflüger's Arch. Bd. 97 S. 419-420. 1903. - W. Völtz, Eine neue Methode der Fettbestimmnng. Ebenda S. 606-633. 1903. 
von $\mathrm{Zuntz}$ ) entfettet worden. Das gelblich-bräunlich gefärbte Extrakt wurde qualitativ in ein tariertes Wägeglas abgegossen, und nach dem Verdunsten des Schwefeläthers 2 Stunden bei etwas unter $100^{\circ}$ C. getrocknet. Das so extrahierte Muskelpulver wurde nun mit Alkohol und 1-3 Tropfen Salzsäure $(1,19)$ in der Wärme behandelt, zum Schluss fein zerrieben und nochmals mit Äther extrahiert. Auf diese Weise wurden bei der ersten Extraktion (drei Bestimmungen) $12,33 \%$ der Trockensubstanz, im ganzen 14,27\% Ätherextrakt erhalten, so dass also bei der zweiten Extraktion noch $13,63 \%$ des zuerst Extrahierten herausgeholt worden waren.

Mit dem zuerst (erste Extraktion mit Schwefeläther) gewonnenen Wert stimmte der Rohfettgehalt, der nach der Kumagawa-Sutoschen Methode ${ }^{1}$ ) (Extraktion nach Verseifung mit Natronlauge) ermittelt wurde, überein. Ich fand hier $12,096 \%$ der Trockensubstanz Ätherextrakt, dagegen nur $10,235 \%$ Petrolätherextrakt.

Die Differenzen zwischen den beiden für das Rohfett gefundenen Werten $(7,5 \%$ an der von wässerigen Extraktivstoffen befreiten Muskelsubstanz, 10,2\% bzw. 14,3\% im ursprünglichen Muskel) sind augenscheinlich durch die Eliminierung von äther- und wasserlöslichen Säuren ${ }^{2}$ ) (z. B. Milchsäure) hervorgerufen.

Das wässerige Extrakt wurde in einer Porzellanschale auf dem Wasserbad eingedampft. Als dann mit heissem Wasser aufgenommen wurde, löste sich alles. bis auf die spärlichen, schon von Frentzel und Schreuer beschriebenen Häutchen. Es wurde durch gewogenes Filter in ein Maasskölbchen filtriert, mit heissem Wasser gewaschen, mit Toluol versetzt und nach dem Abkühlen zur Marke aufgefüllt. Der Rest, der durch das Findampfen unlöslich geworden war (denaturiertes Eiweiss?), machte $0,0158 \mathrm{~g}=0,047 \%$ der Muskeltrocken-

1) M. Kumagawa und K. Suto, Ein neues Verfabren zur quantitativen Bestimmung des Fettes und der unverseifbaren Substanzen in tierischem Material nebst der Kritik einiger gebräuchlichen Methoden. Biochem. Zeitschr. Bd. 8 S. 212-347. 1908.

2) Zur Aziditätsbestimmung der Muskelsubstanz wurde Muskeltrockensubstanz mit destill. Wasser auf dem Wasserbad ausgekocht; dann wurde in ein Kölbchen filtriert, wiederum kurze Zeit gekocht, filtriert usw. bis zu neutraler Reaktion. Die Filtrate wurden vereinigt und unter Zusatz von Phenolphthalein mit wässeriger Kalilauge titriert. Zur Neutralisation wurden, auf $100 \mathrm{~g}$ Trockensubstanz berechnet, $1,864 \mathrm{~g} \mathrm{KOH}(=0,469 \mathrm{~g} \mathrm{KOH}$ für $100 \mathrm{~g}$ frische Substanz) gebraucht. 
substanz, $0,345 \%$ der Trockensubstanz des wässerigen Extraktes aus. Hiernach stellt sich also die Differenzierung in wasserlöslichen und wasserunlöslichen Anteil für $100 \mathrm{~g}$ Muskelsubstanz in folgender Weise dar:

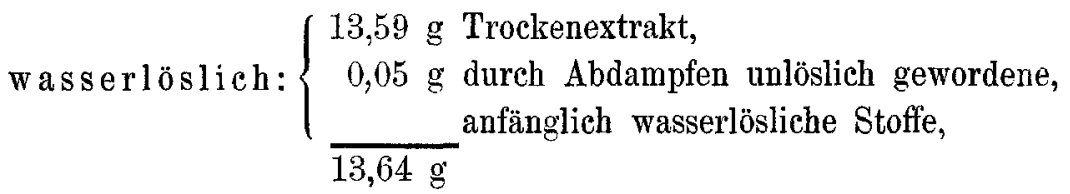
wasserunlöslich : $86,36 \mathrm{~g}$ (davon $7,49 \mathrm{~g}$ petrolätherlöslich).

Die beiden Partien verhalten sich also zueinander wie $1: 6,33$.

Von dem eigentlichen wässerigen Extrakte wurden mit der Pipette gleich abgemessene Mengen auf Seesand getropft, gewogen und dann getrocknet (s. oben). Es wurden (im Mittel) 4,585 g Trockenextrakt in der verarbeiteten Muskelsubstanz gefunden. Der Stickstoffgehalt betrug $0,711 \mathrm{~g}$ im ganzen, der Eiweissstickstoff (Stutzer, vgl. oben) im Mittel 0,222 g. Die prozentualen Werte sind in der Tabelle 66 zusammengestellt.

In der ursprünglichen Trockensubstanz der Muskulatur waren $12,99 \%(3,27 \%$ der frischen Substanz) Stickstoff gefunden worden.

Zur genaueren Charakterisierung des Stickstoffes des Extraktes wurde ein Teil des Filtrates nach den Vorschriften von Hausmann ${ }^{1}$ ) mit Phosphorwolframsäure in der Kälte gefällt. Später wurde filtriert, der Niederschlag aufs Filter gebracht und mit kleinen Mengen Phosphorwolframsäure-Lösung und später mit destilliertem Wasser gewaschen. Das Filtrat vom Phosphorwolframsäure-Niederschlag wurde samt den Waschwässern auf 'bestimmtes Volumen aufgefü]lt und nach $\mathrm{Kj}$ jeldahl verarbeitet. Es wurden, für das ganze wässerige Extrakt berechnet, $0,24 \mathrm{~g} \mathrm{~N}$ gefunden.

Der Niederschlag wurde in einen Messkolben übergespült, mit Kalilauge gelöst, das Filter zugebracht und das Ganze aufgefüllt. In aliquoten Teilen des Filtrats wurde wiederum der Stickstoffgehalt ermittelt. Es wurden $0,561 \mathrm{~g} \mathrm{~N}$ für das ganze Extrakt erhalten.

1) W. Hausmann, Über die Verteilung des Stickstoffs im Eiweissmolekül. Zeitschr. f. physiol. Chem. Bd. 27 S. 95-108. 1899. - Vgl. auch B. Schönd $\bullet \mathrm{rff}$, Eine Methode der Harnstoffbestimmung in tierischen Organen und Flïssigkeiten. Pflüger's Arch. Bd. 62 S. 1-58. 1896. 
Untersuchungen über den Einfluss der Muskelarbeit auf die Organe etc. 491

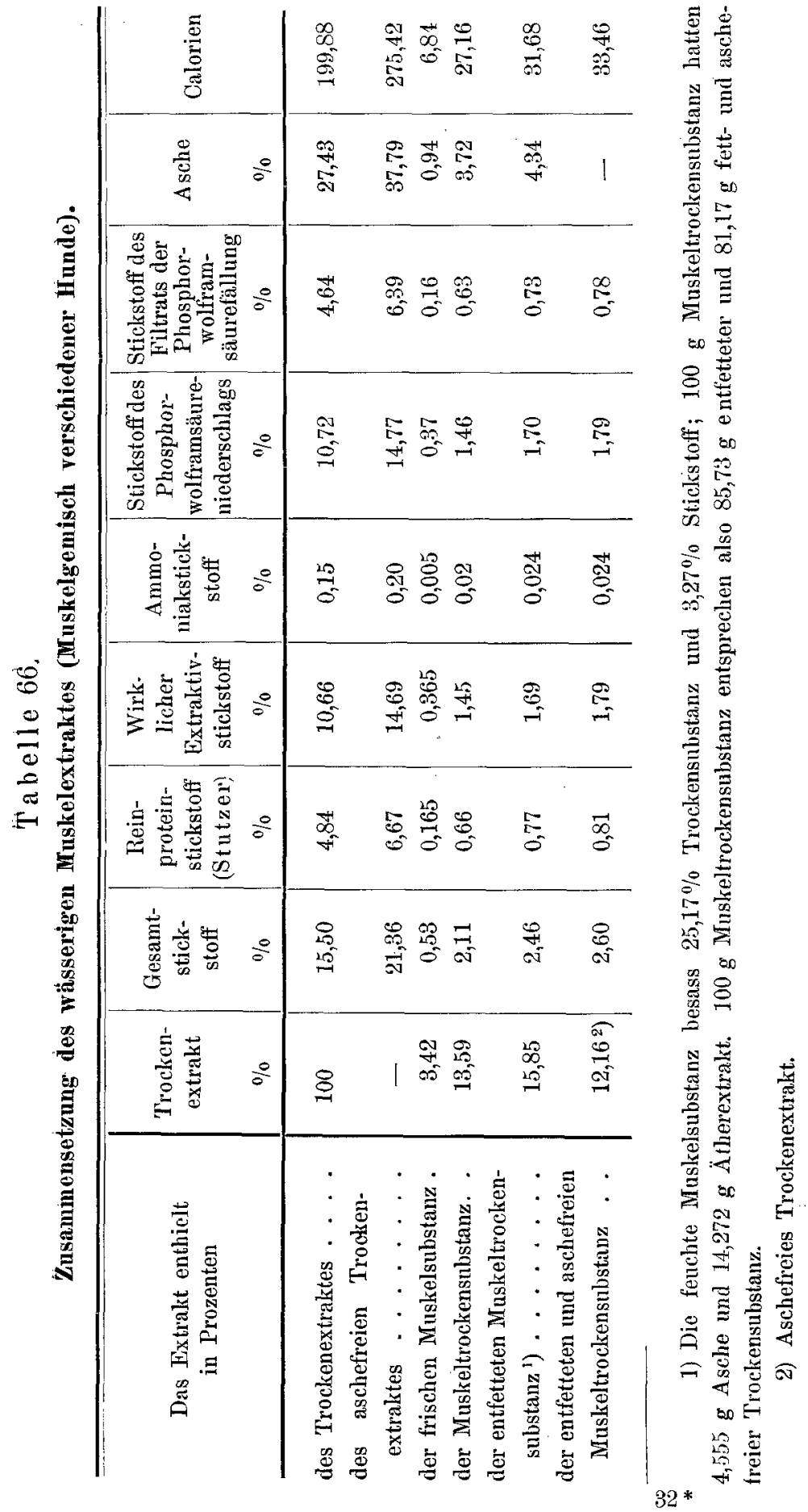


Zur Bestimmung des Ammoniakstickstoffs waren $100 \mathrm{cem}$ der Extraktlösung nach dem Verfahren von $\mathrm{Grafe}^{1}$ ) mit $100 \mathrm{cem}$ gesättigter Chlornatriumlösung, $100 \mathrm{ccm}$ Alkohol (96\%), $100 \mathrm{ccm}$ destilliertem Wasser und $50 \mathrm{ccm}$ gesättigter Natriumkarbonatlösung auf dem Wasserbad erst bei niederer Temperatur, dann bei ca. $60^{\circ} \mathrm{C}$. 8 Stunden erhitzt worden. Als Vorlage diente ein mit wässeriger Schwefelsäurelösung beschickter tubulierter Erlenmeyer-Kolben. Es wurde mit der Wasserstrahlpumpe evakuiert. Die Titration geschah mit Phenolphtbalein als Indikator. Es wurden für das ganze Extrakt $0,0075 \mathrm{~g} \mathrm{NH}_{3}$-Stickstoff gefunden.

Die Verteilung des Stickstoffs ist also:

Stickstoff des Phosphorwolframsäure-Niederschlags (Diaminosäuren-N) . . . . . . . . . . . . . 0,5614 g Davon gehen $\mathrm{ab}$ für $\mathrm{NH}_{3}$. . . . . . . . . . $0,0075 \mathrm{~g}$ Es bleiben. . . . . . . . . . . $\frac{0,0075 \mathrm{~g}}{0,5539 \mathrm{~g}}$ Stickstoff des Phosphorwolframsäure-Filtrats (Aminosäuren-N) $\cdot \dot{*} \cdot \dot{*} \cdot \cdot \cdot \cdot \cdot \cdot \cdot \cdot \cdot \cdot \cdot \cdot \frac{0,240 \mathrm{~g}}{\left.0,8014 \mathrm{~g}^{2}\right)}$

Die prozentuale Zusammensetzung des Stickstoffs: im Extrakt gestaltet sich nach dem Gesagten folgendermaassen:

$$
\begin{aligned}
& \text { Diaminosäuren-N }=69,12 \% \\
& \text { Aminosäuren-N }=29,94 \% \\
& \text { Ammoniak-N }=0,94 \% .
\end{aligned}
$$

Auf den ersteren Anteil würden dann noch 0,222 g Reinprotein. in $0,5539 \mathrm{~g}$ Niederschlags- $\mathrm{N}=40 \%$ der Diaminosäuren-Komponente Reinprotein (Stutzer) entfallen.

Der Aschengehalt wurde zu $27,43 \%$ des Trockenextraktes ermittelt. In der ursprünglichen Substanz waren $4,555 \%$ der absoluten Trockne $=1,15 \%$ der frischen Muskulatur Asche gefunden worden.

1) E. Grafe, Methodisches zur Ammoniakbestimmung in tierischen Geweben. Zeitschr. f. physiol. Chem. Bd. 48 S. 300-314. 1906.

2) Direkt wurden im Extrakt insgesamt $0,7108 \mathrm{~g} \mathrm{~N}$ ermittelt. Die Differenz betrug also bei $38,742 \mathrm{~g}$ Ausgangsmaterial $0,801-0,711=0,09 \mathrm{~g} \mathrm{~N}=0,27 \mathrm{~g}$ von $100 \mathrm{~g}$ trockener Muskelsubstanz. In der Tabelle 66 ist der richtigere Wert der Berechnung zugrunde gelegt und nach dem hier angegebenen Prozentsatz verteilt worden, so dass also für das ganze Filtrat angenommen wurden: Diaminosäuren-N : 0,4914 g; Aminosäuren-N : 0,2129 g; Ammoniak-N: 0,0066 g. 
Im nicht extrahierten getrockneten Muskel war auch der Gly kogengehalt bestimmt worden. Es war genau nach Pflüger's Verfahren [1903] ${ }^{\mathbf{1}}$ ) gearbeitet worden, aber das durch die Zuekerlösung reduzierte Kupfer im Goochtiegel als Kupferoxydul und Kupferoxyd, teils als reines Kupfer (zur Kontrolle) gewogen worden.

In $100 \mathrm{~g}$ Muskeltrockensubstanz waren $0,387 \mathrm{~g}$ Zucker aus Glykogen vorhanden ( $=0,097 \%$ des feuchten Muskels).

Nimmt man mit Zuntz an, dass das Glykogen mit der vierfachen Menge Wasser vorhanden ist, so kämen in $100 \mathrm{~g}$ feuchtem Muskel nur 74,83

$\frac{-0,39}{74,44 \mathrm{~g}}$ Wasser auf das Eiweiss, das $2,9 \mathrm{~g} \mathrm{~N}$ enthält.

Hier ist also die Relation

$$
\frac{\text { Eiweiss- } \mathrm{N}^{\prime \prime}}{\text { Wasser }}=\frac{1}{25,6} \text {. }
$$

Für 1 g. Trockenextrakt wurden nach der schon oben angegebenen Methodik (vier gut übereinstimmende Werte) 1998,8 cal. gefunden.

Dieser Wert liegt böher als meine früher erhaltenen Żahlen (1395 und 1318 pro $1 \mathrm{~g}$ Trockensubstanz), liegt aber noch beträchtlich unter den Werten, die Frentzel und Schreuer $(3130,4$ cal.) und Frentzel und Toriyama $(3177,0)$ angegeben haben. Da es sich in meinem Material um recht nahe beieinanderliegende Werte aus verschiedenem Material handelt und die Richtigkeit der Bestimmungen durch mehrere Kontrollen sichergestellt ist, müssen wir wohl annehmen, dass die enormen Differenzen zwischen den Zahlen der früheren Autoren und mir auf die Versehiedenheit des Ausgangsmateriales $z \mathfrak{u}$ beziehen sind. Bei den genannten Untersuchern handelte es sich um vom Schlächter bezogenes Rindfleisch (Autolyse?), hier um sofort getrocknete Muskulatur vom Hund.

Aus den hier von mir bekanntgegebenen kalorimetrischen Untersuchungen schliesse ich ferner, dass die Brennwerte für das Fleisehextrakt derselben Herkunft doch nicht so konstant sind, wie Frentzel und Schreuer angenommen haben.

Ich habe von dem letztbeschriebenen Hundemuskelfleisch noch mehrere kalorischen Bestimmungen an der fett- und extraktfreien

1) E. Pflüger, Vorschriften zur Ausführung einer quantitativen Glykogenanalyse. Pfl üg er's Arch. Bd. 93 S. 163 ff. 1903. 
Trockensubstanz gemacht und für $1 \mathrm{~g}$ entfetteten und ausgelaugten Muskelrückstand 5748,7 und 5758,2, im Mittel also 5753 cal. gefunden. Frentzel und Schreuer fanden für $1 \mathrm{~g}$ fett- und extraktfreies Trockenfleisch bei drei Bestimmungen die identischen Brennwerte 5760,5758 und 5767,4 , im Mittel also 5761,8 cal., und auch von $\mathrm{Rubner}^{1}$ ) ist ein gleichlautender Wert (5754 cal. pro $1 \mathrm{~g}$ mit Äther und Wasser extrahiertes trocknes Fleisch) ermittelt worden. Die genannten Zahlen beziehen sich auf Muskel vom Rind. Aus der auffallenden Harmonie, in der meine Zahl mit den genannten steht, ziehe ich den Schluss; dass der fett-und extraktfreien Trockensubstanz der Muskeln der verschiedensten Tierarten der gleiche Brennwert zukommt. Die niedrigeren älteren Zahlen von Stohmann und Langbein (5720,5 cal.) und Berthel ot und Andre (5728,4 cal.) können in Änderungen der Fettextraktionsmethodik ausreichende Erklärung finden ${ }^{2}$ ).

$1 \mathrm{~g}$ des ursprünglichen, trockenen Muskels hatte einen Brennwert von 5567,7 und 5566,4 cal, im Mittel also von $55567 \mathrm{eal}$.

Mit diesen Zahlen lassen sich nun einige wichtige Beziehungen aufstellen.

$100 \mathrm{~g}$ Muskelsubstanz (trocken) enthielten 12,99 g Stickstoff. Im entfetteten und ausgelaugten Fleisch sind 2,11 $\mathrm{g}$ Extrakt-Gesamtstickstoff verloren gegangen, so dass auf $100 \mathrm{~g}$ extrahierten Muskel-

1) MI. Rubner, Kalorimetrische Untersuchungen. Zeitschr. f. Biol. Bd. 21 S. 298.1885.

2) Mit den hier mitgeteilten Energiewerten lässt sich übrigens eine Kontrolle des Extraktbrennwertes ausführen. $100 \mathrm{~g}$ trockene Fleischsubstanz enthielten 556,7 Cal. In ihr waren $7,49 \mathrm{~g}$ im ausgelaugten Fleisch verbleibendes Fett (à 9,5 Cal. = 71,15 Cal.) und 13,59 g Trockenextrakt vorhanden. Da $1 \mathrm{~g}$ des entfetteten und ausgelaugten Fleisches 5753 cal. entsprach, kommen auf 78,92 g entfettete und ausgelaugte Fleischsubstanz 454,0 Cal. Auf Fett und Extrakt entfielen also 556,7 - 454,0 = 102,7 Cal., auf die 13,59 g Trockenextrakt, die $9,87 \mathrm{~g}$ organische Substanzen, darunter $6,78 \mathrm{~g}$ ätherlösliche Stoffe enthielten, 102,7 - 71,1 (Fett-Cal.) = 31,6 Cal. Rechnen wir die ätherlöslichen Stoffe als Milchsäure (3,66 Cal. pro $1 \mathrm{~g})=24,8$ Cal. pro $100 \mathrm{~g}$ Fleischtrockensubstanz, so bleiben für die noch übrigen $3,1 \mathrm{~g}$ organischen wohl im wesentlichen $\mathrm{N}$-haltigen Substanzen 6,8 Cal., also 2,2 Cal. pro $1 \mathrm{~g}$.

Mit dem berechneten Wert ron 31,6 Cal. stimmt der direkt gefundene von 27 Cal. genügend überein, um den gefundenen Wert sichergestellt zu wissen. 
rückstand noch $12,99-2,11=10,88 \mathrm{~g}$ Stickstoff kommen, d. h. $1 \mathrm{~g}$ Stickstoff $=9,192 \mathrm{~g}$ ausgelaugtes Muskelfleisch (trocken).

Um die entsprechenden Werte für die fett- und extraktfreie Trockensubstanz zu finden, sind von $100 \mathrm{~g}$ Muskeltrockensubstanz $14,27 \mathrm{~g}$ Rohfett

$$
\frac{13,59 \mathrm{~g} \text { wässeriges Extrakt }}{27,86 \mathrm{~g}}
$$

abzurechnen, so dass auf $100,00 \mathrm{~g}$ Trockensubstanz

$$
=\frac{27,86 \mathrm{~g} \text { Extrakte }}{72,14 \mathrm{~g}} \text { fett- und extraktfreie Trocken- }
$$

substanz 10,88 g Stickstoff entfallen; d. h. 100. g fett- und extraktfreie Trockensubstanz $=15,082 \mathrm{~g} \mathrm{~N}$. $1 \mathrm{~g} \mathrm{~N}=$ 6,63 g völlig extrahierte Muskelsubstanz.

$1 \mathrm{~g}$ Trockensubstanz des extrahierten Fleisches hat einen Brennwert von 5753 cal. Die analoge Rechnung, wie oben, ergibt also: $1 \mathrm{~g} \mathrm{~N}$ in der fett- und extraktfreien Muskeltrockensubstanz entspricht 38,15 Cal.

In das Extrakt waren 3,72\% des trockenen Muskels Mineralbestandteile übergegangen. Im ganzen enthielt die Muskeltrockensubstanz $4,555 \%$ Asche. In dem ausgelaugten und entfetteten Rückstand von $100 \mathrm{~g}$ trockenem Muskel waren also noch

$$
\begin{aligned}
4,55 \mathrm{~g} \text { Asche } \\
-3,72 \mathrm{~g} \text { Extraktasche } \\
\hline 0,83 \mathrm{~g} \text { Asche }
\end{aligned}
$$

enthalten. Kommen diese von den oben genannten $72,14 \mathrm{~g}$ fettund extraktfreien Trockenfleisches noch in Abzug, so entsprechen $72,14 \mathrm{~g}$ völlig extrahiertes Fleisch

$$
=\frac{0,83 \mathrm{~g} \text { Asche }}{71,31 \mathrm{~g} \text { fett- }}
$$
substanz 10,88 g Stickstoff und 72,14 $\cdot 5753=415,02$ Cal.

Daraus ergibt sich: $72,14 \mathrm{~g}$ fett- und extraktfreies Fleisch haben $0,83 \mathrm{~g}$ Asche, $100 \mathrm{~g}$ also $1,1505 \mathrm{~g}$; d. h. 100,0000 g

$$
\frac{1,1505 \mathrm{~g}}{98,8495 \mathrm{~g} \text { fett-, }}
$$

extrakt- und aschefreies Trockenfleisch haben einen Brennwert von 575,3 Cal.; $1 \mathrm{~g}$ entfetteten, extrakt- und aschefreien Trockenfleisches entsprechen also 5819,9 cal.

Ferner ergibt sich: $\mathbf{1 0 0} \mathrm{g}$ fett-, extrakt- und aschefreiem trockenem Muskelfleisch entsprechen $15,257 \mathrm{~g}$ 
Stickstoff, d. h. $1 \mathrm{~g}$ Stickstoff in dieser Substanz $=$ $6,554 \mathrm{~g}$ völlig extrahiertes und aschefreies Fleisch $=$ $38,144 \mathrm{Cal}$.

Mit den oben berechneten Zahlen (S. 481) zusammengehalten, ergeben sich nun folgende Mittelwerte für den Muskel des Hundes: $100 \mathrm{~g}$ fett-, extrakt- und aschefreie Muskeltrockensubstanz besitzen $16,02 \mathrm{~g}$ Stickstoff; $1 \mathrm{~g} \mathrm{~N}=$ $6,24 \mathrm{~g} \mathrm{Substanz}=36,3 \mathrm{Cal}$.

Ich stelle die für die grobe Zusammensetzung des normalen Hundefleisches hier erhaltenen Zahlen in Tabelle 67 nochmals übersichtlich zusammen.

Tabelle 67.

Zusammensetzung ron normaler Hondemuskulatur. (Muskelgemisch von verschiedenen Hunden.)

\begin{tabular}{|c|c|c|c|c|c|c|}
\hline & \multicolumn{6}{|c|}{ Es sind vorhanden in $100 \mathrm{~g}$} \\
\hline & $\begin{array}{c}\text { feuchter } \\
\text { Sub- } \\
\text { stanz } \\
\%\end{array}$ & $\begin{array}{c}\text { Trocken- } \\
\text { substanz } \\
\%\end{array}$ & $\begin{array}{c}\text { fettfreier } \\
\text { Trocken } \\
\text { substanz } \\
\%\end{array}$ & $\begin{array}{c}\text { fett-und } \\
\text { asche- } \\
\text { freier } \\
\text { Trocken- } \\
\text { substanz } \\
\% \%\end{array}$ & $\begin{array}{c}\text { fett- und } \\
\text { wasser- } \\
\text { extraktfr. } \\
\text { Trocken- } \\
\text { substanz } \\
\%\end{array}$ & $\begin{array}{c}\text { fett-, wasser- } \\
\text { extrakt- und } \\
\text { aschefreier } \\
\text { Trocken- } \\
\text { substanz } \\
\% \%\end{array}$ \\
\hline Wasser & 74,83 & - & - & - & - & - \\
\hline Trockensubstanz & 25,17 & - & - & & - & - \\
\hline Stickstoff. . . & 3,27 & 12,99 & 15,15 & 16,00 & 15,08 & 15,26 \\
\hline Atherextrakt - . . & 3,59 & 14,27 & - & - & - & - \\
\hline $\begin{array}{l}\text { Petrolätherextrakt (aus } \\
\text { dem ausgelaugten }\end{array}$ & & & & & & \\
\hline Muskel) . . . . & 1,885 & 7,49 & - & - & - & - \\
\hline Wasserextrakt & 3,42 & 13,59 & 15,85 & 12,16 & - & - \\
\hline Kohlenhydrate & 0,097 & 0,387 & 0,45 & 0,48 & - & - \\
\hline Mineralstoffe. & 1,15 & 4,555 & 5,31 & - & 1,15 & - \\
\hline Calorien. . & 140,1 & 556,7 & - & - & 575,3 & 582,0 \\
\hline
\end{tabular}

In den wiederholt zitierten Arbeiten von Frentzel und Schreuer finden sich Angaben, mit denen analoge Rechnungen, wie sie hier angestellt wurden, für die Fleischfasersubstanz des Rindes durchgeführt werden können.

Frentzel und Schreuer fanden (Abh.III S.307, l. c., s. Anm. 1 auf S. 432) in $19,072 \mathrm{~g}$ fett- und extraktfreiem Trockenfleisch (Nr. II) 109,847 Cal. Aus meinen Versuchen am Hund geht hervor, dass in $100 \mathrm{~g}$ fett- und extraktfreiem Trockenfleisch $1,1575 \mathrm{~g}$ Asche enthalten sind. Wird mit diesem Werte gerechnet, so kommen auf 19,072 g fett- und extraktfreies Trockenfleisch $0,221 \mathrm{~g}$ Asche in Abzug, so dass für 18,851 g asche-, fett- und extraktfreie Trockensubstanz 
109,847 Cal. in Betracht kommen. Daraus berechnet sich für $1 \mathrm{~g}$ asche-, fett- und extraktfreie Trockensubstanz ein Wärmewert von 5827,4 cal.

Für Fleisch A derselben Autoren gilt folgende Rechnung:

18,92 extrahiertes Trockenfleisch $=108,941$ Cal:

18,70 aschefreies extrahiertes Trockenfleisch $=108,941$ Cal. Also $1 \mathrm{~g}$ völlig extrahiertes und aschefreies Trockenfleisch $=$ 5825,7 cal.

In Fleisch B von Frentzel und Schreuer kommen auf $18,284 \mathrm{~g}$ extrakt- und fettfreies Trockenfleisch 105,451 Cal. In Abrechnung kommen $0,212 \mathrm{~g}$ Asche, so dass sich gegenüberstehen $18,072 \mathrm{~g}$ asche-, fett- und extraktfreie Trockensubstanz und 105,451 Cal., d. h. 1 g extrakt-, fett- und aschefreie Trockensubstanz $=5835 \mathrm{cal}$. Ich habe alle Zahlen in der Tabelle 68 zusammengestellt, um die Übersicht zu erleichtern. Die grosse Übereinstimmung in den Werten entspricht durchaus dem oben für die noch aschehaltige Substanz gezogenen Schlusse, dass die völlig extrahierte und aschefreie Muskelsubstanz bei verschiedenen Tieren denselben Brennwert besitzt.

$$
\text { Tabelle } 68 .
$$

Brennwerte der fett-, extrakt- und aschefreien Muskeltrockensubstanz (1 g).

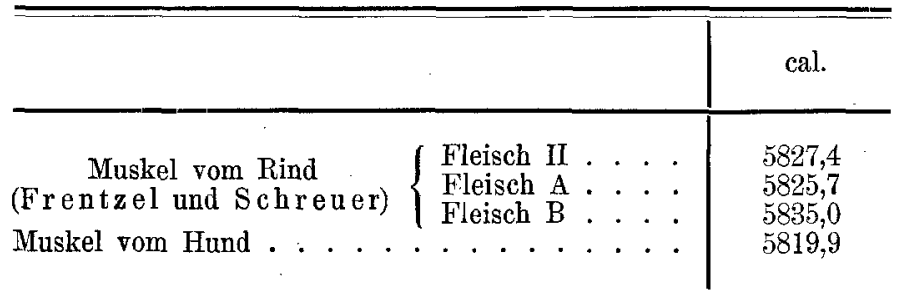

Die Ausdehnung, die die Arbeit angenommen hat, rechtfertigt eine kurze Übersicht über die wichtigsten (nicht analytischen) Ergebnisse:

1. Die Arbeitsleistung der Muskulatur steigert die Harnflut. Hierbei geht die Salzausfuhr (Chlornatrium) der Wasserausscheidung parallel.

2. Die bei der Arbeit produzierte Wärme wird beim Hunde hauptsächlich durch Verdunstung von Wasser, nur zum geringen Teile $(1 / 4)$ durch vermehrte Strahlung und Leitung abgegeben. 
3. Die Aufnahme von Wasser kompensiert nicht vollständig die Ausscheidung von Wasser, so dass es zu einer Verarmung des Organismus an Wasser infolge der Arbeit kommt.

4. Diese Wasserverarmung lässt sich sowohl am Ablauf der Lebendgewichtskurve dartun, wie namentlich an der Wasserbilanz, schliesslich an der chemischen Untersuchung der Organe.

5. Die Wasserabgabe betrifft, wie aus der Mineralstoff bilanz und aus der Untersuchung des Blutes hervorgeht, 1. die zirkulierenden Organflüssigkeiten, 2. hauptsächlich die peripherische Muskulatur.

6. Am Blute des Arbeitstieres lässt sich eine Zunahme der roten Blutkörperchen, des spezifischen Gewichtes und des Hämoglobins, in chemischer Beziehung eine Vermebrung von Trockensubstanz und Stickstoff konstatieren.

7. Die peripherischen Muskeln werden in der Regel infolge der Arbeitsleistung schwerer.

8. Die peripherischen Muskeln besitzen nach der Arbeit weniger Wasser, Mineralstoffe und in der Regel auch weniger leicht extrahierbares Fett, dagegen mehr Stickstoff (N-haltige Extraktivstoffe, mehr Fleischfasersubstanz) und schwer aus dem Muskel mit Äther auszuziehendes Extrakt.

9. Die Zunahme der Trockensubstanz stellt das wichtigste Charakteristikum der Muskel-Arbeitshypertrophie, deren Begriff somit zu revidieren ist, dar, nicht die Gewichtszunahme; denn die Muskeln können so viel Wasser verlieren, dass die Zunahme der Trockensubstanz in der Gewichtsänderung nicht zum Ausdruck kommt.

10. Im Herzmuskel treten keine für die Arbeitshypertrophie der peripherischen Muskulatur charakteristischen chemischen Veränderungen auf. Er besitzt auch nicht an und für sich schon die genannten Merkmale der Arbeitshypertrophie; denn er enthält mehr Wasser und weniger Stickstoff als die peripherischen Muskeln. Der Herzmuskel nimmt aber infolge der Arbeit an Gewicht zu. Ebenso verhält sich anscheinend die Leber.

11. Die Darmperistaltik und die Nährstoffausnutzung werden durch die Arbeitsleistung nicht geändert, die Eiweisszersetzung dagegen wird in geringem Grade vermindert.

12. Der kalorische Quotient des Harns ändert sich nicht.

13. Die Knochenernährung wird durch die Arbeitsleistung nicht alteriert. Die beobachtete Retention von $\mathrm{SO}_{3}$ und $\mathrm{K}_{2} \mathrm{O}$ ist wahrscheinlich auf den Ansatz von Fleischsubstanz zu beziehen. 
14. Beim erwachsenen Vierfüsser gibt es bezüglich des Gewichtes und des Wassergehaltes der peripherisehen Muskulatur keine Unterschiede zwischen rechter und linker Seite, wohi aber zwischen vorderer und hinterer Extremität, sowie zwischen Oberschenkel und Unterschenkel; die hintere Extremität und die Unterschenkel sind wasserärmer. Die hier beobachteten Differenzen stehen im $\mathrm{Zu}-$ sammenhang mit der Arbeitsleistung.

15. Während der Brunst sinkt die Stickstoffausfuhr beim Hunde ab. Dieser Abfall bedeutet aber nicht eine Regulation für den Stickstoffverlust. Es handelt sich hier vielmehr um eine allgemeine Wirkung der Brunst auf den Stoffumsatz. 